\title{
The no-touch isolation technique in colon cancer : report on a multicenter study with analyses of prognostic factors
}

\author{
Citation for published version (APA):
}

Wiggers, T. (1987). The no-touch isolation technique in colon cancer : report on a multicenter study with analyses of prognostic factors. [Doctoral Thesis, Maastricht University]. Rijksuniversiteit Limburg. https://doi.org/10.26481/dis.19870116tw

Document status and date:

Published: 01/01/1987

DOI:

10.26481/dis.19870116tw

Document Version:

Publisher's PDF, also known as Version of record

\section{Please check the document version of this publication:}

- A submitted manuscript is the version of the article upon submission and before peer-review. There can be important differences between the submitted version and the official published version of record. People interested in the research are advised to contact the author for the final version of the publication, or visit the DOI to the publisher's website.

- The final author version and the galley proof are versions of the publication after peer review.

- The final published version features the final layout of the paper including the volume, issue and page numbers.

Link to publication

\footnotetext{
General rights rights.

- You may freely distribute the URL identifying the publication in the public portal. please follow below link for the End User Agreement:

www.umlib.nl/taverne-license

Take down policy

If you believe that this document breaches copyright please contact us at:

repository@maastrichtuniversity.nl

providing details and we will investigate your claim.
}

Copyright and moral rights for the publications made accessible in the public portal are retained by the authors and/or other copyright owners and it is a condition of accessing publications that users recognise and abide by the legal requirements associated with these

- Users may download and print one copy of any publication from the public portal for the purpose of private study or research.

- You may not further distribute the material or use it for any profit-making activity or commercial gain

If the publication is distributed under the terms of Article $25 \mathrm{fa}$ of the Dutch Copyright Act, indicated by the "Taverne" license above, 


\section{THE NO-TOUCH ISOLATION TECHNIQUE IN COLON CANCER}

Report on a multicenter study with analyses of prognostic factors 
CIP.DATA KONINKLIKE BIBLIOTHEEK, DEN HAAG

Wiggers. Theodoor

The mo-touch isolation technique in colon cancer: report on a multicenter study with analyses of prognostic factors / Theodoor Wiggers; [ill. Chr. Voskamp]. [S.I. : s.n.]. III.

Thesis Maastricht. - With ref, - With summary in Dutch.

ISBN $90-9001-499-3$

SISO 605.91 UDC 6 $116-006.6: 611.34 / .35$

Subject heading: colorectal cancer; prognostic factors / no-touch isolation technique

(c) T. Wiggers 


\title{
THE NO-TOUCH ISOLATION TECHNIQUE IN COLON CANCER
}

Report on a multicenter study with analyses of prognostic factors

\author{
PROEFSCHRIFT \\ ter verkrijging van de graad van \\ doctor in de geneeskunde \\ aan de Rijksuniversiteit Limburg te Maastricht, \\ op gezag van de Rector Magnificus. \\ Prof. Dr. F.I.M. Bonke, \\ volgens het besluit van het College van Dekanen, \\ in het openbaar te verdedigen \\ in de aula van de universiteit \\ op vrijdag 16 januari 1987 des namiddags te vier uur \\ door \\ Theodoor Wiggers \\ geboren te Groningen
}


Promotores: Prof. Dr. J.M. Greep

Prof. Dr. J. Jeekel

Referenten : Prof. Dr. F.T. Bosman

P.H. Sugarbaker, M.D., F.A.C.S.

Dr. C.J.H. van de Velde

The publication of this thesis was financially supported by HoffmanLa Roche. 
If the aim of a trial is to test the validity of a biological principle or hypothesis resulting from basic and clinical investigations by employing patient benefit as an end point, no matter what the results of the trial, they are apt to be important.

Bernard Fisher, 1980 



\section{LIST OF CONTENTS}

\section{Chapter 1}

Introduction

1.1. Introduction

1.2. Aim of the study

1.3. Outline of the study

1.4. References

Chapter 2.

Recurrent disease in large bowel cancer

2.1. Lymphovascular anatomy of the colon

2.1.1. Blood supply and venous drainage of the colon

2.1.2. Anatomy and physiology of the lymphatics

2.1.3. Interrelationship between blood-vessels and lymphatic system

2.1.4. Summary

2.2. Pathways of metastases

2.2.1. Intraduction

2.2.2. Invasion and release 9

2.2.3. The lymphatic spread 10

2.2.3.1. Lymphatico-venous connections 10

2.2.3.2. The function of the regional lymph node

2.2.3.3. Histopathology of lymphatic metastases in colorectal cancer

2.2.4. Hematogenous dissemination and circulating tumor cells

2.2.4.1. Introduction

2.2.4.2. Venous invasion

2.2.4.3. Hematogenous spread (experimental) 15

2.2.4.4. Circulating tumor cells in man 16

2.2.4.5. Mallignant cells in the portal blood 17

2.2.5. Direct extension 18

2.2.6. Intramural spread 18 
2.2.7. Exfoliative spread

2.2.7.1. Intraluminal spread

2.2.7.2. Intraperitoneal spread

2.2.8. Summary

2.3. Patterns of recurrent disease

2.3.1. Introduction

2.3.2. Local failure

2.3.3. Distant metastases

2.3.4. Conclusions

2.4. References

Chapter 3.

Current state of surgical therapy in colorectal cancer

3.1. Introduction

3.2. Local resection

3.2.1. Length of resected bowel wall

3.2.2. Involvement of adjacent structures and organs

3.2.3. Prevention of local tumor spill

3.3. Limited versus extended lymph node resection

3.3.1. Introduction

3.3.2. The extent of intramesenteric resection

3.3.3. Extramesenteric resection

3.4. Vascular isolation before mobilization

3.4.1. Introduction

40

3.4.2. The no-touch isolation technique

3.4.3. Results of Turnbull

3.5. Discussion and conclusions

3.6. References

Chapter 4.

A documentation system for a multicenter trial

4.1. Introduction

4.2. Material and methods

4.3. Results

4.4. Discussion

4.5. References 
Chapter 5.

The no-touch isolation technique in colon cancer. A controlled prospective trial

5.1. Introduction

61

5.2. Material and methods

62

5.3. Results

65

5.4. Discussion

71

5.5. References

75

\section{Chapter 6.}

Prognostic significance of CEA immunoreactivity patterns in large bowel carcinoma tissue

6.1. Introduction

6.2. Material and methods

6.3. Results

6.4. Discussion

6.5. References

\section{Chapter 7.}

A multivariate analysis of pathological prognostic indicators in large bowel cancer

7.1. Introduction

7.2. Material and methods

7.3. Results

7.4. Discussion

7.5. References

Chapter 8 .

Regression analysis of prognostic factors in colorectal cancer after 'curative' resections

8.1. Introduction

8.2. Material and methods

8.3. Results

8.4. Discussion

8.5. References 
$x$

Chapter 9.

Discussion and conclusions

9.1. Introduction

9.2. Surgical techniques

9.3. Prognostic factors

122

9.4. Future directions

124

9.4.1. Detection of minimal residual disease

124

9.4.2. Manipulation of minimal residual disease

125

9.5. References

Summary

Samenvatting

133

Acknowledgements

138

Curriculum vitae 


\section{CHAPTER 1}

\section{Introduction}

\subsection{Introduction}

In Western countries the incidence of large bowel cancer is high and second only to that of lung cancer in man and breast cancer in women ${ }^{1.2}$. Survival rates have improved since 1950 only as a result of an increased resectability rate and a decreased perioperative mortality ${ }^{3}$.

Although surgical resection of the primary tumor is still the treatment of choice, there is no standard resection procedure. The advantage of the application of a certain resection technique can not be claimed since no prospective studies distinguishing between surgical methods have been performed up till now. This is why a comparison of the results presented in various publications is of limited value.

Besides the extent of the resection, the application of special intraoperative surgical measures in order to prevent further dissemination during the operation is controversial as well. In this regard, only Turnbull's data ${ }^{4}$, in which he presents the practice of the technique of complete vascular isolation before mobilization of the fumor, are available. Unfortunately, nearly every author uses the term 'no-touch' in referring to this technique. This is in fact incorrect since the main part of the procedure is ligation of blood vessels and bowel lumen before touching the tumor, which of course is unavoidable during every resection. Critics of this technique attribute Turnball's results either to patient selection or to the introduction of a new staging system, and report similar results as a consequence of other techniques.6.

Many colon cancer patients are not cured after operation. There is a big difference between mechanisms of metastatic disease studied in animal experiments and patterns of failure in man. Sometimes it is obvious that local residual or distant disease remains after an operation, but most of the time, one is confronted later with the outgrowth of minimal residual disease of which the distribution is unknown during surgery. Since diagnostic techniques to establish 
microscopic residual disease are not yet available, identification of prognostic factors is needed in order to plan studies for adjuvant therapy. Normally, staging and grading are used for these purposes. In recent years, new modalities like the study of the expression pattern of colorectal cancer associated antigens ${ }^{7}$ and the estimation of the nuclear DNA content in colorectal cancer ${ }^{8.9}$ have been tested for their potential as prognostic parameters. It is difficult to judge the value of a certain prognostic factor from univariate analysis only. Combined multivariate analysis has to be performed before clinical relevance of a new prognostic factor can be established.

Reliable information about both the influence of Iymphovascular isolation on the rate of occurrence of subsequent liver metastases and the existence of minimal residual disease is difficult to retrieve from retrospective studies. Only prospective studies in which all the necessary information is consistently recorded may serve this purpose.

\subsection{Aim of the study}

It is the aim of this study to evaluate the following features prospectively:

1. The effect of the 'no-touch' isolation technique in colon cancer on the rate of occurrence of subsequent metachronous liver metastases and its position in the resection technique will be defined.

2. Clinical, and especially, new pathological data of the multicenter study will be used by means of a regression analysis in order to determine more accurate prognostic factors, hoping to obtain better insight in the biological behavior of colon cancer in this way as well.

\subsection{Outline of the study}

Data on experimental and clinical research of both the pathways of metastases and the patterns of recurrent disease are reviewed in chapter 2. A survey of the literature concerning the possibilities and results of different surgical resection techniques is presented in chapter 3 .

The execution of an extensive multicenter study is possible only if data management is computerized; this is necessary for proper collection as well as evaluation of the data. A description of the design of such a database is given in chapter 4 .

A multicenter prospective trial with the participation of eight 
hospitals, in which a conventional resection technique was compared with the no-touch isolation technique, was performed. Results from the 236 patients enlisted are described in chapter 5 .

A new histopathological variable such as the expression pattern of carcinoembryonic antigen (CEA) at a cellullar level, has been analyzed by means of an univariate analysis in chapter 6 .

In chapter 7 a multivariate analysis of the relative importance of various pathological parameters, from previous studies, is analysed.

This information is combined with the avallable clinical and laboratory data in chapter 8 in order to obtain a prognostic index.

The information derived from this study is summarized and discussed in chapter 9, after which, some future directions both for identification and mamipulation of minimal residual disease are given.

\subsection{References}

1. The National Large Bowel Cancer Project and the Americian College of Surgeons Large bowel cancer. Biology and control, 1980.

2. Boyle $P$, Zaridze DG. Smans M. Descriptive epidemiology of colorectal cancer Int J Cancer 36: 9-18, 1985

3. Cutler SJ. Trends in cancers of the digestive tract. Surgery 65: 740.752, 1969.

4. Turnbull RB Jr, Kyle K. Watson FR, Spratt J. Cancer of the collon: the influence of the no-touch isolation technic on survival rates. Ann Surg 166:420-427, 1967.

5. Stearms MW. Does the no-touch technique really increase survival? In $O^{\prime}$ Connell TX (ed): Surgical oncology. Controversies in cancer treatment. Chapter 12, GK Hall Medical Publishers, Boston, Massachusetts, 1981.

6. Block GE, Enker WEE. Controversies in surgery for large bowel cancer. In Enker WEE (ed): Carcinoma of the collom and rectum, Chapter 5, Year Book Medical Publishers, Chicago-London, 1978.

7. Arends JW. Immunocytochemical studies in colorectal carcinoma. Thesis, Maastricht, 1984.

8. Wolley RC, Schnreiber K, Koss LG, Karas M, Sherman A. DNA distribution in human colon carcinomas and its relationship to clinical behavior. J Natl Cancer Inst 69: 15-22, 1982.

9. Armitage NC, Robins RA, Evans DF, Turner DR, Baidwin RW, Hardcastle JD. The influence of tumour cell DNA abnormalities on survival in colorectal calncer. B.r J Surg 72: 828-830, 1985 



\section{Recurrent disease in large bowel cancer}

\subsection{Lymphovascular anatomy of the colon}

\subsubsection{Blood supply and venous drainage of the colon}

The coecum, ascending colon, hepatic flexure and transverse colon obtain their blood supply from three branches originating from the superior mesenteric artery. The ileocolic artery to the coecum is the last artery branching off to the right from the arteria mesenterica superior. Sometimes it has a common origin with the right colic artery. The middle colic artery arises at the lower border of the pancreas from the superior mesenteric artery. The origin of this artery has a considerable variation. It may be absent ${ }^{1}$ or have an abnormal origin $^{2}$. Sometimes there is an accessory artery arising from the aorta2. Usually, the artery divides into two branches communicating to the right, with the right colic artery, and to the left, with the ascending branch of the left colic artery. Sometimes an extra arcade to the left side is present causing a better collateral circulation (called after Riolan). The inferior mesenteric artery is nearly always present and arises from the aorta about five centimetre proximal of its bifurcation? It supplies the diescending colon, sigmoid and upper part of the rectum, with the left colic artery, the sigmoid arteries and the superior hemorrhoideal artery respectively. All the colonic arteries communicate with each other by forming an arcade that runs parallel to the colon. From this marginal artery (Drummonds artery) the blood rums to the collon via the arteriae rectae (fig. 2.1). The venous outflow from the colon runs parallel with the arteries (fig. 2.2). However, the inferior mesenteric vein follows, proximal retroperitoneal, its own course and enters the splenic vein behind the pancreas at some distance from the artery. As a result, the draining vein of the splenic flexure may enter the vena mesenterica inferior at a much higher level compared with the corresponding artery ${ }^{3}$. After the confluence of the superior mesenteric vein and the splenic vein the portal vein 

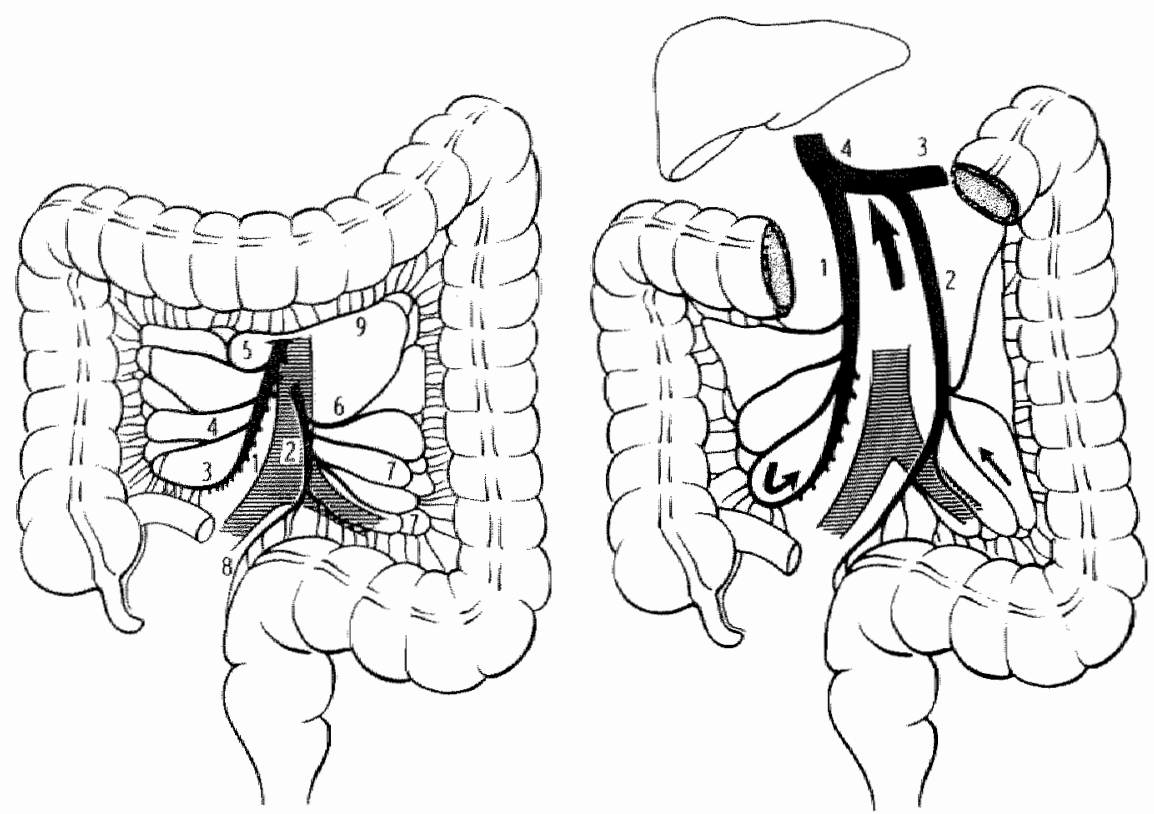

Figure 2.1: Arterial blood supply of the colon.

1. a. mesenterica superion; 2. a. mesenterica interior: 3. a. ileocolica: 4. a. colica dextra; 5 a. colica media; 6 . a. collica sinistra; 7 . aa. sigmoideae; 8 . a. hemorrhoidalis; 9. marginall artery.

Figure 2.2: Venous drainage of the colom

1. v. mesenterica superior; $2 . v$. mesenterica inferior; $3 . v$. lienalis; 4 . v. portae

is formed. Communication between portal and caval system, bypassing the liwer, exists via the superior hemorrhoideal veins (portal system) and the inferior hemorrhoideal veins (caval system). There are also connections between veins in parts in the colon (ascending and descending colon), that lack free mesentery and retroperitoneal veins 4

\subsubsection{Anatomy and physiology of the Iymphatics}

The lymphatic capillaries of the colonic wall start at the level of the muscularis mucosae whereas, bload capillaries are already distributed as a plexus directly under the surface of the epithelium ${ }^{5}$. From here, the lymphatics travel through the colon wall untill they reach the extramural Iymphatic system via the subserous plexus. This system consists of lymph channels running along the course of the mesenteric blood vessels. On their way, they pass five groups 
of lymph nodes (fig. 2.3). The first group consists of the epicolic nodes lying close to the bowel wall. In the sigmoid they are located in abundance in the appendices epiploicae. The paracolic nodes are located along the marginal artery which runs close to the colon. From here, the lymph flow is directed to the intermediate nodes lying in the mesentery. At the origin of the main arteries, at the level of the aorta, is the position of the principal, or main group of nodes. Up to this level the lymph drainage is intramesenteric for the entire colon. From here the flow is directed upwards allong the aorta passing the para-aortic and vena caval nodes before entering the cisterna chylis.

Dye injected into the muscularis mucosae during operation showed a rapid clearing (about 5 to 10 minutes) along the first three groups of nodes till reaching the principal nodes?.

The lymphatic drainage of the rectum is somewhat different. It has been studied in vivo extensively by Enquist and Block ${ }^{8}$. Dye injected submucosally in the rectum at different levels, showed the following drainage pattern at laparotomy; in all instances, there was a strong spread upward via the lymphatic vessels in the mesentery

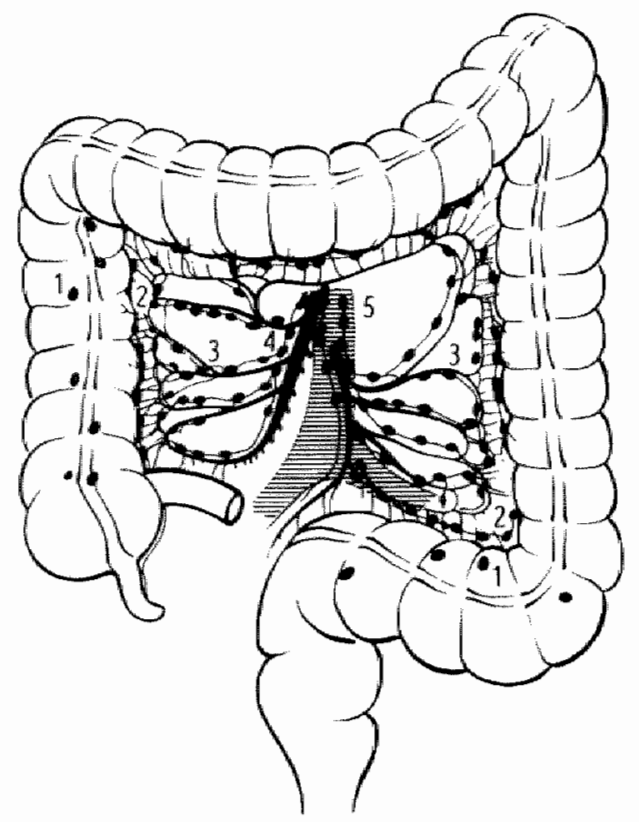

Figure 2.3: Lymph nodes of the colon.

1. epicolic nodes; 2 . paracolic nodes; 3 . intermediate nodes; 4 . central nodes; 5 . paraaortal nodes. 
to the para-aortic nodes. At the level of the anal canal there was, as well as the drainage to the posterior vaginal wall, also spread to the ischiorectal fossae and to the inguinal nodes. At five centimetre from the anal verge the dye showed a very extensive area of staining: laterally to the hypogastric nodes, to the broad ligaments and to the vagina and internal genitalia. Spread of dye towards the uterus and ovaries was decreased in females who had passed the menopause. If the dye was injected at ten centimetre, most of the spread was upward to the mesenteric nodes but there was also spread to the broad ligaments and a moderate spread to the hypogastric nodes. At 15 centimetre all the spread was upward. Others ${ }^{6}$ found no lateral spread demonstrable higher than four centimetre above the anorectal line ( \pm 7 centimetre from the anal verge). This point corresponds with the location of the middle valve of Houston and is the level of entry of the middle hemorrhoideal vessels ${ }^{9}$. Lymphatic channels here, run laterally along these arteries to the internal iliac vessels.

Ackerman ${ }^{10}$ performed experimental studies in dogs to test the fluctuations of lymph flow by mechanical factors. Cannulation of lymphatic vessels in the mesentery was performed in order to measure lymph flow. Massage of the intestinal loop gave an immediate increase in lymph flow. Increase of intraluminal pressure also caused a steep increase in the flow till the pressure exceeded 60 millimeters of mercury after, which the flow decreased, and even stopped. Also, stimulation of peristalsis caused an increase in lymph flow. In the discussion he stated that the spread of tumor cells through the lymphatics may occur by palpation and manipulation of the malignant lesion. The same may occur during diagnostic studies like abdominal palpation, $\mathrm{X}$-ray examinations, colonoscopy and cleansing enemas.

\subsubsection{Interrelationship between blood-vessells and lymphatic system}

Dynamic studies regarding the interrelationship of blood and lymph flow have been conducted by Ackermann 11:12. Cannulation of the lymphatic vessels was performed in the mesentery of dogs during laparotomy. Flow in arteries and veins was measured by an electromagnetic flow meter. Arterial ligation caused a significant decrease of lymph flow. In contrary, the flow in the lymphatics increased with an average of four to five times by venous occlusion. If both vessels were ligated at the same time again lymph flow decreased although it never stopped completely. Lymph flow may even increase after this procedure, if major arterial collaterals are not ligated as well. 


\subsubsection{Summary}

The lymphatic drainage starts at the level of the muscularis mucosae. The lymph vessels of the colon are situated entirely intramesenteric along the course of the main arteries. Also the lymphatic drainage of the rectum is mainly upward along the superior hemorrhoideal vessels but, starting at the level of the middle valve of Houston (7-10 centimetre from the anal verge) there also is an extramesenteric flow laterally to the hypogastric nodes and to the internal genitals. In the lowest part of the rectum there is flow to the inguinal modes as well. Mechanical factors, like massage of the bowel or increased intraluminal pressure cause an increase of the lymph flow. Venous ligation only results in an increased lymph flow while arterial ligation causes the opposite.

\subsection{Pathways of metastases}

\subsubsection{Introduction}

A short review of the literature concerning the metastatic process in general is necessary in order to understand the metastatic spread in colonic carcinomas. Special attention will be paid to the steps that are of most concern for the surgeon.

Metastatic disease may be defined as 'a transfer of the disease from one organ to another not directly connected with it" ${ }^{\prime 3}$ and the metastasis is "a neoplastic lesion arising from another cancer with which it is no longer in contingency ${ }^{\prime 14}$. During this process four steps are necessary ${ }^{95}$ :

1. growth of the tumor;

2. invasion of veins or lymphatics;

3. release of cells and circulation to distant organs;

4. entrapment and growth of tumor cells in distant organs.

Besides invasion of vessels, the spread of the primary tumor may also occur by direct invasion of adjacent organs or, by seeding on serosal surfaces of other organs after shedding of tumor cells.

\subsubsection{Invasion and release}

The final mechanism of invasion is still unclear. Three factors are thought to have a bearing on this phenomenon: mechanical pressure, individual cell motility and production of tissue destructive enzymes ${ }^{13}$. Collagen type IV is a major structural protein of the basement membrane. Collagenase type IV is produced by a murine tumor cell 
line with a high metastatic potential and this enzyme is able to dissolve the basal membrane ${ }^{16}$. This may facilitate the tumor cells to enter the blood vessels.

The second step in the metastatic process is the release of tumor cells. It has been questioned if this release is a specific property of malignant tumors. Also, non-malignant cell conglomerates, like cultures in vitro with an increased growth rate, normal bowel wall and liver cells during regeneration after partial hepatectomy, easily loose cells ${ }^{14}$. On the other hand necrotic parts of the tumor that still have the potential of outgrowth may be released in clumps in the circulation by minor forces ${ }^{17}$. By reviewing the literature, Sugarbaker 18 found evidence that incision of, and manipulation with experimental tumors resulted in an increased number of metastases. Changes in venous pressure, manipulation of the tumor during diagnostic tests and surgery may cause release of cells in man ${ }^{19}$.

\subsubsection{The lymphatic spread}

\subsubsection{Lymphatico-venous connections.}

Splitting up metastatic spread into hematogeneous or lymphatic routes is artificial 13.17 .20 , it facilitates only the study of each pattern. Spread, via the blood, may be frequently initiated via Iymphatic channels and the thoracic duct ${ }^{21}$, and outgrowth of a metastasis in a lymph node may be a second source for dissemination via the bloodvessels $^{22}$. On the other hand liver metastases may allso cause lymphatic metastasis to the nodes draining the liver ${ }^{23}$. Fisher ${ }^{24}$ demonstrated the close relationship between the two systems by injecting radiolabelled tumor cells into the portal or systemic circulation of rats. After one hour he was able to retrieve those cells from the thoracic duct. Lymph obtained from these animals produced tumor growth in healthy rats. The intact passage of tumor cells was a property of living cells only. This suggests that the process of bypassing an organ is an active process. Passage of cells from lymphatic to vascular systems also is possible through the endothelium into the postcapillary venules. This has been demonstrated by serial microsections in combination with electron microscopy in lymph nodes in a rat model25. The opportunities for lymphatico-venous shunts are shown in fig. 2.4 and there is considerable evidence that tumor cells pass freely between vascular and lymphatic vessels.

\subsubsection{The function of the regional lymph node.}

Metastatic spread is influenced in the lymph nodes because tumor cells that enter the regional lymph node may be destroyed ${ }^{26}$, may 


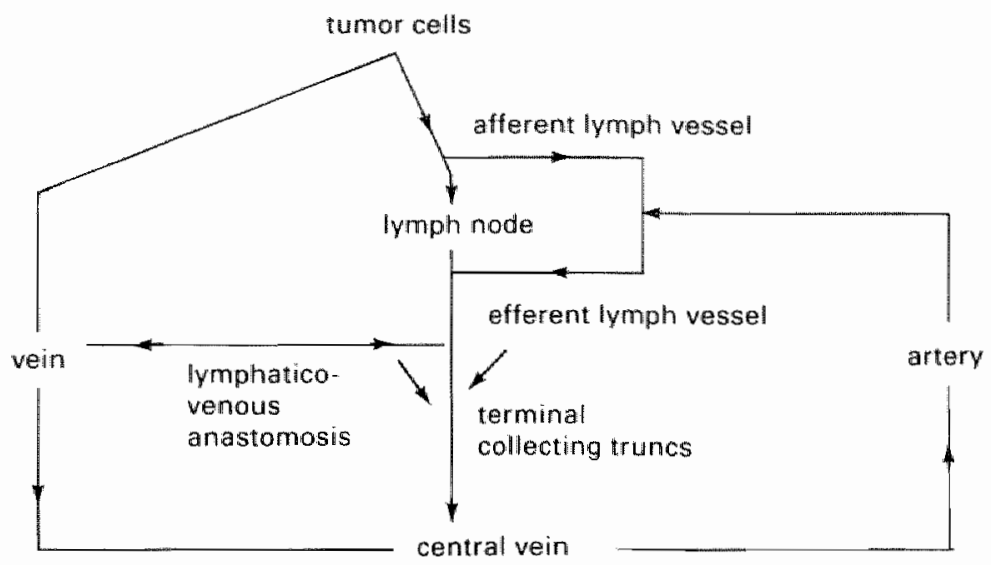

Figure 2.4: Communications between the Iymphatic and blood circulatory system (after Weiss 20 ).

bypass the node entering the efferent lymph or venous system ${ }^{26}$. or may be retained and grow ${ }^{22}$. Only a few tumor cells will grow and become lymph node metastases. New spread is started via the hilar region of the involved lymph node 27 . The filter function of the lymph node is controversial. In one study it was in an animal model, capable of reducing the number of distant metastases ${ }^{21}$, but manipulation of the lymph node by irradiation ${ }^{28}$ or intra-nodal BCG injection ${ }^{27}$ does alter the response on tumor cells in a limited way. Properties of the tumor cell and the number of injected malignant cells are more likely to influence metastatic spread than the supposedly inhibitory effect of the lymph node 28 .

In addition to the filter function, the immunologic role of the regional lymph node is not completely clear. The systemic immune response initiated in the regional lymph node was associated in one animal experiment, with the antigenicity of the primary tumor ${ }^{29}$. In this model, the regional lymph node appears to be important for the induction of systemic immunity in weakly antigenic tumors, but. strongly antigenic tumors were not able to produce these systemic effects ${ }^{29}$. However, others ${ }^{30}$ found the immune response in the regional lymph node itself not influenced by differences in the antigenecity of primary tumors. In breast cancer patients, non-tumorous enlargement of the lymph nodes, due to follicular hyperplasia has been associated with a better prognosis ${ }^{31}$. Inactive lymphocyte depleted lymph nodes were associated with a poorer prognosis in gastric cancer ${ }^{32}$.

Clinically this presumed immune stimulating and filter function of the regional lymph node has led $\mathrm{Crile}^{33}$ to give up "en bloc' resections 
and perform simple mastectomies with good results. The crucial unsolved question for the clinician is whether, the regional lymph node serves as a source for distant disease or is an important factor in immunostimulation. These hypotheses are difficult to evaluate in clinical studies. So far, no study has confirmed the validity of one of the hypotheses. It is possible, that positive and negative effects are in balance. For example, in breast cancer, management of the internal mammary nodes has been the subject of study. Comparison of data of breast cancer patients, with medially or laterally located tumors showed equal survival rates although in the medially situated tumors the regional nodes were not treated ${ }^{34}$. Veronesi et al. showed the inefficacy of internal mammary node dissection in breast cancer ${ }^{35}$ and, of regional node dissection in melanomas ${ }^{36}$. These clinical studies do not show a positive or negative effect on survival of the removal of regionall lymph nodes. The reduction of regional recurrences, in consequence of prophylactic lymph node dissection has to be outweighed by the associated morbidity (e.g. (ymphoedema).

\subsubsection{Histopathology of lymphatic metastases in colorectal cancer.}

Before the modern concept of lymphatic spread was developed, several histopathological studies were performed to examine the direction and extent of lymphatic spread (table 2.1). The rational behind these studies was to determine the extent of radical 'en bloc' resections. Gabriel et al. ${ }^{37}$ dissected 100 specimens of resected rectosigmoid and rectal carcinomas, and found that the metastatic spread was upward from one gland to another along the vessels in a predictable course. Grinnell ${ }^{39}$ extensively studied 322 carcinomas from the entire rectocolon. Over 12.000 nodes were examined. In right sided carcinomas the spread followed the illeocolic artery, whereas distal to the hepatic flexure the middle colic route was followed. Regarding the hepatic flexure two studies ${ }^{7.41}$ are available indicating lymph flow (determined by vital staining and examination of lymph node metastases) along the ileocolic and right colic artery

Table 2.1: Lymph node dissection studies in colorectal cancer

\begin{tabular}{|c|c|c|c|c|c|c|}
\hline Author & Year & $\begin{array}{l}\text { Number of } \\
\text { specimens }\end{array}$ & $\begin{array}{l}\text { Positive } \\
\text { Iymph nodes }\end{array}$ & $\begin{array}{l}\text { Number } \\
\text { Examined }\end{array}$ & Average & Ref \\
\hline Gabriell & 1935 & 100 & $62.0 \%$ & $\max .60$ & 28 & 37 \\
\hline Gilichrist & 1947 & 200 & $62.5 \%$ & $\max .210$ & \pm 50 & 38 \\
\hline Grimnell & 1950 & 322 & $47.0 \%$ & & 38 & 39 \\
\hline Mc|Elwain & 1954 & 90 & $60.0 \%$ & $4-68$ & 31 & 6 \\
\hline Moore & 1959 & 29 & $41.3 \%$ & $20 \cdot 157$ & & 40 \\
\hline
\end{tabular}


in a limited number of cases. The major route is along the right branch of the middle colic artery. In the transwerse colon flow is both to the right and left colonic arteries. The splenic flexure and descending colon drain predominantly along the left colic artery. Although, usually, the lymphatic spread is along one artery of the arcade, the route in the distal transwerse colon and the splenic flexure is uncertain, due to large arcades and the inconstant anatomy of the blood vessels. Drainage may occur along the left branch of the middle colic artery or left colonic artery and both arteries should be resected in order to remove all Iymphatic drainage from that area. From the sigmoid the spread follows all branches of the inferior mesenteric artery.

Although the spread is usually predictable, a few authors ${ }^{37,38}$ document the possibility of skip metastases. In these cases Iymph nodes are involved at a more central level leaving the intermediate nodes untouched. In one series ${ }^{37}$ it was found only once in 100 specimens. Liver metastases without lymph node metastases do occur although this is uncommon ${ }^{6}$.

If afferent lymphatic flow is blocked by metastases in the lymph nodes, abnormal flow with an unpredictable spread may occur $7,37,38,42$. These atypical metastases may occur, due to abnormal spread via the paracolic lymph nodes in areas within the mesentery far from the normal drainage area, but also extramesenteric. Lymph node metastases were found in four cases out of 18 transverse colon carcinoma specimens in the gastro-epiploic glands ${ }^{39}$. This occurred only in cases with heavy central lymph node involvement. On average 16 nodes were positive! Downward and lateral spread in high rectal (> 8 centimetre) and rectosigmoid located tumors, is also associated with heavy lymphatic involvement of the upward stream.

\subsubsection{Hematogenous dissemination and circulating tumor cells}

\subsubsection{Introduction}

Most of the patients dying from metastases from their colorectall carcinoma have deposits in the liver. The most direct way for malignant cells to reach the liver is via the portal vein. Access to the venous circulation is possible after venous invasion and by Iymphatico-venous shunts. In this part of the review special attention will be paid to venous invasion and circulating tumor cells in the portal blood from colonic cancer.

\subsubsection{Venous invasion}

A factor necessary for intravasation of tumor cells is venous 
invasion. A detailed histologic description revealing all the pathological aspects ${ }^{43}$ of this feature will not be given. The presence of venous invasion in colorectal cancer has been documented extensively (table 2.2). The percentages reported differ substantially. This may be due to two factors. Firstly, the percentage of cases with angioinvasive growth increases with the stage of the tumor 40,55 , and several authors have included mainly advanced stages. Secondly, the incidence of this feature is increasing by more carefull histopathological evaluation.

Talbot ${ }^{54}$ studied the histologic specimens of 703 rectal carcinomas in detail. In $51.9 \%$ of the specimens venous invasion was present. He made a subdivision into intramural and extramural angio-invasive growth. The survival rate of the patients was not significantly different if intramural invasion was present or not. Extramural invasion was present in $5 \%$ of the cases where the tumor was confined to the bowel wall, in $70 \%$ if the tumor invaded the whole bowel wall, and in $75 \%$, if regional positive lymph nodes were present. So the presence of the invasion was not influenced by the Iymph node status. Lymph node status and venous invasion were independent of bad prognosis but mutually supportive. If thick walled veins were invaded an increase in liver metastases was seen. The observation that venous invasion is related to more advanced cases, in combination with visceral metastases, is in concordance with many other authors (table 2.3).

Table 2.2: Venous inwasion

\begin{tabular}{llll}
\hline Author & Year & $\begin{array}{l}\text { Venous imvasion in } \\
\text { examined spacimens }\end{array}$ & Ref. \\
\hline Brown & 1938 & $61.0 \%$ & 44 \\
Sunderland & 1949 & $27.6 \%$ & 45 \\
Grinnell & 1950 & $36.0 \%$ & 46 \\
Barringer & 1954 & $37.8 \%(63.91 \%$ & 47 \\
Fisher & 1955 & $28.0 \%$ & 48 \\
Dukes & 1958 & $11.0 \%$ & 49 \\
Moore & 1959 & $68.3 \%$ & 40 \\
Spratt & 1967 & $20.3 \%$ & 50 \\
Copeland & 1968 & $19.3 \%$ & 51 \\
Dwight & 1969 & $14.2 \%$ & 52 \\
Griffiths & 1973 & $42.2 \%$ & 53 \\
Talbot & 1980 & $51.9 \%$ & 54 \\
Knudsen & 1983 & $38.9 \%$ & 55 \\
Bloem & 1985 & $43.0 \%$ & 56 \\
\hline
\end{tabular}

I) Radiographic

2) Mainly advanced cases 
Table 2.3: Venous invasion and prognosis

\begin{tabular}{|c|c|c|c|c|}
\hline \multirow[t]{2}{*}{ Author } & \multirow[t]{2}{*}{ Year } & \multicolumn{2}{|c|}{$\begin{array}{l}\text { Five year survival } \\
\text { Venous invasion }\end{array}$} & \multirow[t]{2}{*}{ Ret. } \\
\hline & & Present & Absent & \\
\hline Sunderlland & 1949 & $44.4 \%$ & $73.2 \%$ & 45 \\
\hline Dukes & 1958 & $35.4 \%$ & & 49 \\
\hline Spratt & 1967 & $27.4 \%$ & $46.8 \%$ & 50 \\
\hline Copeland & 19168 & $22.0 \%$ & $43.0 \%$ & $5 \pi$ \\
\hline Dwight & 19169 & $26.2 \%$ & $48.0 \%(p>0.05)$ & 52 \\
\hline Talbot & 1980 & $330 \%(66 \%)^{2}$ & $73.0 \%$ & 54 \\
\hline
\end{tabular}

$1)$ Corrected survival

2j Venous invasion confined to bowel wall

\subsubsection{Hematogenous spread (experimental)}

After entering the blood stream, the tumor cell is passively carried away. Injection of radiolabeled tumor cells in animals show a rapid clearance from the systemic circulation, and less than $0.1 \%$ of the cells survive ${ }^{5}$. Several factors may be of importance for this rapid clearing: single cells may be traumatised due to blood turbulence ${ }^{13}$, immune reaction of the host ${ }^{58}$, natural killer cells ${ }^{59}$ and lack of feeding substances. On the other hand, stress, as a result of an operation, is able to decrease the resistance of the host to cancer cells ${ }^{60}$. Animal studies have shown a close correlation between the number of tumor cells injected and the probability of formation of metastases ${ }^{14}$. Not only the number of circulating cells but also the size of the tumor emboli is related to the number of metastases ${ }^{61.62}$. Fidler ${ }^{61}$ found a more than threefold increase in the number of pulmonary metastases by injecting i.v. clumps of four to five cells compared to single cells. The explanation of this finding may be, in the first place. a better trapping of the cells in the microcirculation and secondly a more vital undamaged "central cell" in the cell clump ${ }^{13}$. Sugarbaker" suggests that this tendency to release tumor clumps rather than single cells is one of the most important determinants in the process of metastases:. Aggregation with platelets, lymphocytes and fibrin may protect the tumor cell and facilitate its ingrowth ${ }^{13}$. The mechanisms of invasion after entrapment of the tumor cell in the capillary bed are not completely understood. Enzymatic degradation of the basement membrane of the capillaries may play an important role similar as by initial invasion. The next step, after penetration is migration to the interstitial space and proliferation with the induction of a new capillary blood supply ${ }^{17}$. Chemical trauma ${ }^{63}$ "implantation of glass fragments ${ }^{63}$ and surgical manipulation ${ }^{64}$ increase the inci- 
dence of liver metastases in tumor rat models. This has led Fisher ${ }^{64}$ to postulate the hypothesis that 'dormant' or 'latent' tumor cells may become overt metastases after manipulation

This complicated process of establishing metastases does not occur by accident 65 . Both the organ in which the metastasis is likely to grow, and the number of cells which survive are not at random. In a neat and simple study Brunson ${ }^{66}$ injected cells from a B16 melanoma tumor in mice and produced cell lines that metastasized, predominantly, either to the lungs or to the brains or to the ovaries. Cultures of B16 melanoma tumors resulted in several clones, which after inoculation showed a big difference in the number of lung metastases ${ }^{6 i}$. These findings can be explained by the fact that most neoplasms are heterogeneous and contain various subpopulations with a different metastatic potential ${ }^{68}$. This indicates that the metastatic process is not random survival of tumor cells, after their release, but a very selective process in which subpopulations have different outgrowth possibilities in different organs.

\subsubsection{Circulating tumor cells in man}

Next to venous invasion circulating tumor cells have been studied extensively in man during the last half century. Pool ${ }^{69}$ was the first, in 1934, to study circulating cells systematically in living patients. Since this publication, many reports have appeared about malignant cells in the peripheral blood $00.71,72.73$. Although, in some studies, malignant cells in the peripheral blood were identified in up to $57.6 \%$ of the cases ${ }^{70}$, most later reports gave an incidence of around $5 \% 19$. This variation in incidence may be due to many factors ${ }^{19}$. Firstly, technical factors such as the number and size of the blood samples, the site of collection and the method of concentration may be involved. Secondly, criteria for the identification of a malignant cell, with the recognition of atypical non-malignant cells may be relevant. Thirdly. tumor properties such as type of tumor, degree of differentiation and presence of venous invasion may be of influence, and finally, external factors affecting the liberation of malignant cells should be considered. Operative manipulation ${ }^{74}$, diagnostic procedures ${ }^{75}$ and induction of anaesthesia ${ }^{54}$ were associated with an increase of circulating tumor cells, although others ${ }^{70.73}$ were not able to confirm this. Especially in the early series there has been much doubt about the nature of the described cells ${ }^{78}$, and the demonstration of cancer cells in the peripheral blood has been of no diagnostic or prognostic value $^{70.76}$. although Roberts 74 found a reduction in survival if previously negative blood samples became positive during or after operation. 


\subsubsection{Malignant cells in the portal blood}

A higher incidence of cancer cells has been found in samples of venous bload draining from the tumor in comparison with the samples of peripheral blood 40.5370 . After the first identification in 1954 by Cole ${ }^{77}$ of tumor cells in the portal blood of a patient many other investigators have confirmed this finding (table 2.4). Although some ${ }^{40.48}$ observed a positive correlation between the presence of malignant cells in portal blood and venous invasion this was not confirmed by others ${ }^{53}$. Controversial reports are awailable about the number of tumor cells in the blood in relation to the degree of differentiation ${ }^{53.70}$. Not the involvement of lymph nodes, but the degree of infiltration of the tumor through the bowel wall was related to the presence of tumor cell $/ \mathrm{s}^{53}$. Cancer cells tended to occur singly, or occasionally, in clusters of two or more cells in the peripheral blood, but large clusters of malignant celis, sometimes comprising several hundred cells, were found in the local venous bload ${ }^{53}$.

Griffiths ${ }^{53}$ performed perfusion experiments with resected colonic cancer specimens. Normothermic perfusion, with a suspension of red blood cells in a buffered electrolyte/dextran solution at normal flow rates, showed, after 15 minutes an incidence of malignant cells in the venous blood of only $7 \%$ of the cases. After an injection with streptokinase this increased to $31 \%$. Subsequent manipulation of the tumor showed a further increase to $58 \%$. These findings were later confirmed 79 . Moore ${ }^{40}$ had the impression 'that the number of positive samples after surgical manipulation is not greater, but that, the number of cells and particularly clumps of cells per sample is greater'.

A negative correlation, between the presence of tumor cells in local venous blood and survival, was not observed for many different types of tumor ${ }^{53.70}$, although, with small numbers of patients a

Table 2.4: Tumor cells in the portal blood of patients witth colorectal cancer

\begin{tabular}{lcclc} 
Author & Year & $\begin{array}{l}\text { Number of } \\
\text { patients }\end{array}$ & $\begin{array}{l}\text { Tumor cells in } \\
\text { the portal blood }\end{array}$ & Ref. \\
\hline Fisher & 1955 & 25 & $32 \%$ & 48 \\
Engell & 1955 & 107 & $63 \%$ & 70 \\
Moore & 1959 & 44 & $16 \%$ & 40 \\
Salsbury & 1965 & 162 & $37 \%$ & 78 \\
McKinna & 1971 & 34 & $67 \%$ & 79 \\
Griffiths & 1973 & 42 & $59 \%$ & 53 \\
\hline
\end{tabular}

1) resectable

2) non resectable 
decrease of $14 \%$ in five year survival was noted if malignant cells were presemt in the portal blood 53.

\subsubsection{Direct extension}

After complete penetration of the bowel wall, the tumor may grow further into the surrounding tissues such as; mesentery, pericalic and perirectal fat before invading adjacent organs such as; small bowel, abdominal wall, pancreas, bladder, vagina, uterus or duodenum. Areas without peritoneal coverage, where the colon is fixed are especially easily invaded by the tumor. However, not all the adhesions to the adjacent organs are due to carcinoma, in a minority of the cases these adhesions are a result of inflammation (table 2.5 ).

\subsubsection{Intramural spread}

The tumor may also spread within the bowel wall itself. The way and extent of this spread has been studied extensively in high and mid rectal cancers, because of the need, in these cases for the surgeon to work with small margins. The plane of the greatest extension is the submucosa and there is no difference in intramural spread above or below the lesion 87 .

Histopathological dissection of 50 rectal cancers ${ }^{88}$ showed, in $76 \%$ of the cases, no distal intramural spread. In $14 \%$ it was one centimetre or less and only in $10 \%$ of the cases spread was abserved over two centimetres, all these last tumors being poorly differentiated. This confirms other previous reports ${ }^{89}$ which state that intramural spread is uncommon and seldomly exceeds 1.5 centimetre.

Table 2.5: Pencentage of carcinomatous infituration, detemined after resection in adjacent organs

\begin{tabular}{lcclll}
\hline Author & Year & $\begin{array}{c}\text { Number of } \\
\text { patients }\end{array}$ & $\begin{array}{l}\text { Localisation } \\
\text { primary tumor }\end{array}$ & $\begin{array}{l}\text { Carcinomatous } \\
\text { infiltration }\end{array}$ & Fef. \\
\hline Van Prohaska & 1953 & 21 & $\mathrm{C} / \mathrm{R}$ & $100.0 \%$ & 80 \\
Jensen & 1970 & 60 & $\mathrm{C} / \mathrm{R}$ & $61.7 \%$ & 81 \\
El Domeiri & 1970 & 10 & $\mathrm{Cecum}$ & $80.0 \%$ & 82 \\
Polk & 1972 & 19 & $\mathrm{C} / \mathrm{R}$ & $89.5 \%$ & 83 \\
Davies & 1975 & 43 & $\mathrm{C} / \mathrm{R}$ & $74.4 \%$ & 84 \\
Bonfanti & 1982 & 61 & $\mathrm{~S} / \mathrm{R}$ & $44.0 \%$ & 85 \\
Durdey & 1984 & 169 & $\mathrm{R}$ & $74.0 \%$ & 86 \\
\hline
\end{tabular}

Y $\mathrm{C}=$ entire colon: $\mathrm{S}=$ sigmoid; $\mathrm{R}=$ rectum 


\subsubsection{Exfoliative spread}

\subsubsection{Intraluminal spread.}

Malignant cells have been isolated from the luminal side of the bowel by making smears from the mucus of resected specimens ${ }^{90}$. Smears were more often positive, distal to the tumor. With an increasing distance, the percentage of positive smears diminished. Distal from occlusive ligatures the smears were negative, suggesting the exfoliation to be a result of the manipulation. It has been shown in experimental animal tumor models $5^{91.92}$, that tumor cells implant into the anastomosis and produce anastomotic line recurrences. The normal and even damaged mucosa, is most likely resistant to tumor implantation ${ }^{93}$. Occasionally patients have been described who developed a metastasis in the wound of a hemorrhoidectomy while suffering from a not yet detected rectal carcinoma ${ }^{3}$ or, after resection, in a hemorrhoid ${ }^{94}$. Umblepy was able to identify viable colonic cancer cells from the lavage fluid after irrigation of the colon pre- or peroperatively ${ }^{95}$. Viability, although denied by some ${ }^{96}$ was neatly tested by morphology and trypan blue exclusion in a first study ${ }^{95}$ and by thymidine incorporation and growth as a xenograft in nude mice in a second study ${ }^{97}$.

\subsubsection{Intraperitoneal spread.}

Cells may also be identified in washings from the peritoneal cavity 40.98 in colorectal cancer. Especially tumors penetrating the serosa are shedding malignant cells ${ }^{40,99}$. Animal studies show that the intact peritoneal layer is rather resistant to the implantation of tumor cells, but removal of a part of the peritoneum resulted after one hour in tumor cells capsulated in a fibrin sheat at that spot. These encapsulated tumor cells are no longer reached by cytotoxic fluids such as Dakin's solution ${ }^{100}$.

\subsubsection{Summary}

The biological function of the regional lymph node in colonic cancer is controversial. The mechanical filter theory of the lymph node is too simple and the presence of lymph node metastases is as in other malignancies an indicator for the existence of a tumor-host interaction. Circulating tumor cells in the peripheral blood have no prognostic significance. In portal blood tumor cells are found both spontaneously and, after manipulation. The incidence is higher than in peripheral blood and cell clumps occur more often than single cells. Clumps of malignant cells have a higher potential of establishing 
organ metastases in experimental tumor models. Although tumor dissemination is a continuous process, both spread and take are easier during diagnosis and treatment of the primary tumor. This is a result of an increased liberation of tumor cells and a better take of the cells in the immunosuppressed host.

The intramural spread of colonic cancer is limited. Exfoliated cells are viable and may grow if the peritoneal layer of the mucosa of the colon wall is not intact.

\subsection{Patterns of recurrent disease}

\subsubsection{Introduction}

The end result of metastatic spread is recurrent disease at some site in the patient. The knowledge of patterns of failure after intentional curative resection is the rationale behind the planning of both primary and adjuvant therapy. For instance, a very high incidence of local failure in the absence of distant metastases may be an indication for more extended surgery in combination with radiotherapy.

Presently, clinical examination, CEA levels, radiologic studies, reexploration or autopsy are the modalities for the determination of recurrent disease. They all have the same disadvantage in diagnosing recurrent disease at a late stage. A survey of the literature of series with large number of patients is presented in table 2.6. A more detailed description of local recurrence and distant metastases will be given in the next paragraphs.

\subsubsection{Local failure}

Local failure is a recurrence occurring either, within the primary tumorbed, at the suture line, in adjacent organs or in regional lymph modes. Not every author uses the same definition, making comparison of series difficult. Also, the way of determinating the recurrence (clinically with or without biopsy, second look operation, autopsies, CT-scan) influences both the incidence, and the mutual relation of local recurrence, and distant metastases (table 2.6). The clinical diagnosis of local recurrence for colon cancer is difficult. This failure pattern occurs more frequently after resection of left in comparison with right sided tumors 109.111 . Conflicting data are available for the retroperitoneal situated parts. Some describe higher incidences of local failure 104.111 but others, do not confirm this ${ }^{109}$. Probably due to limited possibilities of local extension before invading in, and close 


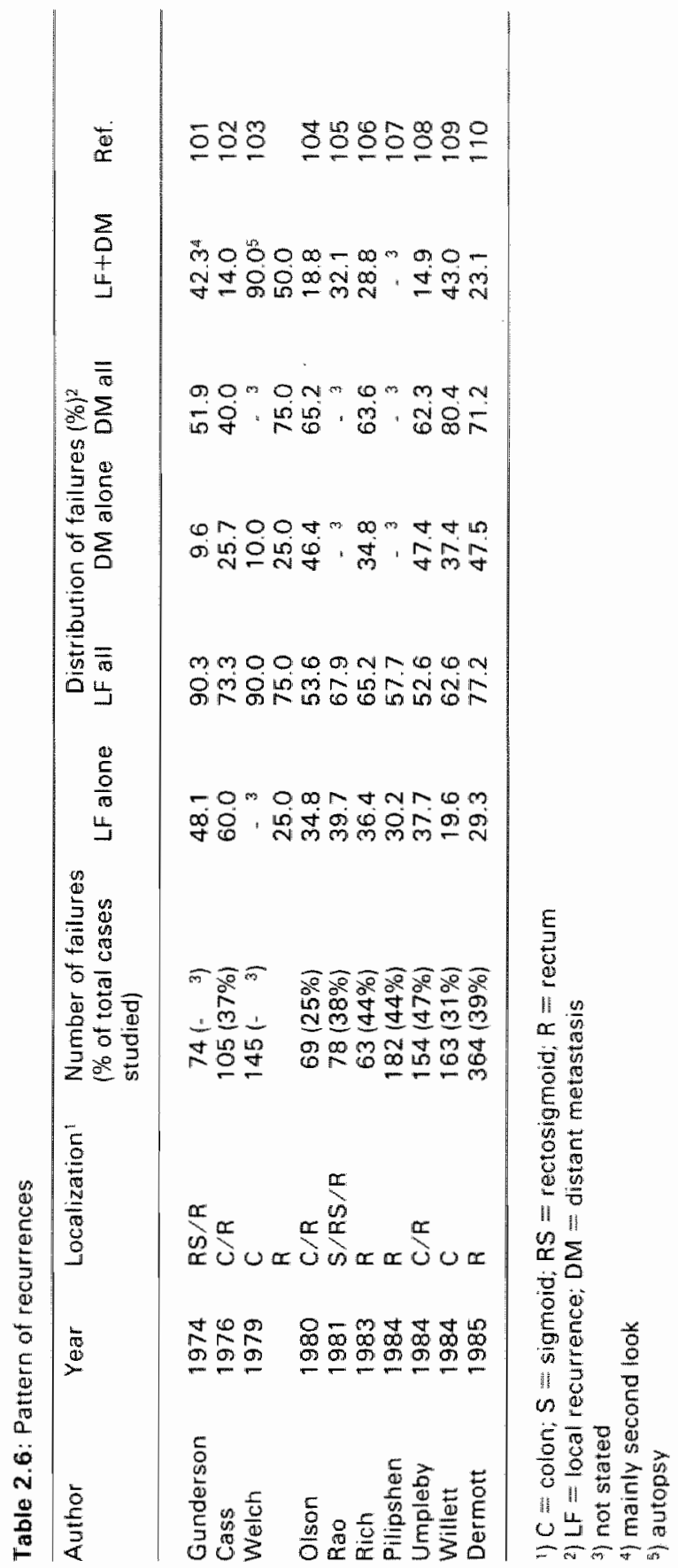


relation to other organs, the highest rate of local recurrence is found within the pelvis. Tumors of the lower one third of the rectum are more frequently followed by local recurrence than tumors located in the upper third 103,107.812,113.

The source of this type of recurrence is most likely outgrowth of locally residual disease. Not only recurrence of remnants of the primary tumor but also tumor in thrombosed extramural veins or affected lymph nodes may be responsible. Other possible mechanisms are the implantation of viable exfoliated tumor cells, and the homing of circulating tumor cells from metastases elsewhere in the primary tumor bed. Finally both animal experiments 114 and pathological studies ${ }^{115}$ have suggested that traumatized colon tissue le.g. sutureline) may be a site with less resistance to the carcinagens still present in the bowel lumen. As a consequence, this may be the localization for new arising carcinomas mimicing recurrences.

Several authors have tried to evaluate the relative importance of the different factors. Lofgren ${ }^{115}$ studied specimens of locally recurrent carcinornas of the sigmoid and the rectum removed by a second operation or found at autopsy. The growth pattern of the recurrence at or near the suturelline was classified as extra-anastomotic, anastomotic, intraluminal or extramural. There was no relationship between the length of the "normal' distal mucosa and the subsequent recurrence. Residual tumor in advanced cases with extramural extension seemed to be of more importance than the extent of lymph node involvement. Recurrence rates determined by a unique series of 68 patients undergoing, both symptomatic and asymptomatic second look operations, were very different if a subdivision was made in cases with microscopic or macroscopic extension of the tumor through the bowel wall. In this series, the local failure was $100 \%$ if there was adherence or adhesion to adjacent organs at the first operation ${ }^{101}$. The fact that the depth of invasion is more important than the extent of the lymph node involvement is in agreement with many other authors $100,116,117$.

Especially cases with the only lymph nodes involved near or at the bowel wall (most of them called $\mathrm{C}$ 1) have low local recurrence rates ${ }^{101.102}$. Usually these lymph nodes are removed 'en bloc' during the operation and no tumor is left behind. This phenomenon is reflected in 5-year survival rates as well, being only related to the extent of tumor growth through the bowel wall ${ }^{118}$. It is possible, that cases with extensive lymph node involvement (C2) have more local failure than has been described. An explanation may be the fact that the prognosis of these patients is anyway very poor due to the early occurrence of distant metastases. During this period the local failure may still be without clinical symptoms. 
A low degree of differentiation is also associated with an increased risk of local recurrence 102,104.106.110.113 although this is not generally confirmed 12,115

It is difficult to determine the role and exact site of implantation of viable tumor cells although it has been considered the major cause of local failure ${ }^{116}$. Mucosa and even the damaged mucosa are rather resistent to implantation ${ }^{93}$. The sutureline itself seems not to be very important as implantation site since the same rate of local recurrences within the pelvis is found for both low anterior resections and abdominoperineal resections ${ }^{106.107}$. It is more likely that viable tumor cells, implanted within the primary tumor bed, grow into the lumen through the place of the least resistance which is, under these conditions, the sutureline. Nevertheless, local tumor spill as a result of intraoperative perforation seems an important factor in both local recurrence and survival rate ${ }^{19,120}$ and there is evidence of a reduced percentage of 'sutureline recurrences if protective measures, such as irrigation are taken'121,122,123.

\subsubsection{Distant metastases}

Metastatic disease is the transfer of malignant disease from one organ to another not directly connected with it ${ }^{13}$. For colorectal carcinomas the liver is the most frequently involved intra-abdominallly organ, both as single organ and as a part of multifocal metastastic disease ${ }^{106.109}$. Next in frequency are the peritoneal layer and the abdominal wall. Extra-abdominally the main areas of failure are in order of decreasing frequency the lung, the skeleton and the central nervous system 107.124 .125 . Twenty percent of the newly diagnosed patients with colorectal carcinomas already have detectable liver metastases $^{126}$ and finally up to $80 \%$ (table 2.6) have these deposits at autopsy.

Hepatic deposits are most frequently situated in the right lobe suggesting a mechanical factor due to the greater blood flow from the inferior mesenteric vein to this area ${ }^{103}$ but, according to others ${ }^{125}$ this phenomenon is due to the larger volume of the right lobe. The vallue of mechanical factors is assured, by the higher incidence of pulmonary metastases in cases with rectal cancer due to direct drainage in the caval system via the hypogastric veins ${ }^{103.127}$. The number of liver metastases is also increasing in combination with local failure in cases with widespread disease ${ }^{101}$.

The low incidence of peritoneall metastases ${ }^{102,106}$ is in contrast with the high incidence of peroperatively detectable tumor cells in peritoneal smears. This finding suggests that tumor cell implantation 
and outgrowth on the intact peritoneal layer is not of great importance. Implantation of tumor cells in the wound of the abdominal wall must often occur. Recurrence at this site is rare and, if it occurs, it is usually (as in mammary carcinoma) the first presentation of wide spread metastatic disease ${ }^{122}$.

\subsubsection{Conclusions}

The cause of local recurrence is multifactorial. Extension of growth of the primary tumor outside the bowell wall seems to be more important than the number of involved lymph nodes. The contribution of the implantation of exfoliated cells is uncertain. The true incidence of local recurrence is still unknown due to the lack of accurate diagnostic methods. Even second look operations are not hundred percent diagnostic as in Gunderson's series 101 seven out of 29 patients with a negative exploration later developed evidence of local recurrent disease. There is doubtlessly, an additional group of patients with clinically silent local failure in the presence of distant metastases but due to the short survival and the severity of the symptoms these failures remain undetected.

The liver is the most common site of distant failure. Again there is a contrast between the clinically detected isolated recurrences and the widespread disease usually diagnosed at autopsy (table 2.6). In general about $25 \%$ of the patients with disseminated colorectal cancer die because of distant metastases, $50 \%$ as a result of both distant and local failure and the remaining $25 \%$ die as a result of local tumor recurrence. The first detected site of recurrent disease is most of the time unimportant since survival is mostly not dependent upon the site of first presentation 110. Only a minority of both distant and local failures can be cured if complete resection is still possible.

In fact, a literature study of the patterns of recurrent disease gives hardly any information about the biological behavior of a tumor and it is impossible to determine the relevance of certain factors responsible for the failures independently. Due to the lack of adequate diagnostic methods we only observe the final stages of the disease. Depending on the methods used, and the material studied, slight differences regarding the outcome of the metastatic process are observed. This has led Dionne ${ }^{125}$ to accept venous invasion as the main route of spread for large bowel cancer, whereas Taylor 129 suggests, local invasion, and Gabriel ${ }^{37}$ lymphatic involvement as the most important source of recurrent disease. On the base of experimental data all the pathways should be considered as important. 


\subsection{References}

1. Morgan CN, Griffiths JD. High ligation of the inferior mesenteric artery during operations for carcinoma of the distal colon and rectum. Surg Gynecol Obstet 108: $641-650,1959$.

2. Netter FH. Digestive System. Part II: Lower digestive tract, The Ciba collection of medical illustrations, Ciba Pharmaceutical Company, 1973

3. Goligher JC. Surgery of the anus. Bailliere Tindall, 4 th ed, London, 1980

4. Anson BJ. McVay CB. Surgical Anatomy. Saunders Company. Philadelphia. London, Toronto, 1971

5. Fenoglio CM. Kaye GI. Lane $\mathbb{N}$. Distribution of human colonic lymphatics in normal, hyperplastic and adenomatous tissue. Gastroenterology 64:51-66, 1973

6. McElwain JW, Bacon HE. Trimpi HD. Lymph node metastases: experience with aortic ligation of inferior mesentery artery in cancer of the rectum. Surgery 35 $513-531,1954$.

7. Phillips JW, Waugh JM, Dockerty MB. The surgical significance of regional Iymphatic drainage of the hepatic flexure. Surg Gynecol Obstet 99: 455-461, 1954

8. Enquist IF, Block $\mathbb{R}$. Rectal cancer in the female: selection of proper operation based upon anatomic studies of rectal lymphatics. Prog Clin Cancar 2: 73-85. 1966.

9. Sauer I, Bacon HE. Influence of lateral spread of cancer of the rectum on radicability of operation and prognosis. Am J Surg 81: 111-120, 1951.

10. Ackerman NB. The influences of mechanical factors on intestinal lymph flow and their relationship to operations for carcinoma of the intestine. Surg Gynecol Obstet 138: 677-682,974.

11. Ackerman NB. Vascular influences on intestinal lymph flow and their relationship to operation for carcinama of the intestine. Surg Gynecol Obstet 137: 801-804, 1973

12. Ackerman NB. Primary arterial ligation in resection of cancer of the colon. Am J Surg 133: 73-77, 1977

13. Fidler IJ. Hart IR. Principles of cancer biology: biology of cancer metastasis. In: De Vita VT. Hellman S. Rosenberg SA (ed): Cancer principles and practice of oncology. Chapter 5, Lippincott Company. Philadelphia, Toronto, 1982.

14. Weiss L. A pathobiologic overview of metastasis. Semin Oncol 4: 5-17, 1977.

15. Hoover HC, Ketcham AS. Techniques for inhibiting tumor metastases Cancer 35: $5-14,1975$

16. Liotta LA. Tryggwason K, Garbisa S, Hart I, Foltz CM, Shafie S. Metastatic potential correlates with enzymatic degradation of basement membrane collagen. Nature 284: $67-68,1980$.

17. Sugarbaker EV. Cancer metastasis: a product of tumor-host interactions. Im: Current problems in cancer, vol. III (7). 1979

18. Sugarbaker EV, Ketcham AS. Mechanisms and prevention of cancer dissemination; an overview. Semiln Oncol 4: 19-32, 1977.

19. Salsbury AJ. The significance of the circulating cancer cell. Cancer Treat Rev 2. $55-72.1975$.

20. Weiss L. The pathophystology of metastasis within the lymphatic system. In Weiss L. Gilbert HA. Ballon SC (eds): Lymphatic system metastasis, Chapter 1, GK Hall Medical Publishers, Boston, Massachusetts, 1980.

21. Del Regato JA. Pathways of metastatic spread of malignant tumors. Semin Oncol 4: $33-38,1977$

22. Zeidman 1, Buss JM. Experimental studies on the spread of cancer in the lymphatic system. 1. Effertiveness of the lymphnodes as a barrier to the passage of embolic tumor cells. Cancer Resi 14:403-410, 1954.

23. August DA, Sugarbaker PH, Schneider PD. Lymphatic dissemination of hepatic metastases. Implications for the follow-up and treatment of patients with colorectal cancer. Cancer 55: 1490-1494, 1985. 
24. Fisher B, Fisher EP. The interretationship of hematogenous and lymphatic tumor cell dissemination. Surg Grnecol Obstet 122: 791-798. 1966.

25. Farr $A G$, De Bruyn PPH. The mode of lymphocyte migration through postcapillary venule endothelium in Iymphi node. Am J Anat 143: 59-92. 1975.

26. Fisher $B$. Fisher ER. Barrier function of lymph node to tumor cells and erythrocytes. I Normal nodes. Cancer 20: 1907-1913,1967.

27. Carr I. McGinty F. Lymphatic metastasis and its inhibition: an experimental model. $J$ Pathal 113:85-95, 1974.

28. Fisher $B$, Fisher ER. Barrier function of lymph node to tumor cells and erythrocytes. II Effect of $X$-ray, inflammation, sensitization and tumor growth. Cancer 20:19141919,1967

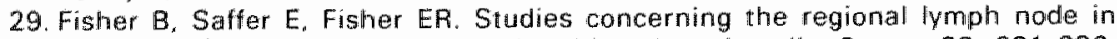
cancer. IV Tumor inhibition by regional lymph node cells. Cancer 33: 631-636. 1974

30. Van de Velde C.JH, Mever CJLM, Cornelisse CJ, Van der Velde EA, Van Putten $L M, Z$ waveling $A$. A morphometrical analysis of lymph node responses to tumors of different immunogenicity. Cancer Res 38: 661-667, 1978.

31. Berg JW. Huvos AG, Axtell LMI, Robbins GF. A new sign of favorable prognosis in mammary cancer: hyperplastic reactive lymph nodes in the apex of the axilla. Ann Surg 177. 8-12, 1973

32. Black MM. Freeman C. Mork T. Harvei S. Cutler SJ. Prognostic significance of microscopic structure of gastric carcinomas and their regional lymph nodes. Cancer 27: $703-711,1971$.

33. Crile G. Possible rale of uninvolved regional nodes in prevention metastasis from breast cancer. Cancer 24: 1283-1285, 1969.

34. Fisher B. Wolmark $N$, Redmond C, Deutsch M. Fisher ER. Findings from NSABP protacol nr. B-04: Comparison of radical mastectomy with alternative treatments II. The clinical and biologic significance of medial-central breast cancers. Cancer 48: 1863-1872, 1981 .

35. Veronesi U, Valagussa $P$. Inefficacy of internal mammary nodes dissection in breast cancer. Cancer 47: 170-175, 1981.

36. Veronesi $U_{i}$ Adamus J. Bandiera $D C$ et al. Inefficacy of immediate node dissection in stage I melanoma of the limbs. N Engl I Med 297:627-630, 1977

37. Gabriel WB. Dukes C. Bussey HJR. Lymphatic spread in cancer of the rectum. $\mathrm{Br} J$ Surg 23: 395-413, 1935.

38. Gilchrist RK, David VC. A consideration of pathological factors influencing five year survival in radical resection of the large bowel and rectum for carcinoma. Ann Surg 126: 42 \$-438, 1947.

39. Grimnell RS. Lymplyatic metastases of carcinoma of the colon and rectum. Ann Surg 131:494-506, 1950 .

40. Moore GE. Sako $K$. The spread of carcinoma of the colon and rectum: a study of invasion of blood vesisels, lymph nodes and peritoneum by tumor cells. Dis Colon Rectum 2: 92.96, 1959

41. Coller FA, Kay EB, Maclntyre RS. Regional Iymphatic metastases of carcinoma of the colon. Ann Surg 114:56-67, 1941.

42. Grinnell RS Lymphatic block with a typical and retrograde /ymphatic metastasis and spread in carcinoma of the colon and rectum. Ann Surg 163: 272-280, 1966.

43. Talbot $\| C$, Ritchie S, Leighton M, Hughes AO. Bussey HJR, Morson BC. Invasion of veins by carcinoma of rectum: method of detection, histological teatures and significance. Histopathology 5: 141-163, 1981.

44. Brown CE. Warren $\mathrm{S}$. Visceral metastasis from rectal aarcinoma. Surg Gynecol Obstet 66: 611-621, 1938 .

45. Sunderland DA. The significancie of vein inwasion by cancer of the rectum and sigmoid. Cancer 2: 429-437, 1949.

46. Grinnell RS. The spread of carcinoma of the colon and rectum. Cancer 3: 641 652,1950 .

47. Barringer PL, Dockerty MB, Waugh JM. Bargen JA. Carcinoma of the large 
intestine. A new approach to the study of venous spread. Surg Gynecol Obstet $98: 62-72,1954$.

48. Fisher ER, Turnbull RB Jir. The cytologic demonstration and significance of tumor cells in the mesenteric venous blood in patients with colorectal carcinoma. Surg Gynecol Obstet 100:102-108, 1955

49. Dukes CE. Bussey H.JR. The spread of rectal cancer and its effect on prognosis. Br J Cancer 12: 309 320, 1958

50. Spratt JS. Spiut HJ. Prevalence and prognosis of individual clinical and pathologic variables associated with colorectal carcinoma. Cancer 20:1976-1985, 1967.

51. Copeland EM, Miller LD. Jones. FS. Prognostic factors in carcinoma of the colion and rectum. Am J Surg 116:875-881, 1968

52. Dwight RW, Higgins GA, Keehn RJ. Factors influencing survival after resection in cancer of the colon and rectum. Am J Surg 117:512-522, 1969.

53. Griffiths JD, McKinna JA Rowbotham HD, Tsolakidis P. Salsbury AJ. Carcinoma of the colon and rectum: circullating malignant cells and five-year survival. Cancer $31: 226-236,1973$

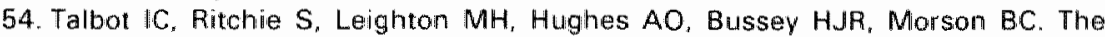
clinical significance of invasion of veins by rectal cancer. $\mathrm{Br} J$ surg $67: 439$. 442,1980 .

55. Knudsen JB, Nilsson $T$, Sprechler $M$, Johansen $\AA$, Christemsen $\mathbb{N}$. Venous and nerve invasion as prognostic factors in postoperative survival of patients with resectable cancer of the rectum. Dis Colon Rectum 26:613-617, 1983.

56. Bloem RM. Colon-en rectumcarcinoom. Behandelingsresultaten, classificatie en prognose. Thesis, Leiden, 1985.

57. Fidler IJ. Metastasis: quantitative analysis of distribution and fate of tumor emboli labelled with 125/-5-iodo-2' deoxyuridine. J Natl Cancer Inst 45:773-782, 1970.

58. Vaage J. Humoral and cellular immune factors in the systemic control of artificially induced metastases in C3Hf mice. Cancer Res 33: 1957 $1965,1973$.

59. Poste G. Fidler lll. The pathogenesis of cancer metastasis. Nature 283: 139-146, 1980.

60. Buinauskas $\mathrm{P}$, McDonald GO, Cole WH. Role of operative stress on the resistance of the experimentall animal to inoculated cancer cells. Ann Surg 148: 642-648. 1958

61. Fidler IJ. The relationship of embolic homogeneity, number size and viability to the incidence of experimental metastasis. Eur J Cancer 9: 223-227, 1973.

62. Liotta LA, Kleinerman J, Saidel GM. The significance of hematogenous tumor cell clumps in the metastatic process. Cancer Res 36: 889-894, 1976.

63. Agostino $D$. Cliffton EE. Organ localization and the effect of trauma on the fate of circulating cancer cells. Cancer Res 25: 1728-1732, 1965.

64. Fisher B, Fisher ER. Experimental studies of factors influencing hepatic mete. stases. III. Effect of surgical trauma with special reference to liwer injury. Anm Surg 150: 731-744, 1959 .

65. Greene HSN. Harvey EK. The relationship between the dissemination of tumor cells and the distribution of metastases. Cancer Res $24: 799-811,1964$.

66. Nicolson GL. Cancer metastasis. Sci Am 203: 50 60, 1979.

67. Fidler IJ. Kripke ML. Metastasis results from preexisting variant cells within a malignant tumar. Science 197: 893-895, 1977.

68. Fidler I $\rfloor$. Tumor heterogeneity and the biology of cancer invasion and metastasis Cancer Res 38: $2651-2660,1978$.

69. Pool E.H. Dunlop GR. Cancer cells in the blood stream. Am J Cancer 21: 99. 102, 1934

70. Engell. HC. Cancer cells in the circulating blood. Acta Chir Scand Suppl 201 $10-70,1955$

71. Pruitt JC. Hilberg AW, Kaiser RF. Malignant cells in peripheral blood. N Engl J Med 259: 1161-1164, 1958.

72. Long L, Jonasson O, Roberts S, McGrath R, McGrew E, Cole WH. Cancer cells in bliood. Arch Surg 80: 910,919, 1960 
73. Sellwood RA, Kuper SWA, Burn J1, Wallace EN. Circulating cancer cells: the influence of surgical operation. 8r J Surg 52:69, 1965.

74. Poberts $\$$, Jonassan O. Long L. McGrath R, McGrew EA, Cole WH. Clinical significance of cancer cells in the circulating blood. Ann Surg 154: 362-371. 1961

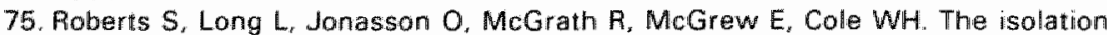
of cancer cells from the blood stream during uterine curettage. Surg Gynecol Obstet 111: 3-111, 1960.

76. Roberts SS, Hengesh JW, McGrath RG, Valaitis J. McGrew EA, Cole WH. Prognostic significance of cancer cells in the circulating blood. A ten year evaluation. Am J Surg 113: 757-762, 1967.

77. Cole WH, Packard D, Southwick HW. Carcinoma of the colon with special reference to prevention of recurrence. JAMA 155: 1549-1553, 1954.

78. Salsbury A., McKinna JA, Griffiths.JD, Morgan CN. Circulating cancer cells during excision of carcinomas of the recturn and colon with high ligation of the inferior mesenteric vein. Surg Gynecol Obstet 120:1266-1270, 1965.

79. Mckinna JA, Rowbotham HD. Experimental studies of factors causing blood-borne dissemination in cancer of the colon and rectum. Proc Roy Soc Med 64:569. 1971.

80. Van Prohaska J, Gowostis MC, Wasick M. Multiple organ resection for advanced carcinoma of the collon and rectum. Surg Gynecol Obstet 97: 177-182, 1953.

81. Jensen HE, Balslew I, Nielsen J. Extensive surgery in treatment of carcinoma of the colon. Acta Chir Scand 136:431-434, 1970.

82. El-Domeiri A, Whitelley HW. Prognostic significance of abdominal wall involvement in carcinoma of cecum. Cancer 26:552-556, 1970.

83. Polk HC. Extended resection for selected adenocarcinomals of the large bowel. Ann Surg 175: 892-899. 1972.

84. Davies GC, Ellis H. Radical surgery in locally advanced cancer of the large bowel. Clin Oncol 1:21-26, 1975 .

85. Bonfanti G. Bozzetti F, Doci R, Baticci F, Marolda R, Bignami P. Gennari L. Results of extended surgery for cancer of the rectum and sigmoid. Br J Surg 69: 305 307,1982

86. Durdey $P$, Williams NS. The effect of malignant and inflammatory fixation of rectal carcinoma on prognosis after rectal excision. Br. J. Surg. 71: 787-790, 1984.

87. Black WA, Waugh JM. The intramural extension of carcinoma of the descending colon, sigmoind and rectosigmoid. Surg Gynecol Obstet 87: 457-464, 1948.

88. Williams NS. Dixon MF, Johnston D. Reappraisal of the 5 centimetre rule of distal excision for carcinoma of the rectum: a study of distal intramural spread and of patients' survival. Br J Surg 70: 150-154. 1983.

89. Ouer EA, Dahlin DC, Mayo CW. Retrograde intramural spread of carcinoma of the recturn and rectosigmoid. Surg Gynecol Obstet $96: 24-30,1953$

90. McGrew EA, Laws JF, Cole WH. Free malignant cells in relation to recurrence of carcinoma of the colon. JAMA 154:1251-1254, 1954

91. Vink $M$. Local recurrence of cancer in the large bowel: the role of implantation metastases and bowell desinfection. Br J Surg 41:431-433, 1954.

92. Cohn I. Impliantation in cancer of the colon. Surg Gymecol Obstet 124: $501-508$, 1967.

93. Yu SK, Cohn I. Tumor implantation on colon mucosa. Arch Surg 96: 956-958, 1968.

94. Norgren J, Svensson JO. Anal implantation metastasis from carcinoma of the sigmoid collon and rectum - a risk when performing anterior resection with the EEA stapler? Br J Surg 72:602, 1985.

95. Umpleby HC. Fermor B. Symes MO, Williamson RCN. Viability of exfoliated colorectal carcinoma cells. Br J Surg 71:659-663, 1984

96. Rosenberg IL. Russell CW. Giles GR. Cell viability studies on the exfoliated colonic cancer cell. Br J Surg 65: 188-190, 1978. 
97. Fermor B. Umpleby HC, Lever JV, Symes MO, Wiltiamson RCN. Proliterative and metastatic potential of exfoliated colorectal cancer cells. JNCI 76:347-349. 1986

98. Quan SHO. Cul-de-sac smears for cancer cells. Surgery 45: 258-263, 1959.

99. Moore GE, Sako K, Kondo T. Badillo J. Burke E. Assessment of the exfoliation of tumor cells into the body cavities. Surg Gyn Obstet 112:469.47.4, 1961 .

100.Zoetmulder FAN. Modelstudies over het colorectale carcimoom. Thesis, Leiden, 1982 .

101. Gunderson LL, Sosin $H$. Areas of fallure found att reoperation isecond or symptomatic look) following "curative surgery" for adenocarcinoma of the rectum. Cancer 34: 1278-1292, 1974 .

102. Cass AW, Million RR. Pfaff WW. Patterns of recurrence following surgery alone for adenocarcinoma of the colon and rectum. Cancer $37: 2861-2865,1976$

103. Welch JP. Donaldson GA. The clinical correlation of an autopsy study af recurrent colorectal cancer. Anı Surg 189:496-502, 1979.

104. Olson RM, Perencevich NP, Malcolm AW, Chaffey JT, Wilson RE. Patterns of recurrence following curative resection of adenocarcinama of the colon and rectum. Cancer 45: 2969-2974, 1980.

105. Rao AR, Kagan AR, Chan PM, Gilbert HA, Nussbaum H, Hintz BL. Patterns of recurrence following curative resection alone for adenocarcinoma of the rectum and sigmoid colon. Cancer 48: 1492-1495, 1981.

106. Rich T. Gunderson LL, Lew R. Galdibini JU, Cohen AMn Donaldson G. Patterns of recurrence of rectal cancer after potentially curative surgery. Cancer 52:1317. 1329,1983

107. Pilipshen SJ, Heilweil M, Quan SHQ, Sternberg SS, Enker WE. Patterns of pelvic recurrence following definitive resections of rectal cancer. Cancer 53:1354-1362. 1984.

108. Umpleby HC, Bristol JB, Rainey JB. Williamson RCN. Survival of 727 patients with single carcinomas of the large bowel. Dis Colon Rectum 27:803-810, 1984.

109. Willett CG. Tepper JE, Cohen AM, Orlow Ex Welch CE. Failure patterns following curative resection of colonic carcinoma. Ann Surg 200:685-690, 1984.

110. McDermott FT, Hughes ESR, Pihl E, Johnson WR, Price AB. Local recurrence after potentially curative resection for rectal cancer in a series of 1008 patients. Br J Surg 72: 34-37, 1985.

111. Beal JM, Cornel: GN. A study of the problem of recurrence of carcinoma at the anastomotic site following resection of the colon for carcinoma. Ann Surg 143: 1.7. 1956

112. Moossa AR, Ree PC, Marks JE, Lewin B, Platz CE, Skinner DB. Factors influencing local recurrence after abdominoperineall resection for cancer of the rectum and rectosigmoid. Br J Surg 62: 727 730, 1975

113. Morson BC. Vaughan EG, Bussey H.JR. Pelvic recurrence after excision of rectum for carcinoma. Br Med J 2: 13-18, 1963.

114. Terpstra OT, Peterson Dahl E. Williamson PLN, Ross JS, Malt RA. Colostomy closure promotes cell proliferation and di-methylhydrazine induced carcinogenesis in rat distal colon. Gastroenterology 81: 475-480, 1981

115. Lofgren EP. Waugh JM. Dockerty MB. Local recurrence of carcinoma after anterior resection of the rectum and the sigmoid. Arch Surg 74: 825-838, 1957.

116. Tyrndai EC. Dockerty MB, Waugh JM. Pelvic recurrence of carcinoma of the rectum. Surg Gynecol Obstet 118: 47-51, 1964.

117. Gilbertsen VA. Adenocarcinoma of the large bowell 1.340 cases with 100 percent follow-up). Surgery 46, 1027-1042, 1959

118. Wood CB, Gillis CA. Hole D, Malcolm A.JH, Blumgart LH. Local tumour invasion as a prognostic factor in colorectal cancer. Bir J Surg 68: 326-328, 1981

119. Ranbarger KR. Johnston WD, Chang JC. Prognostic significance of surgical perforation of the rectum during abdominoperineal resection for rectal carcinoma. Am J Surg 143: 186-188, 1982.

120. Slanetz CA. The effect of inadvertent intraoperative perforation on survivall and recurrence in colorectal cancer. Dis Colon Rectum 24: 792-797, 1984 
121. Keynes WM. Implantation from the bowel lumen in cancer of the large intestine Ann Surg 153: 357-364, 1961

122. Morgan CN. Trends in the treatment of tumours of the rectum, rectosigmoid and left colon. I R Coll Surg Edinb 1:112-125, 1955

123. Southwick HW. Harridge WH. Cole WH. Recurrence at the sutureline following resection for carcinoma of the colon. Am J Surg 103: 86-89, 1962.

124. Eisenberg B. DeCosse $J$. Harford F. Michalek J. Carcinoma of the colon and rectum: the natural history reviewed in 1704 patients. Cancer $49: 113 \%-1134$. 1982.

125. Dionne $L$. The pattern of blood-borne metastasis from carcinoma of rectum. Cancer 18: $775-781,1965$.

126. Blumgart LH. Surgical treatment of liver metastases. In Welvaart $K$ e.a. (eds): Colorectal Cancer, Boerhaave series vol. 18. Leyden University Press, The Hague. Boston, London, 1980.

127. Berge T, Ekelund G, Mellner C. Phi B. Wenckent A. Carcinoma of the colon and rectum in a defined population. Acta Chir Sicand Suppl 438, 1973.

128. Hughes ESR, McDermott FT, Polglase AL, Johnson WR. Tumor recurrence in the abdominal wall scar tissue after large-bowel cancer surgery. Disi Colon Rectum 26: $571-572,1983$

129. Taylor FW. Cancer of the colon and rectum: a study of routes of metastases and death. Surgery 52; 305-308, 1962. 


\section{Current state of surgical therapy in colorectal cancer}

\subsection{Introduction}

At present, surgery offers the best possibility for cure in primary colorectal cancer. Cure by radiotherapy alone, has been claimed in small rectal cancers only. Radiotherapy in combination with chemotherapy may play an important role as adjuvant treatment ${ }^{2}$. Prolongation of disease free survival has not yet been demonstrated by the use of adjuvant chemotherapy ${ }^{3}$.

The first aim of surgery is to relieve the patient of his complaints (e.g. blood loss or bowel obstruction) by removal of the primary tumor. The surgical therapy may consist of local resection of the tumor alone or of resection of a segment of the bowell including mesentery and, if necessary, with adjacent organs that are involved with the tumor. Local excision is reserved for malignant adenomas or polypoid carcinomas. This method of (endo-)resection should meet "strict criteria $^{4}$. It is also possible ${ }^{5.6}$, but controversial?, in small rectal cancers. After the Second World War the resectability rate of colonic cancer has increased from 60 to 80 percent $^{8}$ and most surgeons 9.10 .11 .12 .13 .14 are now resecting between 85 and 95 percent of all tumors.

The second purpose of surgery is the prevention of lacal recurrence and distant metastases. The extent of the local removal of all the tumor should influence the chance of local control and, if possible, efforts should be made to prevent further dissemination, not only during the operation but also during the preceding diagnostic procedures such as biopsy ${ }^{15}$, barium enemas and colonoscopy.

Although surgical resection seems to be a standard procedure this is not true and the extent of local resection, the extent of lymph node dissection and the necessity of Iymphovascular isolation is not well defined. No prospective studies regarding any of these aspects are available, and the only information obtainable is from retrospective series, of which a review will be given. 


\subsection{Local resection}

Theoretically, removal of the entire tumor and prevention of local tumor spill should reduce the problem of locall recurrence. Several factors may be of importance: the length of resected bowel segment, 'en bloc' resection of adjacent organs and the implantation of exfoliated tumor cells.

\subsubsection{Length of resected bowell wall}

The relation between the length of resected bowel and the incidence of local recurrence has been the subject of several clinical reports. This is particularly relevant in the rectosigmoid area where margins of less than five centimetre are sometimes necessary in an attempt to preserve the sphincter function. It is of interest that the lack of intramural spread, of more than two centimetre in histopathologic studies (Chapter 2.2.6) is confirmed in clinical studies. Pollett and Nicolls ${ }^{16}$ studied 334 patients with single rectal carcinomas treated by anterior resection. A subdivision was made by dividing the length of the distal margin into three categories $<2 \mathrm{~cm}, 2-5 \mathrm{~cm},>5 \mathrm{~cm}$ ). The percentages for local recurrence and survival among the three categories were similar. The irrelevance of the relation between local recurrence, the margin between the tumor and the level of resection has been confirmed by others ${ }^{17.18}$.

When comparing data of abdominoperineal resections and low anterior resections for rectal cancer the likelihood of local recurrence or survival is equal ${ }^{19.20}$

Only a few authors have a different opinion about the length of tumor free margin and prognosis. A suture line recurrence rate of $18.4 \%$, with a diminished five year survival, was reported ${ }^{13}$ if one of the margins of the resected specimens was less than five centimetre. Lack of details regarding the anatomic site of the lesion, the number of involved lymph nodes and type of surgery make these data difficult to interpret. Enker et al. ${ }^{21}$ found, in cases with involved lymph nodes a local recurrence of $36.8 \%$ if the distal margin was less than ten centimetre and $7.4 \%$ with a margin exceeding ten centimetre. However, his data on local recurrence, by comparing low anterior and abdominoperineal resections were in favour of the first group $(12.5 \%$ versus $24 \%)$. This suggests the incidence of local recurrence to be more a result of the degree of Iymph nade involvement and largely independent of the length of the distal free margin.

An extended removal of the dorsally located mesorectum includes not only affected lymph nodes but also, microscopic deposits in lymphatics 22 . 
The conclusion based on both histopathological and clinical studies is that the length of the tumor free bowel wall is not an important factor in the occurrence of local recurrence and survival.

\subsubsection{Involvement of adjacent structures and organs}

Before invading adjacent organs, the tumor passes through the perimural fat. The extent of extramural growth is correlated with the chance of $\|$ ocal recurrence (Chapter 2.2.5). No clinical data are available about a possible benefit of increasing the extension of clearance of the pericolic and perirectal fat.

In about ten percent of patients with primary colorectal cancer involvement of the adjacent organs is found $23,24,25,26.27$. Sometimes the percentage is higher ${ }^{28}$. Up to $48 \%$ of the tumors are not mobile during surgery ${ }^{29}$, if the definition of involvement is extended to fixity of the primary tumor. Although adherence is associated with a poor prognosis and a high operative mortality, five year survival of "en bloc' resections exists (table 3.1 ). This is partly a result of the fact that not all adhesions are of carcinomatous origin (Chapter 2.2.5). A second reason for survival in these cases may be as Spratt ${ }^{39}$ suggests, he describes a biological variant of colorectal cancer that

Table 3.1: Five year survival in cases with resection of adjacent organs

\begin{tabular}{|c|c|c|c|c|c|c|}
\hline Author & Year & Number & Sites: & $\begin{array}{l}\text { Five year } \\
\text { survival }(\%)\end{array}$ & $\begin{array}{l}\text { Operative } \\
\text { mortality }(\%)\end{array}$ & Ref. \\
\hline Gilchrist & 1947 & 35 & All & 40 & 20 & 30 \\
\hline Varu Prohaska & 1953 & 21 & All & 66.6 & 4.8 & 23 \\
\hline Gilbertsen & 1959 & 100 & All & 30 & 27 & 10 \\
\hline Brunschwig & 1961 & 19 & RS & 33.3 & - & 31 \\
\hline Rasi & 1962 & 24 & $S / R$ & 63.6 & 8.3 & 11 \\
\hline Bacon & 1965 & 75 & $\mathrm{RS} / \mathrm{R}$ & 41.1 & 8.0 & 32 \\
\hline Jemsen & 1970 & 60 & All & 28 & 22 & 25 \\
\hline El-Domeiri & 1970 & 10 & Cecum & 71.4 & 10 & 33 \\
\hline Polk & 1972 & 24 & All & 42 & 4.0 & 34 \\
\hline Welch & 1974 & 164 & All & 34 & 6.0 & 24 \\
\hline Davies & 1975 & 43 & All & 19 & 18.6 & 28 \\
\hline Newinan & 1975 & 52 & All & 21.2 & - & 35 \\
\hline Bonfanti & 1982 & 61 & $\mathrm{~S} / \mathrm{R}$ & $32.75^{2}$ & 8.2 & 36 \\
\hline Rich & 1983 & 21 & $R$ & 19.1 & - & 27 \\
\hline Dutrdey & 1984 & 169 & $\mathrm{R}$ & $28.5-64.6^{2}$ & -3 & 37 \\
\hline Eldar & 1985 & 84 & All & 35 & 5.9 & 38 \\
\hline
\end{tabular}

i) $\mathrm{RS}=$ rectosigmoid; $\mathrm{S}=$ sigmoid; $\mathrm{R}=$ rectum; $\mathrm{All}=$ entire colon including rectuim

21 Depending if the adherence was due to inflammation (first figure) or carcinomatous infiltration (second figure). 
has extensive local growth but does not metastasize to the lymph nodes. Especially in cases without lymph node involvement the prognosis is not so bad ${ }^{35}$ and comparable with patients in which less extensive growth but involved lymph nodes were found 10.29.36. The combination of growth in adjacent organs and lymph node metastases has the worst prognosis and no five year survivors ${ }^{27}$.

In 1975 the Memorial Sloan Kettering Cancer Centre ${ }^{35}$ reported their experience of re-exploration for cancers determined 'unresectable" by previous exploration by the referring hospitals. Of the 52 patients, 32 still underwent a curative resection $(60 \%)$ with a five year disease free survival of $28 \%$.

Also, indirect information about the advantage of performing more resections, in locally advanced cases, is available. The increase in resectability rates in patients with extended disease (estimated in periods of five years) was probably responsible for an overall increase of five year survival in colorectal cancer, since survivall data over the different periods of the patients treated by resection remained similar $^{8}$. Péloquin ${ }^{40}$ addressed the problem in another way, by analysing the resectability rates in the practice of three groups of surgeons over a same period. The crude survival rates increased by a more aggressive surgical approach from $35.0 \%$ to $47 \%$. This improved survival was obtained by an increased resectability rate (from $72 \%$ to $92 \%$ ) because corrected survival rates for resected cases only, remained more or less the same. A similar relationship between the proportion of radical operations and survival among patients treated for large bowel cancer at various centers was observed in England ${ }^{41}$.

A special problem is prophylactic oophorectomy in colorectal cancer. Six percent of the primary cases, and up to $16 \%$ of the cases with involved lymph nodes have metastases in their ovaries ${ }^{42}$. It has been suggested that these ovaries should be routinely removed ${ }^{43}$. However, survival of patients with ovarian metastases is poor, and in two recent series, with comparison of cases with or without prophylactic oophorectomy $y^{44.45}$, no advantage of standard remowal was shown.

\subsubsection{Prevention of local tumor spill}

Exfoliated cells may be present in the abdominal cavity due to shedding from the outside of the tumor or , from the luminal site. Precautions to prevent dissemination via this route may be taken by mechanical measures or, by irrigation of the operation field with cytotoxic solutions.

Covering of the tumor during surgical manipulation with a pad, sometimes in combination with cytolytic agents and fixating ligatures 
on both sides of the tumor, is advocated by some authors ${ }^{46,47}$, but no reports are available about the effectiveness of this procedure. A similar effect is possible after electrofulguration of the serosal side of the tumor, if serosal involvement by the tumor is clear ${ }^{80}$. Ligation of the bowel lumen several centimetres away from the tumor is easy and was already advocated in 1954 by Cole ${ }^{48}$. Smears from the inside of the resected bowel segment showed only tumor cells on the tumor side of the ligature, supporting the effectiveness of this measure ${ }^{49}$.

Irrigation is a second measure and, is possible in the abdominal cavity and the bowel lumen distal or proximal of the anastomotic side. Several authors (table 3.2) describe a reduction of local recurrences at the suture line after ligation and irrigation of the bowel lumen. This effect has been studied mainly in low left sided tumors with a small distal margin and requiring extensive manipulation of the tumor. In these cases, most authors irrigate the rectal stump from below ${ }^{11.50}$. Rinsing the abdominal cavity must prevent the growth of free malignant cells on the peritoneal laver or in the primary tumorbed. Several solutions have been tested but either, ineffectiveness ${ }^{53}$ or adverse effects, due to the chemical peritonitis furthering implantation in animal experiments ${ }^{54}$ have prohibited general acceptance of this procedure. The use of iodized suture materiall and the technique of a closed anastomosis reduced the incidence of tumor implantation on the suture line in an experimental tumor system ${ }^{53}$, in which tumar cells were injected in bowel segments followed by transsection and anastomosis.

None all of these measures have been the subject of a prospective study but, the ligation of the bowel wall on both sides of the tumor and irrigation of the rectal stump and tumorbed in the pelvic cavity without damaging the peritoneal layer, are such easy measures to take that they may be routinely applied. Data on cytotoxic fluids for irrigation of the whole abdominal cavity are more conflicting and do not warrant routine application.

Table 3.2: Suture line recurrences before and after precautions

\begin{tabular}{lcccc} 
Author & Year & $\begin{array}{l}\text { Recurrences at the sulture line } \\
\text { Before } \\
\text { precautions }\end{array}$ & $\begin{array}{c}\text { After } \\
\text { precautions }\end{array}$ & Ref. \\
\hline Goligher & 1951 & $10.0 \%$ & 'lower & 50 \\
Morglan & 1955 & $21.4 \%$ & $2.1 \%$ & 9 \\
Keynes & 1961 & $13.0 \%$ & $2.6 \%$ & 51 \\
Rosi & 1962 & $18.0 \%$ & $2.7 \%$ & 11 \\
Southwick & 1962 & $8.7 \%$ & $0.0 \%$ & 52 \\
\hline
\end{tabular}




\subsection{Limited versus extended lymph node resection}

\subsubsection{Introduction}

Miles $^{55}$ and Moynihan ${ }^{56}$ both focussing on the zone of the upward spread introduced in 1908, removal of the lymphatic drainage area in combination with the resection of the primary tumor. Miles advocated ligating the vessels just below the branching off of the left colic artery, but Moynihan was in favor of a more extended resection up to the origin of the inferior mesenteric artery. Since that time, controversy has existed about the level of lymph node resection in colorectal cancer. Advocates of extended resections claim a higher five vear survival rate. Opponents doubt the validity of these conclusions and warn of the higher morbidity following these resections.

Since no prospective randomized trials, comparing a limited versus an extended lymph node resection, have been performed we have to study the subject from retrospective analyses. One possibility of studying the problem is the shifting in stage, as a result of more extended resections because prognosis is related to the highest lymph node involved. Also, information is available from authors comparing their material with historical or non-randomized control series. Finally the need of extramesenteric lymph node resection will be discussed.

\subsubsection{The extent of intramesenteric resection}

Histopathological studies of Iymphatic metastases have provided information about the pathways, and the extent, of this metastatic route (Chapter 2.2.3). The only suitable area for studying the effect of extension of resection is for left sided tumors. Dissection upward is generally possible up to three levels (figure 3.1). The first level implies removal of lymph nodes till the branching of the left colic artery from the inferior mesenteric artery. Another four to five centimetres of gland bearing mesentery may be removed if the vascular ligation is performed at the origin of the inferior mesenteric artery ${ }^{46.50 .57}$. An additional $10 \| y m p h$ nodes may be removed by this technique 58 . The third level involves resection of the para-aortic and precaval lymph nodes together with dissection of the whole retroperitoneum up to the duodenum 46.59 . For low lying lesions this dissection may include pelvic lymphadenectomy as well60.61.62. At most, ten percent of the patients have positive lymph nodes between level 1 and 2 which would not have been removed if ligation was performed at the level of the left colic artery ${ }^{11.57 .58}$. Unfortunately, 


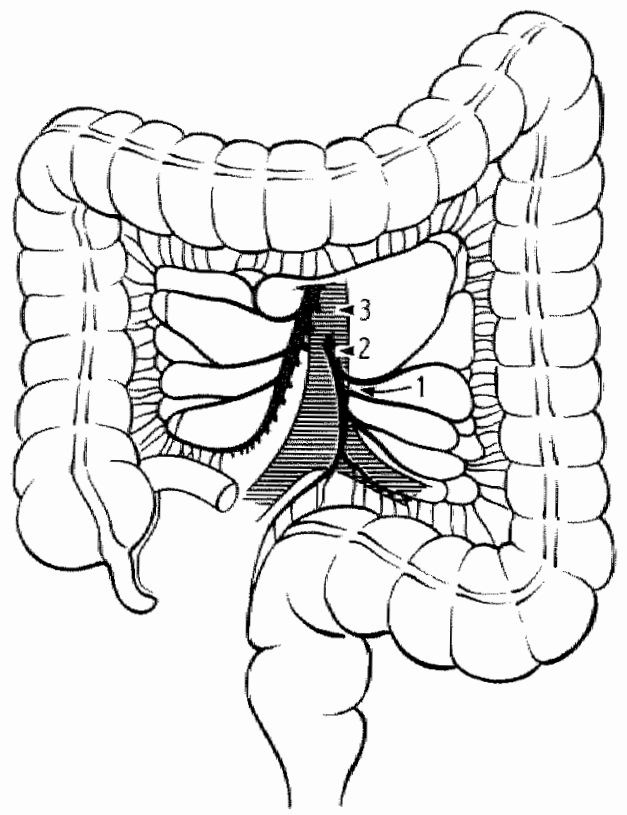

Figure 3.1: Levels of lymph node dissection. Level 1: upto the branching of the left colic artery. Level 2: upto the origin of the inferior mesenteric artery. Levell 3 including the para-aortic lymph nodes.

it was not indicated whether or not positive lymph nodes were present at a higher level in these patients and, no detailed histopathological reports were presented in case reports where the para-aortic lymph nodes of the resected specimens were studied.

Gilchrist and Davies ${ }^{30}$ performed postmortum studies on 11 patients who died in the postoperative period. In eight cases they removed all retroperitoneal tissue, examining between 96 and 168 lymph nodes. Four patients who had metastases in the resected specimen also had metastases in the retroperitoneal specimen. In three of the four cases the metastastic lymph nodes could have been removed if resection had been increased by another 1.5 centimetre. However, if we study the drawings of the dissected specimens of these cases, heavy lymph node involvement (average 19 positive) is present, with a poor prognosis anyway.

The effectiveness of high ligation may also be judged from a decrease in the percentage of the highest node involvement. In one report ${ }^{63}$, in which an author compares his own material pre-and post high ligation, we find a reduction in five year survival of $8 \%$ but in another report 58 no difference is noted (13\% versus $11.3 \%$ ) 


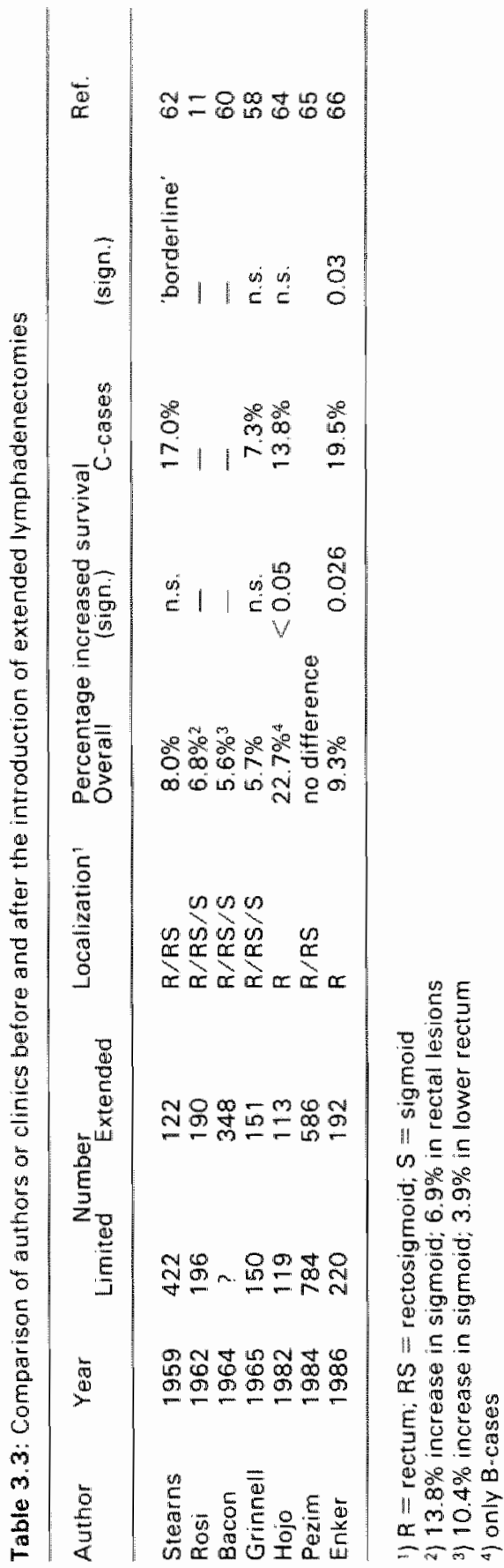


and most authors 57.58 .60 find that, even with an extended resection, a high proportion of lymph nodes remains positive at the highest level.

Four reports ${ }^{11.58 .60 .62}$ have been published comparing survival data before and after the introduction of high ligation. Another three authors ${ }^{64.65 .66}$ compare the results of two different groups of surgeons in the same clinic, one performing a limited, the other an extended lymphatic dissection. The outcome (table 3.3) among these series differs considerably. Small, mainly non-significant differences regarding survival are found in the first group of series. Two authors ${ }^{11.60}$ state a big difference for lesions in the sigmoid area. The largest differences between the two techniques were found by $\mathrm{Hojo}^{64}$ for Dukes $B$ lesions. In addition to the fact that there were rather different numbers of patients ( 33 versus 51 ) in this group, he only found a reduced number of local recurrences and not of distant metastases. This suggests that there is an advantage obtained by local extended resection and not by extended lymphadenectomy. In cases with involved lymph nodes close to the bowel wall figures were similar. The extension of the operation showed an improved prognosis in patients with heavier lymph node involvement, but nothing is stated in his article about the way of determining the presence of metastases in the Iymph nodes in the base of the inferior mesenteric artery and along aorta, for the conventionally operated group.

The recent non-randomized data from Memorial Sloan Kettering address more, the effect of three dimensional resection within the pelvic cavity and not, the effect of high ligation 66 . Five year survival data show an improvement of $9.3 \%$ especially for the cases with lymph node metastases close to the bowel wall. Unfortunately, no specific data on the differences of local recurrence for both techniques are stated.

The data from St. Marks Hospital comprising 1370 patients between 1953 en 1972, showed no difference in survival between the "high" and "low' ligation technique 65 . Although earlier reports" had shown a significant advantage with an increase of $18.8 \%$ in five year survival for $\mathrm{Cl}$ cases $(<5$ nodes involved) this difference disappeared after correction for age in the final report. A special analysis was made of the $C 1$ cases in the upper two thirds of the rectum, for which the technique could be beneficial on theoretical grounds. Although in this group no difference was observed, a shifting of stages may have occurred in the high ligation group from $\mathrm{C} 2$ (highest node involved) to $\mathrm{C} 1$.

Data on the effect of dissection around the aorta are not available but, in the report of an adjuvant chemotherapy trial of the Veterans 
Administration Surgical Adjuvant Group, it was stated in the discussion that peri-aortic node dissecting performed in 345 operations did not improve survival' 67 .

\subsubsection{Extramesenteric resection}

Although in low rectal carcinoma the spread may occur in a lateral, or downward extramesenteric, route this occurs in higher lesions only if there is a blockage of the lymphatic stream due to heavy node involvement (Chapter 2.2.3.3). Authors ${ }^{21,62.64}$ reporting on extended pelvic clearance with dissection along the iliac vessels do not observe an increase in survival if lateral metastases are present. Although both Enker" ${ }^{21}$ and Hojo ${ }^{64}$ promote the extended operation, they had to admit during the discussion after the oral presentation, which is mentioned after the original articles and in later studies ${ }^{66}$, their failure in curing these cases. Grinnell ${ }^{68}$ studied 28 patients with atypical lymph node metastases. No patient survived with abnormally located paracolic or pararectal metastases. In 1950 he still stated ${ }^{59}$ that it is in this group in which wide removal of bowel and mesentery is especially needed' but, in 1965 after knowing the fate of these 28 patients he writes: "these findings should discourage resection of wide segments of bowel on either side of the tumor beyond the usual areas of lymphatic drainage in the hope of affecting cure by removing outlying metastases' 68 .

\subsection{Vascular isolation before mobilization}

\subsubsection{Introduction}

Early blockage of blood-vessels and lymphatic channels during surgery is based upon the finding that tumor cells appear in the portall blood during surgery as a result of manipulation of the primary tumor. The credit for the first description of vascular isolation for colonic cancer has to be given to Barnes ${ }^{70}$. He described, in 1952. the details of this technique for right sided colonic lesions only. Cole $e^{48}$ after finding a cancer cell in a vein, from a resected colonic segment, recommended early ligation for all sides of the colon. For left sided tumors the technique was first described in detail in 1958 by Ault ${ }^{46}$. He introduced the term 'cancer isolation'. The name of Turnbull was connected with this technique because he was the first one to provide clinical data by routinely applying $\mathrm{it}^{12}$. For a better understanding of the value of this procedure will first be described before examining the outcome 


\subsubsection{The no-touch isolation technique}

The principle of this technique already can be applied during the preoperative period. Palpation of an abdominall mass may be discouraged by sticking an adhesive tape on the abdominal wall with the wording 'DO NOT PALPATE'. The radiologist is asked to avoid manipulation with a lead glove during diagnostic studies 71 . In the theatre cleaning of the skin is done by gently soaping instead of scrubbing. After opening of the abdomen the cancer bearing segment is inspected without palpating it. After identification the lymphovascular bundles are selectively ligated and divided (figure 3.2). The artery has to be sacrified as the first step in preventing venous overflow to the marginal veins ${ }^{72}$. Next, the bowel wall has to be divided in combination with the marginal vessels. Tapes have to be applied, just distal to the line of transection, to prevent the escape of exfoliated cells. An extra measure of protection may be the injection of $40 \%$ ethylalcohol into the lumen of the bowel ${ }^{71}$. Although not especially emphasized in Turnbull's descriptions, extended lymphadenectomies (not extramesenteric) were a part of the procedure. Detailed descriptions, for left and right sided tumors including drawings are

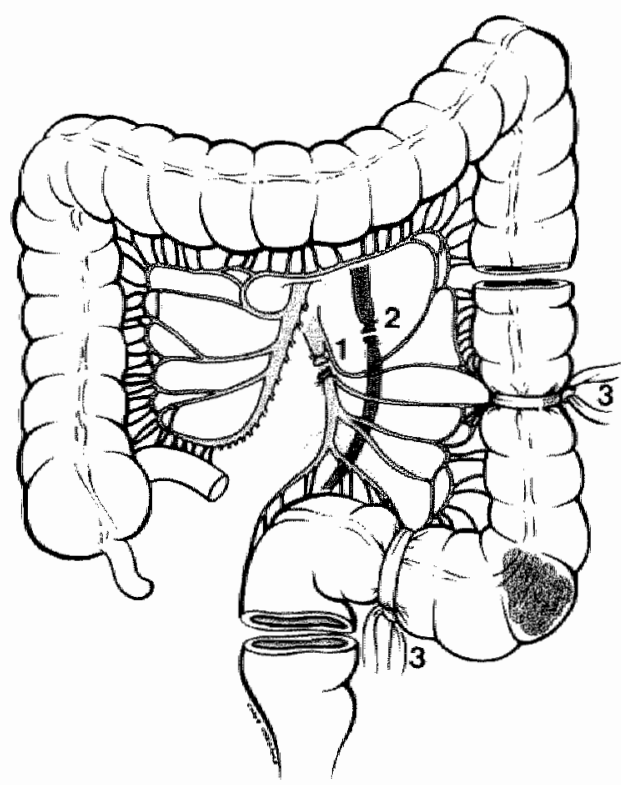

Figure 3.2: Principles of the no-touch isolation technique. 1. ligation of the central artery: 2 ligation of the central vein: 3 . ligation of the bowel lumen including the marginall vessells. 
ductus will be beneficial or not. There just won't be any doubt about it, if it's going to be as good as he says. But Friesen put the question: 'Is it really the avoidance of manipulation or is it the wider excision of the left colon mesentery that gives the better results?'. In nearly every publication about surgery in colorectal carcinoma after 1967. Turnbull's article is quoted. Authors such as Copeland ${ }^{13}$, who study the impact of venous invasion are adwocates of the technique. He stated in 1968: 'The no-touch isolation technique appears to be logical and a potentially productive refinement of operative technique'. But Enker ${ }^{79}$, an advocate of lymph node dissection wrote a paper with the subtitle: 'The fallacy of the no-touch technique".

Although nobody doubts Turnbull's results there have been several points of criticism ${ }^{80}$. Firstly, the new clinicopathological staging system may have shifted many, previously classified $C$ cases, into the D group explaining the dramatic improvement for cases with lymph node metastases. Secondly, the sellection of the patients referred to a private clinic may have played a role. Thirdly, the combined introduction by Turnbull of an extended (lymph node) resection and lymphovascular isolation makes conclusions of one step difficult. Fourthly, there has been criticism about the size and composition of his historical control group. In the last two publications ${ }^{71.78}$ he did not refer to this control group. Another difficulty in interpretating this data is the fact that the gain of survival is achieved in the cases with lymph node metastases only. Venous invasion is present in a similar way in $B$ and $C$ cases ${ }^{81}$. Turnbull did not state carefully the pattern of recurrences in his series. Apart from the statement that 'most of the deaths were due to metastasis to the liver' he did not give any further details. Finally, the reduced blood loss, needing less transfusion by performing early vascular ligation 70.74 , may have played a role in the final outcome.

\subsection{Discussion and conclusions}

Sugarbaker ${ }^{82}$ gives an accurate definition for surgical treatment of large bowel cancer: 'the objective is to remove the primary tumor and any regional spread that may have occurred without causing further dissemination of the tumor and leaving the patient with a reasonable quality of life:

The removal of the primary tumor, if necessary with adjacent organs should be performed 'en bloc'. An increased resectability rate, in combination with a diminished postoperative death rate has improved five year survival especially in the first part of the past forty years ${ }^{8.40 .83 .84}$. This gain in survival is partly due to the non- 
carcinomatous origin of some adhesions but also, histologically confirmed tumor growth in adjacent organs may be cured by radical resections. Only a few centimetres of normal bowel wall in conjunction with the tumor have to be removed. The extent of bowel wall resection is predominantly defined by the extent of Iymphatic resection along the marginal artery.

There is a difference in five year survival rates of about ten percent between reports from large series from different countries (table 3.6) as compared with reports from authors claiming a certain technique (table 3.7). These authors claim quite similar results (table 3.7 ) but, their techniques differ from limited to extended lymphatic dissection or no-touch isolation technique. The optimal extent of the removal of lateral and central Iymphatic spread is uncertain. The value of extended resections is based on a comparison of survival data derived from literature figures since no detailed studies about the pattern of recurrences are available. Several authors ${ }^{9.64}$ but not al| ${ }^{58.65}$ report differences in survival in cases with central extended lymphadenectomies. They compare their data with the results from other surgeons in their own clinic or by the data before their own change of limited to extended resections. Besides the fact that extension of lymph node dissection does not fit in modern concepts about tumor dissemination other factors, like an increased local resectability rate, diminished blood loss, surgical trauma, type of anaesthesia and finally selection of patients may have played a role in determining the outcome. In this regard no final conclusions and recommendations can be given for extended lymphatic clearance. The only exception is perhaps the pelvic cavity in which due to small margins radical extended resections may result in better local contral and in improved survival ${ }^{22.66}$.

Extramesenteric Iymph node dissection ${ }^{68}$ or prophylactic removal of the ovaries ${ }^{44}$ are unlikely to effect survival. In case of metastatic disease in these structures, the tumor is usually widely disseminated with a poor prognosis anyway.

Already during the diagnostic process iatrogenic dissemination may occur. It is clear that during an operation shedding of tumor cells into the portal vein ${ }^{98}$ does occur due to manipulation. Also, an increased lymphflow has been reported ${ }^{99}$ as a result of handling of the bowel segment. It is impossible to judge from Griffith's data ${ }^{98}$ the clinical relevance of tumor cells in the portal blood. The proof of the effect of prevention of tumor emboli to the liver by early vascular isolation may not be derived from Turnbull"s data 12. Other authors claim similar results without the use of this technique 21.97 .

Measures to prevent local exfoliative tumor spill are easily taken and should not be omitted, even if the effect on survival is limited. 


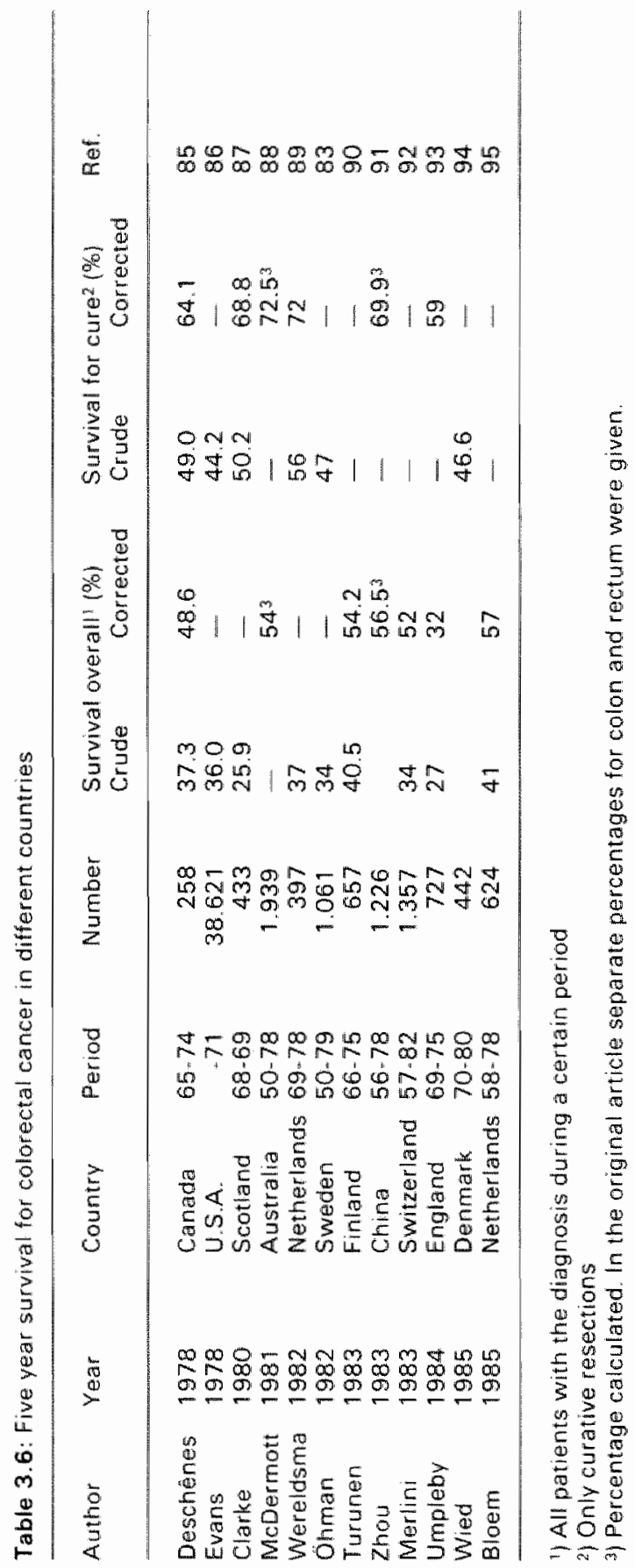




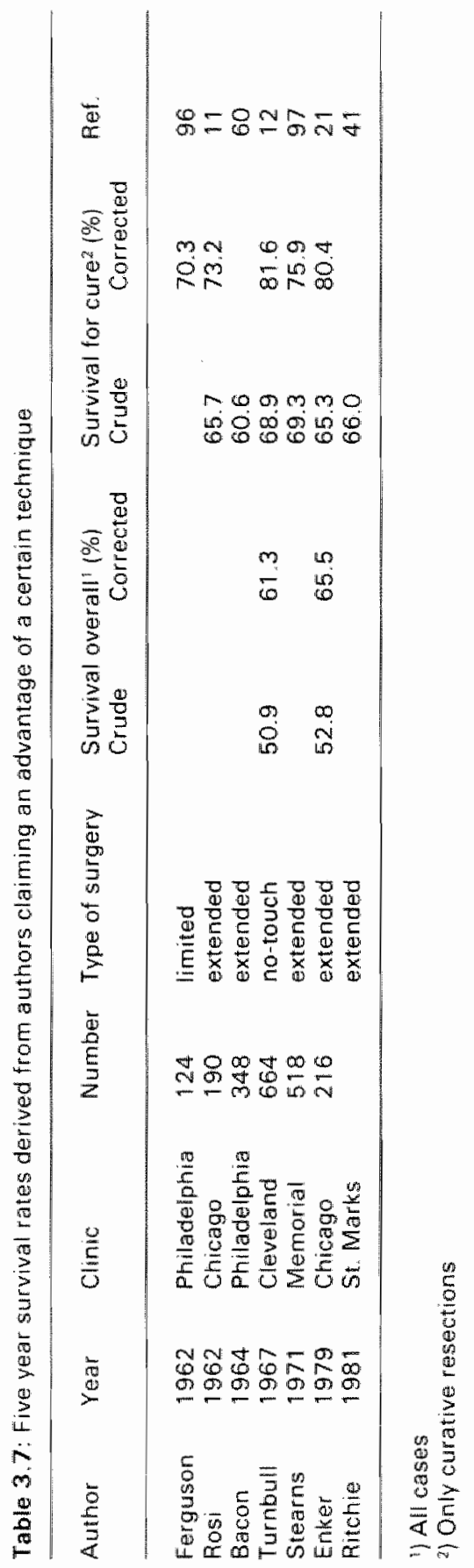


The last part of Sugarbaker's definition regards the quality of life and reflects on the morbidity and mortality as a result of the operation. Factors, like sphincter saving procedures by stapling techniques or coloanal anastomoses are not considered in this review. Extended resections involving the extramesenteric tissues are associated with a higher postoperative death rate and an increased number of urological problems ${ }^{62}$. This type of operation should not be advocated as a routine procedure. For limited indications it may be performed by individuals who are able to carry out this operation without an increased mortality rate.

Hence, a standard resection procedure in large bowel cancer does not exist. No adequate prospective studies regarding either lymph node dissection or vascular isolation are available. The strong interrelationship between lymphatic and hematogenic spread should stop dividing surgeons into those who remove lymph nodes and those who ligate blood-vessels. It is theoretically possible that the combination of techniques reinforces the effect on each other. The influence of both aspects should be the subject of further studies because even small improvements of five year survival may be of clinical relevance due to the high incidence of this tumor. The final conclusion of this overview is that a surgeon should resect a large bowel tumor locally as adequate as possible. The effect of all additional measures is unclear.

\subsection{References}

1. Papillon J. Intracavitary irradiation of early rectal cancer for cure. Cancer 36 : $696-701,1975$.

2. Gastrointestinal tumor study group. Pralongation of the disease-free interval in Surgically treated rectal carcinoma. N Engl J Med 312:1465-1472, 1985

3. Gastrointestinal tumor study group. Adjuwant therapy of colon cancer - results of a prospectively randomized trial. N Engl J Med 310: 737-734. 1984.

4. Tan KG. Colonoscopic polypectomy. Thesis, Maastricht, 1981.

5. Grigg M. McDermott FT. Pihl EA. Hughes ESP. Curative local excision in the treatment of carcinoma of the rectum. Dis Colon Rectum 27: 81-83, 1984.

6. Whiteway J Nicholls Ru, Morson BC. The role of surgical local excision in the treatment of rectal cancer. Bir J Surg 72:694-697, 1985.

7. Baker AR. Local procedures in the management of rectal cancer. Semin Oncol 7: $385-391,1980$.

8. Cutler SJ. Trends in cancers of the digestive tract. Surgery 65: 740-752, 1969.

9. Morgan $\mathrm{CN}$. Trends in the treatment of thumours of the rectum, rectosigmoid and left colon. IR Coll Surg Edinb 1: 112-125, 1955.

10. Gilbertsen WA. Adenocarcinoma of the large bowell1.340 cases with 100 percent follow-up). Surgery 46: 1027-1042. 1959.

11. Rosi PA, Cahill WJ, Carey J. A ten year study of hemicolectomy in the treatment of carcinoma of the left half colon. Surg Gynecoll Obstet 114: 15-21, 1962

12. Turnbull RB Jr, Kyle K, Watson FR, Spratt J. Cancer of the colon: the influence of the no-touch isolation technic on survival rates. Ann Surg 166:420-427, 1967. 
13. Copeland EM. Miller LD, Jones RS. Prognostic factors in carcinoma of the colon and rectum. Am J Surg 116:875-881, 1968.

14. Berge T. Ekelund G, Mellmer C. Pihl B. Wenckert A. Carcinoma of the colon and rectum in a defined population. Acta Chir Scand Suppl 438, 1973.

15. Hoover HC Ketcham AS. Techniques for intribiting iumor metastases. Cancer 35: $5-14,1975$

16. Pollett WG, Nicholls R. The relationship between the extent of distal clearance and surwival and local recurrence rates after curative anterior resection for carcinoma of the rectum. Ann Surg 198:159-163,1983.

17. Wilson SM, Beahrs $\mathrm{OH}$. The curative treatment of carcinoma of the sigmoid, rectosigmoid and rectum. Ann Surg 183, 556-565, 1976.

18. Williams NS, Dixon MF. Johnstan D. Reappraisal of the 5 centimetre rule of distal excision for carcinoma of the rectum: a study of distal intramural spread and of patients' surwival. Br J Surg 70: 150-15.4, 1983.

19. Slanetz CA. Herter FP. Grinnell RS. Anterior resection versus abdominoperineal resection for cancer of the rectum and rectosigmoid. Am J Surg 123: 110-117, 1972.

20. Williams NS, Purdey P, Johnston D. The outcome following sphincter saving resection and abdominoperineal resection for low rectal cancer. Br J Surg 72: 595-598, 1985.

21. Enker WE, Laffer UTH, Block GE. Enhanced survival of patients with colon and rectal cancer is based upon wide anatomic resection. Ann Surg 190:350-360. 1979.

22. Heald RJ. Husband EM, Ryall RDH. The mesorectum in rectal cancer surgery - the clue to pelvic recurrence? Br J Surg 69:613-616, 198.2.

23. Van Prohaska J, Gorowtis MC. Wasick M. Muliple organ resection for advanced carcinoma of the colon and rectum. Surg Gynecol Obstet 97: 177-182, 1953.

24. Welch JP, Donaldson GA. Perforative carcinoma of colon and rectum. Ann Surg 180: $734740,1974$.

25. Jensen HE, Balslew I. Nielsen J. Extensive surgery in treatment of carcinome of the colon. Acta Chir Scand 136: 431-434, 1970

26. Kelley WE, Brown PW, Lawrence W. Terz JJ. Penetrating obstructing and perforating carcinomas of the colon and rectum. Arch Surg 116:381-384, 1981.

27. Rich T, Gunderson LL, Lew R, Galdibini لlJ, Cohen AM, Donaldson G. Patterns. of recurrence of rectal cancer after potentially curative surgery. Cancer 52:1317. 1329. 1983.

28. Davies GC, Ellis $\mathrm{H}$. Radical surgery in locally advanced cancer of the liarge bowel. Clin Oncol 1: 21-26, 1975.

29. Habib NA, Peck MA, Sawyer CN, Blaxland JW. Luck R. Does fixity affect prognosis in colorectall tumours? Br J Surg 70: 423-424. 1983.

30. Gillchrist RK, David VC. A consideration of pathalogical factors influencing five year survival in radical resection of the large bowel and rectum for carcinoma. Ann Surg 126: $421.438,1947$.

31. Brunschwig A. Radical surgical management of cancer of the colon spread to tissues and organs beyond the colon. Dis Colon Rectum 4:83-87, 1961.

32. Bacon HE, Zuber WF Panhysterectomy concomitant with bowel resection for carcinoma: 75 cases. Surgery 57: 370-376, 1965.

33. El-Domeiri A, Whiteley HW. Prognostic significance of abdominal wall involvement in carcinoma of cecum. Cancer 26: 552-556, 1970.

34. Polk $H C$. Extended resection for selected adenocarcinomas of the large bowel Ann Surg 175: 892-899, 1972.

35. Newman HK. Slearns MW. Re-exploration for 'unresectable' colonic cancer. Dis Colon Rectum 18:576-580, 1975

36. Bonfanti G, Bozzetti F, Doci R, Baticci F. Marolda R, Bignami P, Gennari L. Results of extended surgery for cancer of the rectum and sigmoid. Br J Surg 69:305. 307, 1982

37. Durdey P. Williams NS. The effect of malignant and inflammatory fixation of 
rectal carcinoma on prognosis after rectal excision. Br. J. Surg. 71: 787-790, 1984.

38. Eldar S. Kemeny MM. Terz JU. Extended resections for carcinoma of the colon and rectum. Surg Gynecol Obstet 161:319-322, 1985

39. Spratt JS. Spjut HJ. Prevalence and prognosis of individual clinical and paithologic variables associated with colorectal carcinoma. Cancer 20: 1976-1985, 1967.

40 . Pelloquin $A B$. Cancer of the colon and rectum: comparison of the results of three groups of surgeons using different techniques. Can J Surg 16:28-34, 1973.

41. Nicholls RJ. Surgery. In: Duncan W led. Recent results in cancer research. Colorectal Cancer. Springer-Verlag, Berlin. Heidelberg, New York, 1982.

42. Quan SHO. Seltew MK. Pelvic surgery concomitant with bowell resection for carcinoma Surg Clin North America 54:881-886, 1974.

43. Graffner HCL, A.Im POA, Oscarson JEA. Prophylactic oophorectomy in colorectal carcinoma. Am J Surg 146:233-235, 1983.

44. Ballantyne GH. Reigel MM, Wolff BG, Histrup DM. Oophorectomy and colon cancer. Ann Surg 202: 209.214, 1985

45. Cutait R, Lesser ML. Enker WE. Prophylactic oophorectomy in surgery for largebowel cancer. Dis Colon Rectum 26:6-11, 1983.

46. Ault GW. A technique for cancer isolation and extended dissection for cancer of the distal colon and rectum. Surg Gynecol Obstet 106: 467-477, 1958.

47. Pomeranz AA, Garlock JH. Postoperative recurrence of cancer of colon due to desquamated malignant cells. JAMA 158: 1434-1436, 1955.

48. Cole WH. Packard D, Southwick HW. Carcinoma of the colon with special reference to prevention of recurrence. JAMA 155: 1549-1553, 1954

49. McGrew EA. Laws JF. Cole WH. Free malignant cells in relation to recurrence of carcinoma of the colon. JAMA 154: 1251-1254, 1954.

50. Goligher JC. Dukes CE, Bussey HJR. Local recurrences after sphinctersaving excisions for carcinoma of the rectum and rectosigmoid. Br J Surg 39: 199. $211,1951$.

51. Keynes WM. Implantation from the bowel lumen in cancer of the large intestine. Ann Surg 153: 357-364, 1961

52. Southwick HW. Hartidge WH, Cole WH. Recurrence at the suturelline following resection for carcinoma of the colon. Am J Surg 103: 86-89, 1962.

53. Cohn I. Implantation in cancer of the colon. Surg Gymecol Obstet 124: 501-508, 1967

54. Cole WH. Mrazek RG. Economou SG, McDonald GO, Slaughter DP. Strehl FW. Adjuvani chemotherapy. Cancer 18: 1529-1535, 1965.

55. Miles WE. A method of performing abdominoperineal excision for carcinoma of the rectum and of the terminal portion of the pelvic colon. Lancet ii: $1812-1813$. 1908 .

56. Moynihan BGA. The surgical treatment of cancer of the sigmoid flexure and rectum with especial reference to the principles to be observed. Surg Gynecol Obstet 6: $463-466.1908$.

57. MoElwain JW, Bacon HE, Trimpi HD. Lymph node metastases: experience with artic ligation of inferior mesentery artery in cancer of the rectum. Surgery 35 : $513.531,1954$.

58. Grinnell RS. Results of ligation of inferior mesenteric artery at the aorta in resections of carcinoma of the descending and sigmoid colon and rectum. Surg Gynecol Obstet 120:1031-1036, 1965

59. Castro AF. Surgical technique of ligation of inferior mesenteric artery and preaortic lymphadenectomy. Surg Gynecol Obstel 102: 374-376, 1956.

60. Bacon HE, Khubchandani, IT. The rationale of aortoiliopelvic Uymphadenectomy and high ligation of the inferior mesenteric artery for carcinoma of the left half of the colon and rectum. Surg Gynecol Obstet 119:503-508, 1964.

61. Enker WE. Surgical treatment of large bowel cancer. In Enker WEE (ed): Carcinoma of the colon and rectum. Year Book Medica: Publishers, Chicago-London, 1978.

62. Stearns MW. Deddish MR. Fivenyear results of abdomimopelvic lymph node dissection for carcinoma of the rectum. Dis Colon Rectum 2: $169-172,1959$. 
63. Morgan CN, Griffiths JD. High ligation of the inferior mesenteric artery during operations for carcinoma of the distal colon and rectum. Surg Gynecol Obstet 108: $641-650,1959$

64. Hojo $K$, Kovama $Y$. The effectiveness of wide anatomical resection and radical iymphadenectomy for patients with rectal cancer. Jap J Surg 12:111-116, 1982

65. Pezim ME, Nicholls RJ. Survival atter high or low ligation of the inferior mesenteric artery during curatiwe surgery for rectal cancer. Ann Surg 200: 729-733, 1984.

66. Enker WE, Hellweil ML. Hertz REL. Pilipshen SJ. Stearns MW. Sternberg SS, Janov A. En bloc pelvic lymphadenectomy and sphimcter preservation in the surgical management of rectal cancer. Ann Surg 203: 426-433, 1986.

67. Dwight RW. Higgins GA, Keehn RJ. Factors influencing survival after resection in cancer of the colom and rectum. Am J Surg 117:512-522, 1969.

68. Grinnell RS. Lymphatic block with atypical and retrograde lymphatic metastasis and spread in carcinoma of the colon and rectum. Ann Surg 163: 272-280. 1966.

69. Grinnell RS. Lymphatic metastases of carcinoma of the colon and rectum. Ann Surg 131: 494-506, 1950.

70. Barnes JP. Physiologic resection of the right colon. Surg Gynecol Obsiet 94 : 723-726. 1952 .

71. Turmbull RB $J$ r. Cancer of the colon. The five- and ten-year survival rates following resection wilizing the isolation technique. Ann $R$ Coll Surg Engl 46: 243-350, 1970

72. Turnbull RB Jr. Cancer of the sigmoid colon: the influence of no-touch isolation technique on survival. In $O^{\prime}$ Connell TX (ed): Surgical oncology. Controversies in cancer treatment, Chapter 12, GK Hall Medical Publishers, Boston, Massachusetts. 1981

73. Jagelman DG, Turnbull RB jr. Colectomy for malignant disease of the colon: The 'no-touch' isolation technique. In Todd IP (ed): Operative surgery fundamental techniques: colon, rectum and anus, 106-117, Butterworths, London-Boston, 1977.

74. Bacon HE, Dirbas F. Myers TB, Ponce de Leon F. Extensive lymphadenectomy and high ligation of the inferior mesenteric artery for carcinoma of the left colon and rectum. Dis Colon Rectum 1: 457-465, 1958.

75. Verschueren RCJ, Lavery IC, Fazio VW, Jagelman DG. The curative treatment of rectal cancer at the Cleveland Clinic. Arch Chir Neerl 31:29-41, 1979.

76. Salsbury AJ, McKinna JA, Griffiths JD, Morgan CN. Circullating cancer cells during excision of carcinomas of the rectum and colon with thigh ligation of the inferior mesenteric vein. Surg Gynecol Obstet 120: 1266-1270, 1965.

77. Morgan CN. Carcinoma of the rectum. Ann R Coll Surg Engl 36: 73-97, 1965.

78. TurmbulI RB Jr. Cancer of the sigmoid colon. The influence of the no-touch isolation technic on survival. In; Welvaart $K_{\text {, e. }}$. (eds): Colorectal cancer. Boerhaave series. wol. 18. Leiden University Press, The Hague, Boston, London, 1980.

79. Black GE, Enker WEE. Controversies in surgery for large bowel cancer. In Enker WEE (ed): Carcinoma of the colon and rectum, chapter 4. Year Book Medical Publishers, Chicago-London, 1978.

80. Fazio VW. Pilipshen SJ. Techniques for the resection of colon cancer: An appraisal of the no-touch isolation techmique. In Bearhs $\mathrm{OH}$. Higigins GA and Weinstein IJ (eds): Colorectal tumors, chapter 22, JB Lippincott Company, Philadelphia, 1985

81. Talbot IC, Ritchie S, Leighton MH, Hughes AO, Bussey HJR, Morson BC. The clinical significance of invasion of veins by rectal cancer. Br J $5 u r g$ 67: 439 442. 1980 .

82. Sugarbaker PH, Corlew S. Influence of surgical techniques on survival it pratients with colorectal cancer. A review. Dis Colon Rectum 25: 545-557. 1982.

83. Ömman U. Collorectal carcinoma - Trends and results over a 30 -year period. Dis Colon Rectum 25:431-440, 1982.

84. Cutler SJ, Myers MH, Green SB. Trends in survival rates of patients with cancer N Englall Med 293: 122-124, 1975. 
85. Deschênes L, Fabia ل, Douwlle Y. Dutour C. Survival in collorectal cancer. Can J Surg 21:254-256, 1978 .

86. Evans J., Wana J, Aronoff BL. Baker HW, Murphy GP. Management and survival of carcinoma of the colon: results of a nationall survey by the American College of Surgeons. Ann Surg 188: 716-720, 1978.

87. Clarke DN, Jones PF, Needham CD. Outcome in colorectal carcinoma: sevenyear situdy of a population. Br Med J 280:431-435, 1980.

88. McDermott FT. Hughes ESR, Pihl E. Mine B. Price AB. Comparative results of surgical management of single carcinomas of the calon and rectum: a series of 1939 patients managed by one surgeon. Br ل Jurg 68: 850-855, 1981.

89. Wereldsma JCJ. Hop WCJ. Resultaten van 10 jaar curatieve chirurgie van colonen rectumcarcinoom. Ned Tijdschr Geneeskd 1126: 1262-1268, 1982.

90 . Turumen MJ, Peltokallio P. Surgical results in 657 patients with colorectal cancer. Dis Colon Rectum 26; 606-612, 1983.

91. Zhou $X-G$, Yu $B-M$, Shen $Y-X$. Surgical treatment and late results in 1226 cases of colorectal cancer. Dis Colon Rectum 26:250-256, 1983.

92. Merlini M, Besson A. Saegesser F. Traitement pronostic du cancer colo rectal. Schweiz Med Wschr 113: 785-793, 1983

93. Umpleby HC. Bristol JB, Rainey JB, Williamson RCN. Survival of 727 patients with single carcinomas of the large bowel. Dis Colon Rectum 27: 803-810, 1984.

94. Wied U, Nilsson T, Knudsen JB, Sprechler M, Johansen A. Postoperatiwe survival of patients with potentially curable cancer of the colon. Dis Colon Rectum 28 : $333-335,1985$

95. Bloem RM. Colon en rectumcarcinoom (Behandelingsresultaten, classificatie en prognase). Thesis, Leiden, 1985

96. Ferguson LK, Boland JP. Thomen FJ. Anterior segmentall resection for carcinoma of the upper rectum, rectosigmoid and sigmoid. Surgery 52: 741-746, 1962

97. Stearns MW, Schottenfeld D. Techniques for the surgical mamagement of colon cancer. Cancer 28: 165-169, 1971.

98. Griffiths JD. Mckinna JA. Rowbotham HD. Tsolakidis P, Salsbury AJ. Carcinoma of the colon and rectum: circulating malignant cells and five-year survival. Cancer 31: 226-236, 1973

99. Ackermann NB. The influences of mechanical factors on intestinal lymph flow and their relationship to operations for carcinoma of the intestine. Surg Gynecol Obstet 138: 677-682, 1974 . 


\section{A documentation system for a multicenter trial}

\subsection{Introduction}

Data base systems for the registration of cancer patients may differ substantially depending on the purpose of the investigation (table 4.1). A national tumor register for instance, will record mainly personal, but limited diagnostic and survival data with special emphasis on the completeness of the registration of all cancer patients.

For a specific disease, clinical trials are often the only possible answer to a question about the value of a certain treatment. Comparison with historical controls is unreliable because patient selection, both in the control and treatment arm may cause better results in both groups ${ }^{1,2}$. In order to detect small significant differences, large numbers of patients are required. The only way to conduct such a trial, in a short time with a great accrual rate, is a multicenter trial. These kinds of trials involving many hospitals are difficult to organize. It is frequently difficult to obtain an agreement about the protocol.

Besides quality control on treatment and pathology, special efforts should be made to collect proper follow-up data. After the initial enthusiasm, participants often become less strongly motivated because the results of the study are not quickly available and sometimes, new doctors have to conduct follow-up without special knowledge of the set of required investigations.

In addition to information to participants regarding the (possible) results of the trial, support for the administration in the participating hospitals is necessary in order to reduce the extra work load.

Cancer of the large bowel has a high incidence in Western countries. Survival rates have reached a plateau ${ }^{3}$. With the intention of studying the effect, of a certain surgical technique in colonic cancer and of preoperative irradiation in rectal cancer, in January 1979 two prospective multicenter trials were started. Since no software for an adequate data base was available a new program had to be developed.

This paper addresses some of the demands of a database necessary 
Table 4.1: Types of cancer registration

\begin{tabular}{|c|c|c|c|c|}
\hline & National & Hospital & $\begin{array}{l}\text { Specific } \\
\text { disease (trial) }\end{array}$ & $\begin{array}{l}\text { Treatment } \\
\text { plan }\end{array}$ \\
\hline $\begin{array}{l}\text { Personal data } \\
\text { Medical history } \\
\text { Diagnosis } \\
\text { Treatment } \\
\text { Disease free period } \\
\text { Survival }\end{array}$ & $\frac{4+4}{\frac{4}{4}}$ & $\begin{array}{l}+1 \\
+1 \\
+4 \\
+4 \\
+4 \\
+4 \\
+4\end{array}$ & $\begin{array}{l}+ \\
+t+ \\
+t+ \\
+t \\
+t+\end{array}$ & $\begin{array}{l}+ \\
+ \\
+t \\
++4 \\
-\end{array}$ \\
\hline
\end{tabular}

*) Difference noted between non-disease related death and overall survival

for such a study and sets guidelines according to which an adequate follow-up program can be achieved with sufficient quality control.

\subsection{Material and methods}

The database requirements for this system can be classified into three groups. The first demand was for a flexible interactive patient data entry allowing eas $y$ intake and modification. Secondly, a strong administrative support, both for the participants and the central data office was desirable. Finally, statistics based on up-to-date data had to be presented at regular intervals.

The system design had the following characteristics. It was developed on the central university computer (first a VAX11/780, recently a VAX11/785 from DEC). To have easy access to the system it was possible to obtain, after a period of a telephone connection, permanent on-line facilities, with an own entry on the computer via the word processor, at the secretary's office. The logical form of the program structure is shown in figure 4,1 . Via a menu procedure it is possible to make a choice between the interactive data entry facilities, the batch program for the production of the forms, the interactive command procedure to produce statistics and finally the back-up facilities.

The data were collected on forms identical with the screen lay out. The interactive procedures for data entry were developed in Datatrieve-11, an administrative language with strong possibilities for find, select, sort and modify procedures. It also had the capacity of report writing. With the exception of blood group and rhesus factor, all data input was numeric. For privacy reason, a division between personal and disease data was made. Via the menu options it also was possible, with different degrees of protection to adjust, modify or consult the patient data (not only the personal, but also the on- 


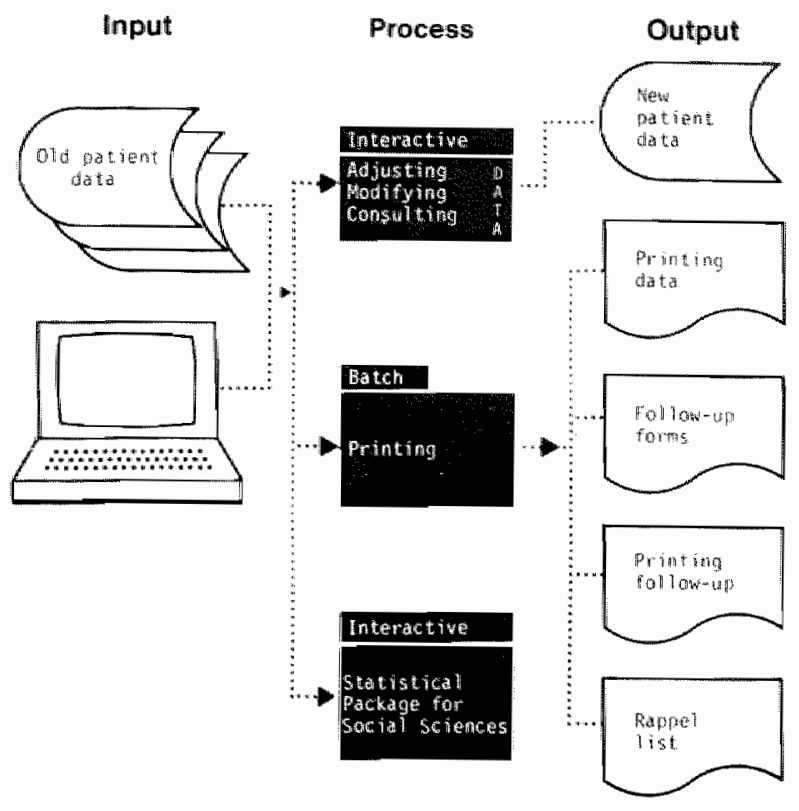

Figure 4.1: Program structure

study and follow-up dataj. During data entry the program screens for non logic errors.

Once a month the batch program written in COBOL, is started via the command PRINT. Several combined functions are enlisted in this procedure. Firstly, it prints twice a summary of the inserted data of the preceeding period. The lay-out is quarto form. After checking the original form for input errors one copy is for the central patient file. The other copy is for the patient file in the participating hospital. Secondly, empty follow-up forms, (in total 11 times during the five year period after operation) with only the check-up items necessary for that particular follow-up (schedule figure 4.2), are printed one month ahead of the actual visit to the out-patient department. The data of that visit is calculated on the basis of the operation day. This enables the participating surgeon to know in advance which patient, during a certain month, needs a check-up and which investigations are necessary for that particular visit.

Two special codes were necessary for a correct execution of the COBOL program. The first one is the $\mathrm{P}$ (patient) code. It determined whether the patient was in the trial (0), in the trial with distant metastases (1). dead (2) or not eligible for the trial (3). This code shifted automatically from 0 to 1 if, during follow-up, recurrent 
Follow-up

\begin{tabular}{|l|c|c|c|c|c|c|c|c|c|c|c|}
\hline Months & 3 & 6 & 12 & 18 & 24 & 30 & 36 & 42 & 48 & 54 & 60 \\
\hline Laboratory & $X$ & $X$ & $X$ & $X$ & $X$ & $X$ & $X$ & $X$ & $X$ & $X$ & $X$ \\
\hline CEA & $X$ & $X$ & $X$ & $X$ & $X$ & $X$ & $X$ & $X$ & $X$ & $X$ & $X$ \\
\hline Chest X-ray & & $X$ & & $X$ & & $X$ & & $X$ & & $X$ & \\
\hline Barium enema & & $X$ & & $X$ & & & & $X$ & & & \\
\hline Liver scan / ultrasound & & $X$ & & $X$ & & $X$ & & $X$ & & $X$ & \\
\hline Colonoscopy & & $X$ & & & & $X$ & & & & $X$ & \\
\hline
\end{tabular}

Figure 4.2: Necessary investigations during follow-up

disease, according to the preset criteria, was observed. Under these circumstances all the regularly requested investigations for determination of the disease-free period are no longer necessary and only forms with two final questions were produced. One question was regarding present therapy and the other, was enquiring if the patient was still alive. The other questions necessary for the determination of recurrent disease were not printed. After the filling in of the date of death, the code moved automatically from 1 to 2 after which, no more forms were produced. The second code $S$ (status) is necessary for the print order and applicable on all forms. It has three values changing automatically, monthly, after execution the batch program: $0=$ no data entered, $1=$ data entered and $2=$ data entered and printed. Next to this, a list of patient numbers comprising the numbers of the missing follow-up data is printed every month, if completed forms are not entered in time.

The command BACK-UP in the menu is able to execute a security procedure by putting all data on tape. Three generations of the file are kept on the tape erasing the oldest version as soon as a recent version from the data is copied.

The last possibility of the menu is STAT (statistics). Via a separate program, the data necessary for analysis only, are compiled in a special file. A second menu driven procedure asks for S (SPSS) ${ }^{4}$ or B (BMDP) ${ }^{5}$. During this procedure, a control file, in which a complete list of all variables, all value labels and missing values is present, incorporates the raw data file and produces an up-to-date system file. Raw data files and old system files are automatically deleted. It is now possible to execute statistics in an easy way via the editor. 


\subsection{Results}

During the period 1979-1980 350 patients from nine participating centres were entered. In total, approximately 2500 preprinted followup forms were distributed. In the early period sometimes up to 45 forms were sent out every month. 236 Patients were entered in the surgical trial. 117 Patients were entered in the group in which a special surgical technique was used. The first step in this operation was to perform a complete vascular isolation before the tumor was mobilized ${ }^{6}$. The intention of this measure is to reduce dissemination of tumor cells via the portall blood. The group of patients operated on in a conventional way was 119. Preliminary results have been published?. In the final analysis, after a follow-up of 58 months, liver metastases were less frequent in the no-touch group. In the notouch group five vear survival was better $(64.1 \%$ versus $60.5 \%)$ but this difference was not significant $(p=0.2851)$.

The total of 350 patients registered was used for extensive analyses of pathology data in relation to survival. For this purpose, all pathological material was centrally reviewed and several new pathological items, such as antigen expression and DNA index, were adjusted in a later phase. Figure 4.3 is an example of the strongest variable regarding prognosis, the so called Dukes' classification. This curve has been prepared via the word processor. This technique is

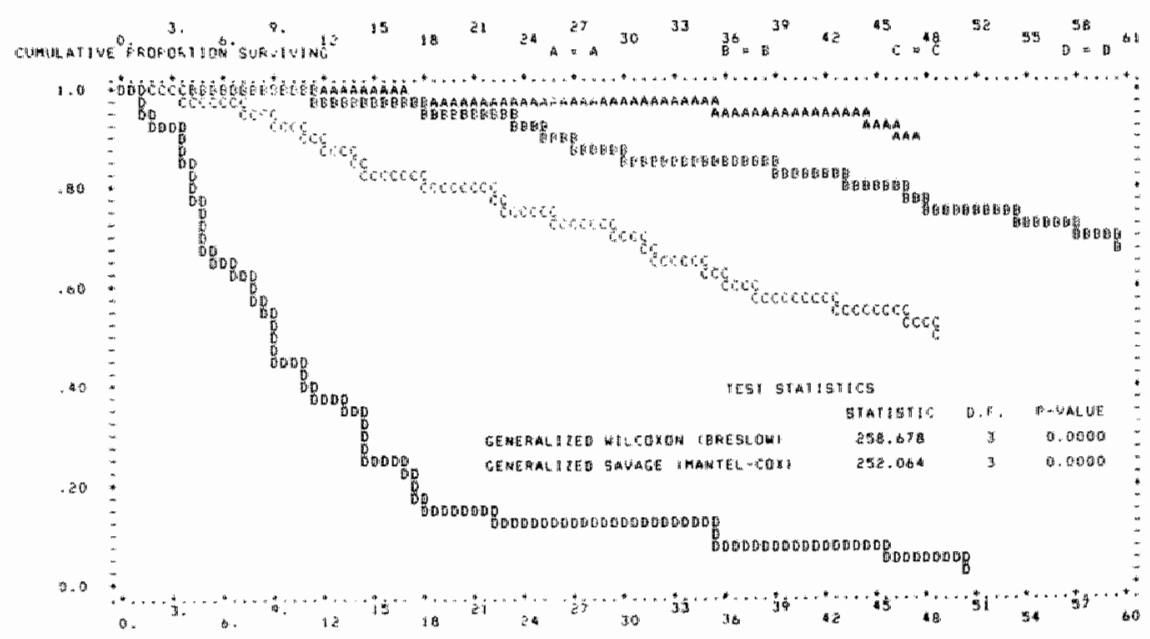

Figure 4.3: Non-disease related survival for the Dukes' classification.

Lay-out via the word processor.

$A=$ Dukes $A ; B=$ Dukes $B, C=$ Dukes $C, D=$ Dukes $D$ 


\section{Stage (Dukes)}

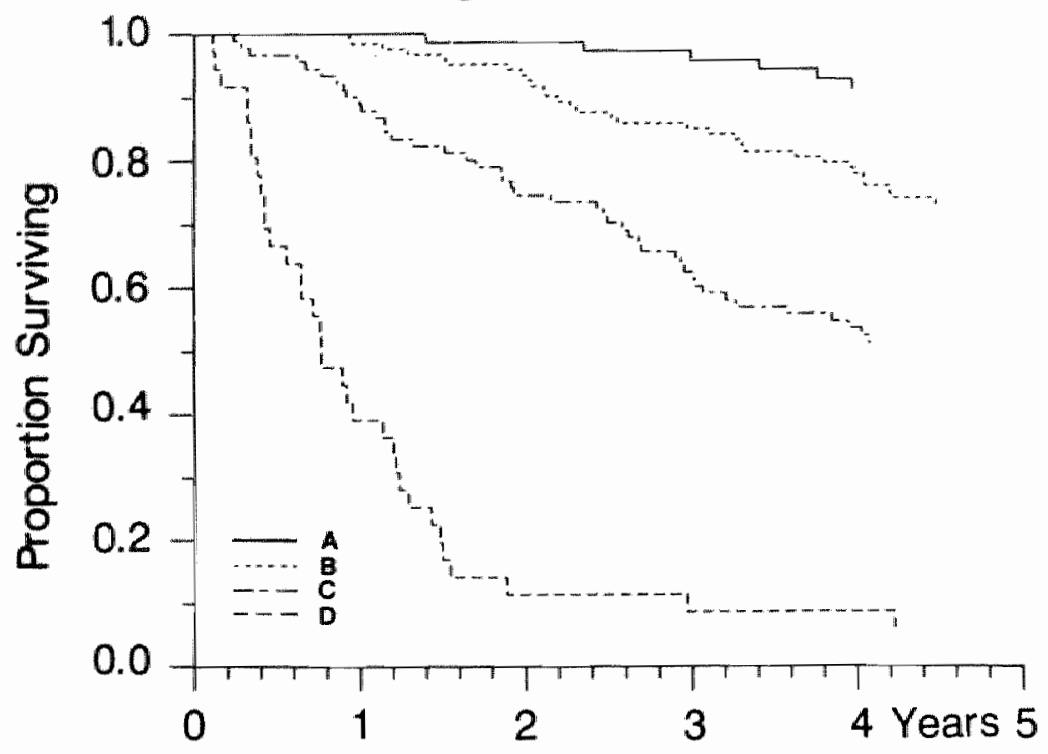

Figure 4,4: Non-disease related survival for the Dukes. classification. Lay-out via the plotter.

quick and easy for the preparation of slides. The same curve in figure 4.4 has been produced via the plotter.

Finally, a multivariate analysis has been prepared, both for pathological data and the clinical data, available from the on study form.

\subsection{Discussion}

This paper describes the design and results of a cancer documentation system, with special emphasis on data entry, administrative support and statistics. Traditionally, data of multicenter trials are collected at a specially equipped central data management office. The collection and processing of the data had to be conducted on a self reliant basis with only limited secretarial assistence since, for our trial, no grants were available.

The on-line connection of the word processor with the computer made data entry easy. Although Datatrieve-11 has strong capacities for finding. selection and modifying entry of new data it was not easy due to the structure of the program.

A major disadvantage was the fixed record length. During the study new items for investigation became available for analysis. Every long 
running study needs extra capacity and flexibility, for adjusting new variables which can be added later via a special procedure without completely changing the structure of the program ${ }^{8}$. To avoid these problems in future programs separated blacks for history, laboratory. diagnostic studies, therapy and pathology will be used.

Studies, about the outcome of treatment in primary cancer have a few essential prerequisites which can not be obtained from hospital cancer registries ${ }^{9}$. Follow-up has to be performed during a long time at regular intervals, with a predefined series of tests. This enables the estimation, as precisely as possible of the disease free period, since mortality statistics may be influenced by therapeutic interventions. After the determination of recurrent disease only, data on survival are collected. In this respect the batch program gave us a great help by supplying the right form at the right time. It was also a great help for the secretary to send monthly, empty, computer printed forms, without going through all the patient files. Also, the participating surgeon was helped because he knew which patient was due for follow-up and which investigations were required.

The summarized copies were used at the central office for error checking, but proved to be of limited value in the participating hospitals. Every hospital has its own design of patient files and the prints, although of a correct size (quarto), did not get their own place in these files. In the improved program for a second multicenter trial, only a limited summary of the on study form will be returned to the participants.

During follow-up in the next study a new service for the participating surgeons will be tested. For colorectal cancer, the marker carcinoembryonic antigen (CEA) allows early detection of recurrent disease ${ }^{10}$. Small early rises in the follow-up period are of interest. The computer counts on basis of the two last CEA levels the significance of the raise. If this occurs, a graphically printed warning with slope analysis ${ }^{11}$, is sent to the physician, suggesting further enquiries.

Statistics, including multivariate analyses, could be produced with an up-to-date data collection. The total material was used for several lectures and publications.

In conclusion, the method of data collection proved to be an essential part of the whole study. Before a prospective multicenter trial is started data management has to be organized properly in order to facilitate both the collection and analysis of the data, with special emphasis on avoidance of missing vallues. 


\subsection{References}

1. Gastrointestinal tumor study group. Adjuwant therapy of colon cancer - results of a prospectiveiy randomized trial. N Engl J Med $310: 737-734,1984$.

2. Rosenberg SA, Tepper $\mathrm{j}$, Glatstein $E$, Costa J, Young R, Baker A, Brennan MF, Demoss EV, Seipp C. Sindelar WF. Sugarbaker P. Wesley R. Prospective randamized evaluation of adjuvant chemotherapy in adults with soft tissue sarcomas of the extremties. Cancer $52: 424-434,1983$.

3. Cutler SJ, Myers MH, Green SB. Trends in surwival rates of patients with cancer. N Engl J Med 293: 122-124, 1975.

4. Hull CH, Nie NH. SPSS update. McGraw Hill, New York, 1979

5. Dixon WJ. Brown MB. BMDP-79. Biomedical Computer Programs P-Series, University of California Press. Berkeley, 1979.

6. Turnbull RB Jr. Kyle K. Watson FR, Spratt J. Cancer of the colon the influence of the no-touch isolation technic on survival rates. Ann Surg 166:420-427, 1967.

7. Wiggers T. Jeekel J, Arends JW, Brinkhorst AP, Kluck HM, Luyk Cl, Munting JDK, Povel AJ, Rutten APN, Greep JM. The no-touch isolation technique in colon cancer: a prospective controlled multicentre trial. Br J Surg 72 suppl: 5 ॥3. 1985.

8. Laszla J. Cox E, Angle C. Special article on tumor registries: the hospital tumon registry. Cancer $38: 395-401,1976$

9. Palmer MK. Survival studies using a computer based hospital registry of 29.000 cancer patients. In Tagnon HJ. Staguet MJ (Eds): Controversies in cancer. Design of trials and treatment, Chapter 4. Masson Publishing, USA, 1979.

10. Anonymous. Carcinoembryonic antigen: its role as a marker in the management of cancer - National institutes of health consensus development conference statement. Cancer Res 41: 2017-2018, 1981.

11. Staab HJ, Anderer FA, Stumpf E. Fisher R. Slope analysis of the postoperative CEA time course and its possible application as an aid in diagnosis of disease progression in gastrointestinal cancer. Am J Surg 136:322-327, 1978. 


\section{The no-touch isolation technique in colon cancer (a controlled prospective trial)}

\subsection{Introduction}

Until now surgery offers the best possibility for cure in colon cancer. Adjuvant chemotherapy has not been able to prolong disease free survival ${ }^{1}$ and radiotherapy is of limited value in rectal cancer either as a primary ${ }^{2}$ or as an adjuvant therapy ${ }^{3}$. Despite an increased resectability rate and a diminished postoperative death rate, overall five year figures have improved only slightly during the last forty years ${ }^{4.5}$.

Surgical therapy consists of removal of the primary tumor in combination with, a segmental resection of the adjoining normal bowel wall, including the mesentery and, if necessary, with the adjacent organs invaded by the tumor. The first aim of surgery is to relieve the patient of his complaints (such as blood loss or bowel obstruction), but secondly, the possibility of local recurrence after the resection should be minimal and, no further dissemination should be caused during the operation. Although surgical resection seems to be a standard procedure this is not true, and the extent of local resection, the necessity for and the extent of lymph node dissection and the effectiviness of measures preventing local or systemic spread during operation are not well defined ${ }^{6}$.

Several investigators ${ }^{7.8 .9}$ have identified malignant cells, in particular in cell clumps due to tumor manipulation", in the portal blood of patients with colon carcinomas. Experimental data have shown the effectiveness of injected cell clumps, compared with solitary cells, in causing distant metastases ${ }^{10}$. The take of tumor cells appears to be more effective during operation 11 and anesthesia12. This effect is probably a result of immunosuppression ${ }^{13}$.

The first description of lymphovascular ligation, before mobilization of the cancer bearing segment in colon cancer, in the hope of reducing peroperative dissemination, was given by Barnes in 1952 14. The name 
of Turnbull 15 has been definitively connected with this technique, because he was the first to provide promising clinical data using the so called 'no-touch' isolation technique in collon cancer. He also stated that a reduction of cancer cells in the portal blood occurred from $30 \%$ to $15 \%$ by application of this technique ${ }^{16}$. Opponents ${ }^{17,18}$ of this technique attributed his results either to patient selection or to the introduction of a new staging system and claimed similar results as a consequence of extended resections only (table 5.1).

Since prospective studies concerning resection techniques, with a control group, have not been performed for colon cancer it is impossible to determine the value of extended lymphadenectomies or Iymphovascular isolation. The aim of this study was to evaluate, by means of a prospective controlled study, the effect of the notouch isolation technique in colon cancer and to define its position in standard colon resections.

\subsection{Material and methods}

Eligibility criteria and randomization.

Patients were eligible for the study if they fulfilled the following criteria:

1. histological proof of carcinoma in the preoperative biopsy or a radiologicall lesion suspected of malignancy;

2. distal margin of the tumor $8-15$ centimetre from the anal verge allowing a sphincter saving resection;

3. no previous malignancy in the preceding five years except basal cell carcinoma of the skin;

4. general condition sufficient to undergo resection therapy:

5. no acute resections because of perforation;

6. no previous surgery for this carcinoma, except the construction of a diverting colostomy;

Table 5.1: Comparitive five year survival' in canver of the colon

\begin{tabular}{llll}
\hline Stage & $\begin{array}{l}\text { Turnbul15 } \\
\text { (Cleveland) }\end{array}$ & $\begin{array}{l}\text { Stearns'7 } \\
\text { (Memorial) }\end{array}$ & $\begin{array}{l}\text { Enker'9i2 } \\
\text { (Chicago) }\end{array}$ \\
\hline With lymph node involvement & $57.9 \%$ & $52.2 \%$ & $56.5 \% \%^{3}$ \\
For cure & $68.9 \%$ & $69.3 \%$ & $65.3 \%$ \\
All stages & $50.9 \%$ & -4 & $52.8 \%$ \\
\hline
\end{tabular}

\footnotetext{
I) absolute survival

3) rectum included

3) not $\mathrm{C} 1$ sases included

4) not stated
} 
7. no multiple colonic carcinomas;

8. no presumable bad compliance for follow-up.

Patients were randomized preoperatively through central registration, either to a conventional resection technique or to the "no-touch" isolation technique.

\section{Surgical therapy including quality-assurance.}

In order to compare the effect of Iymphovascular isolation only, no special attempts were made to perform extended lymphatic dissections. During the conventional resection the first step of the operation, after inspection and palpation of the liver and para-aortic lymph nodes consisted of the mobilization of the tumor bearing segment. This was performed before any vessels were ligated.

The principles of the 'no-touch' isolation technique were started in the theatre after the opening of the abdomen. The cancer bearing segment was inspected without palpating it. After identification, the Iymphovascular bundles were selectively ligated and divided. The artery had to be sacrified in this phase as the first step, preventing venous overflow to the marginal arteries. Secondly, the marginal vessells and the bowel lumen, proximal and distal of the tumor, were ligated. Details of the technique for the different locations are described in a protocol, according to the guidelines of Jagelman 20 .

Operations were performed both by surgeons and residents. During the first year and part of the second year of the trial every no-touch operation in all the participating hospitals, was assisted by a member of a group of staff surgeons from the central university hospital ensuring a standard procedure without violation of the no-touch principles.

\section{Localization.}

Tumors of cecum and ascending colon were classified as right sided tumors. Tumors of both flexures were included in the transverse colon. Left sided tumors compromised the colon descendens and the sigmoid. Below the promontorium all tumors in this study were classified as rectosigmoid.

\section{Pathology.}

In all cases, the original diagnosis made by the local pathologist was centrally reviewed regarding stage, grade and angio-invasive growth. Staging was done according to the modification of the Dukes' classification by Turnbull ${ }^{15}$. Strict criteria were employed for grading ${ }^{21}$. Available $\mathrm{H} / \mathrm{E}$ sections were studied for at least 20 minutes for the presence of angio-invasive growth. 


\section{Patient follow-up.}

A standard computerized follow-up program was instituted which delivered the necessary forms, for each individual patient, monthly. The frequency of the follow-up was every three months during the first year and every six months from there on. At five years the patient's status, regarding disease free survival and survival ${ }^{\prime}$ was evaluated and registration of follow-up was stopped. Every evaluation consisted of history, physical examination, blood chemistries (including hemoglobin, liver functions, carcinoembryonic antigen level). Every year, or on indication, an ultrasound or isotope scan of the liver, a chest $X$-ray, a colonoscopy or barium enema was required. Neither radiotherapy nor chemotherapy were allowed as adjuvant therapy.

\section{Criteria for recurrence.}

If possible, histological or cytological evidence was obtained to confirm metastatic or recurrent disease. Characteristic changes on chest X-ray, liverscan (repeatedly) or abdominal CT-scan preferably in combination with a raised CEA level were accepted as well. Abnormal liver function tests or carcinoembryonic antigen level raise without a strongly suspected anatomical site were not accepted as a proof of recurrent disease. Recurrence was considered local if it occurred in the primary tumorbed or adjacent organs. Carcinomas were classified as new if there was a distance of several centimetres from the suture line. If close follow-up, according to the preset criteria, was not longer possible, the patient was determined as lost for followup of disease free interval at the last day of adequate evaluation. The patient was, after that date, still evaluable for survival because it is possible in the Netherlands to obtain this information via the general practitioner of the patient, in combination with the death records of the registration services.

\section{Statistical analysis.}

The preset number of patients necessary for the confirmation of the difference in five year survival observed by Turnbull, was 125 patients per group (one tailed $a=0.05, b=0.05$ ). All patient data were recorded in the computer. A chi-square analysis for association was used for interpretation of the cross tabulations between the patient characteristics and the two treatment groups. For comparison of numbers the median of age and size of the tumor was used. These calculations were made with the aid of SPSS (Statistical Package for Social Sciences) ${ }^{22}$

After the exclusion of postoperative deaths/defined as death within 30 days after the operation) life tables were callculated both for disease 
free interval and overall survival (absolute and diseasemrelated death rates). The life tables were computed with the BMDP program (Biomedical Computer Program P-series) ${ }^{23}$, using the product limit method of individual survival times (Kaplan-Meier) ${ }^{24}$. Comparison of distribution of survival was made by means of the logrank test ${ }^{25}$ and of the disease free period with the generalized Wilcoxon test ${ }^{26}$. This last test is more sensitive for detection of early differences which is of importance since morbidity starts as soon as a recurrence is documented.

\subsection{Results}

\section{Patient characteristics.}

Between January 1979 and February 1982 a total of 304 patients were entered by eight participating centers. In order to have proper supervision by a limited group of surgeons from the center, randomization had to be performed preoperatively. Forty-eight patients were withdrawn during the operation. After exploratory laparotomy (without palpation of the tumor) liver metastases were determined in 22 patients. Extensive advanced local tumor growth, determined by inspection necessitating mobilization of the tumor as a first step to assess resectability excluded another 26 patients. Postoperatively 20 patients were found ineligible because either no malignancy was found or more than one carcinoma was discovered in the resected specimens ( 12 vs. 8 ). These cases appeared to be equally distributed among the treatment arms (table 5.2). This left 236 patients for the final analysis, 119 in the conventionally operated group and 117 in the no-touch group.

In table 5.3 the comparability of the patients among the two groups is shown. Patient related variables, such as sex and age, showed an imbalance for sex. In the conventional group more females were inclluded whereas, in the no-touch group males predominated. The first presenting symptoms and the duration of the symptoms were

Table 5.2: Status of the patients in the study

\begin{tabular}{|c|c|c|c|}
\hline & Conventional & No-touch isolation & Total \\
\hline Patients randomized & 150 & 154 & 304 \\
\hline resection & 21 & 27 & 48 \\
\hline Postoperatively ineligible & 10 & 10 & 20 \\
\hline Patients analyzed & 119 & 117 & 236 \\
\hline
\end{tabular}


Table 5.3: Comparibility of the two ireatment groups

\begin{tabular}{|c|c|c|c|c|}
\hline Characteristic & $\begin{array}{c}\text { Conventional } \\
(\%)\end{array}$ & $\begin{array}{l}\text { No-touch } \\
\text { isolation }(\%)\end{array}$ & P.value & Total \\
\hline Total patients & 119 & 117 & & 236 \\
\hline \multicolumn{5}{|l|}{ Sex } \\
\hline mate & $46(38.7)$ & $60(51.3)$ & 0.0512 & 106 \\
\hline Temale & $73(61.3)$ & $57(48.7)$ & & 130 \\
\hline \multicolumn{5}{|l|}{ First symptom } \\
\hline blood loss & $34(28.6)$ & $39(33,3)$ & & 73 \\
\hline change bowel habits & $25(21.0)$ & $20(17.1)$ & & 45 \\
\hline ileus & $4(3.4)$ & $4(3.4)$ & & 8 \\
\hline other & $56(47.1)$ & $5.4(46.2)$ & 0.8212 & 110 \\
\hline \multicolumn{5}{|l|}{ Duration of symptoms } \\
\hline$<2$ weeks & $13(11.4\}$ & $9(7.8)$ & & 22 \\
\hline$>2$ weeks $<2$ months & $31(27.2)$ & $36(31.3)$ & & 67 \\
\hline$>2$ months & $70(61.4)$ & $70(60.9)$ & 0.5781 & 140 \\
\hline \multicolumn{5}{|l|}{ Tumor location } \\
\hline right sided & $29(24.4)$ & $29(24.8)$ & & 58 \\
\hline transverse & $15(12.6)$ & $13(111)$ & & 28 \\
\hline left sided & $49(41.2)$ & $43(36.8)$ & & 92 \\
\hline rectosigmoid & $26(21.8)$ & $32(27.4)$ & 0.7679 & 58 \\
\hline \multicolumn{5}{|l|}{ Stage (Dukes) } \\
\hline A & $30(25.2)$ & $26(22.2)$ & & 56 \\
\hline $\mathrm{B}$ & $53(44.5)$ & $54(46.2)$ & & 107 \\
\hline C & $36(30.3)$ & $37(31.6)$ & 0.8642 & 73 \\
\hline \multicolumn{5}{|l|}{ Grade } \\
\hline well & $18(15.4)$ & $8(7.0)$ & & 26 \\
\hline moderately & $90(76.9)$ & $94(82.5)$ & & 184 \\
\hline poorly & $9(7.7)$ & $12(10.5)$ & 0.1152 & 27 \\
\hline \multicolumn{5}{|l|}{ Angio-invasive growth } \\
\hline absent & $89(75.4)$ & $85(72.6)$ & & 174 \\
\hline present & $29(24.6)$ & $32(27.4)$ & 0.6277 & 61 \\
\hline Age (vears) & 69.8 & 68.0 & n.s. & \\
\hline CEA preoperatively2 & 4.4 & 3.6 & n.s. & \\
\hline CEA postoperatively ${ }^{2}$ & 2.2 & 2.8 & n.s. & \\
\hline Size primary lumor (cm) & 6.2 & 6.9 & n.s. & \\
\hline $\begin{array}{l}\text { Number af resected } \\
\text { lymph nodes }\end{array}$ & 3.8 & 4.8 & n.s. & \\
\hline $\begin{array}{l}\text { Number of lymph nodes } \\
\text { containing metastases }\end{array}$ & 0.21 & 0.23 & n.s. & \\
\hline
\end{tabular}

\footnotetext{
* Median value of numbers

2) Upper limit of normal $5 \mathrm{ng} / \mathrm{mt}$
}

equally distributed among the tumor groups. There were no significant differences between the groups regarding tumor localization, size of the primary tumor, grade and angio-invasive growth. The extent of the resection, both of the tumorfree bowel margins and the number of resected lymph nodes were similar.

Unfortunately CEA levels were not determined for all patients. The median walues preoperatively were $4.4 \mathrm{ng} / \mathrm{ml}$ for the conventional 
group (84 observations) and $3.6 \mathrm{ng} / \mathrm{ml}$ for the no-touch group (83 observations). One month postoperatively the values in the no-touch group were insignificantly higher $(2.8 \mathrm{ng} / \mathrm{ml})$ in comparison with the conventional group $(2.2 \mathrm{ng} / \mathrm{ml})$. The numbers of observations were 66 and 69 respectively. The CEA levels did not differ significantly among the two groups. All these known prognostic data confirmed an equal balance between the two protocol arms despite the withdrawals. There were also no significant differences in randomization over the several institutions regarding treatment arm, stage and complications (data not shown).

\section{Morbidity and mortality.}

Morbidity and mortality as a result of the therapy were consistently recorded and the data are shown in table 5.4. No significant differences were observed between the two treatment groups. Four patients in the no-touch group died within 60 days of the operation due to septic complications, one suffered from an anaphylactic shock and another from a cerebrovascular accident. In the conventionally operated group, two patients died within 60 days of septic complications but two other patients died respectively three and four months after the primary operation as a late result of sepsis. The other patients died as a result of myocardial infarction, rupture of a cerebral aneurysm and an acute severe bronchospasm. The overall mortality within 30 days was $3.0 \%$ and the total death rate as a direct result of the operation was $5.1 \%$.

Recurrent disease.

At the time of analysis the median follow-up time after surgery

Table 5.4: Complications according to treatment

\begin{tabular}{lccc} 
Variable & Conventional & No-touch & P-value \\
\hline Total patients & 119 & 117 & \\
Peroperative complications & 3 & 4 & \\
$\quad$ blood loss $>1$ litre & 4 & 7 & \\
fecal spill & 2 & 2 & 0.2366 \\
$\quad$ tumor spill & 15 & 10 & \\
Postoperative complications & 3 & 2 & 0.6352 \\
wound infection & 4 & 4 & \\
septic complications & $3(2.5 \%)$ & $4(3.4 \%)$ & n.s. \\
surfure line dehiscence & 5 & 6 &
\end{tabular}


was 58 (48-60) months. In the no-touch group eight out of 111 patients (excluding postoperative death) had no reliable follow-up at the twovear point, regarding disease free interval and seven more at the end point of the study. For the conventional group these figures were ten out of 114 at two years and another eight patients at the end point.

Seventy-three of the 236 patients suffered from recurrent disease (including four metachronous carcinomas) according to the preset definition. Table 5.5 shows the proportions, according to site and treatment arm among stage, angio-invasive growth and localization. Although these proportions did not differ significantly from each other. the difference observed was in the number of liver metastases: 21 in the conventional and 13 in the no-touch operated group. There was a tendency for an increased number of liver metastases in the conventional operated group for advanced sigmoid carcinomas when angio-invasive growth was present. For all the other parameters there

Table 5.5: Fecurrences according to the initial site and pathology among the treatment groups

\begin{tabular}{|c|c|c|c|c|c|c|c|}
\hline \multirow[t]{2}{*}{ Variable } & \multicolumn{3}{|c|}{ Conventional } & \multicolumn{3}{|c|}{ Nowtouch isolation } & \multirow[t]{2}{*}{ Total } \\
\hline & Liver & $\begin{array}{l}\text { Elsewhere } \\
\text { (incl.local) }\end{array}$ & Total & Liver & $\begin{array}{l}\text { Elsewhere } \\
\text { finclllocall) }\end{array}$ & Total & \\
\hline Total & 21 & 17 & 38 & 13 & 18 & 31 & 69 \\
\hline \multicolumn{8}{|l|}{ Localization } \\
\hline right & 5 & 5 & 10 & 4 & 0 & 4 & 14 \\
\hline transwerse & 2 & 6 & 8 & 2 & 3 & 5 & 13 \\
\hline left & 10 & 4 & 14 & 3 & 9 & 12 & 26 \\
\hline rectosigmoid & 4 & 2 & 6 & 4 & 6 & 10 & 16 \\
\hline \multicolumn{8}{|l|}{$\begin{array}{l}\text { Angio-invasive } \\
\text { growth }\end{array}$} \\
\hline absent & 13 & 10 & 23 & 10 & 9 & 19 & 42 \\
\hline present & 8 & 7 & 15 & 3 & 9 & 12 & 27 \\
\hline \multicolumn{8}{|l|}{ Stage (Dukes) } \\
\hline A & 3 & 2 & 5 & 1 & 1 & 2 & 7 \\
\hline$B$ & 8 & 7 & 15 & 7 & 8 & 15 & 30 \\
\hline $\mathrm{C}$ & 10 & 8 & 18 & 5 & 9 & 14 & 32 \\
\hline \multicolumn{8}{|l|}{ Grade } \\
\hline well & 2 & 0 & 2 & 0 & 2 & 2 & 4 \\
\hline moderately & 16 & 14 & 30 & 11 & 14 & 25 & 55 \\
\hline poorly & 2 & 3 & 5 & 2 & 2 & 4 & 9 \\
\hline
\end{tabular}


was a striking similarity between both the initial site of recurrence, treatment group and stage. Estimates of the probability of time to recurrent disease, for all failures is plotted in figure 5.1. If only liver metastases are considered there is a strong tendency $(p=0.0587)$ for an early difference in favour of the no-touch group (figure 5.2). No subgroup could be identified with a more convincing $p$ value, most likely due to small sample sizes. Besides the smaller number of liver metastases in the no-touch group they also tended to occur later: 19.9 versus 11.2 months.

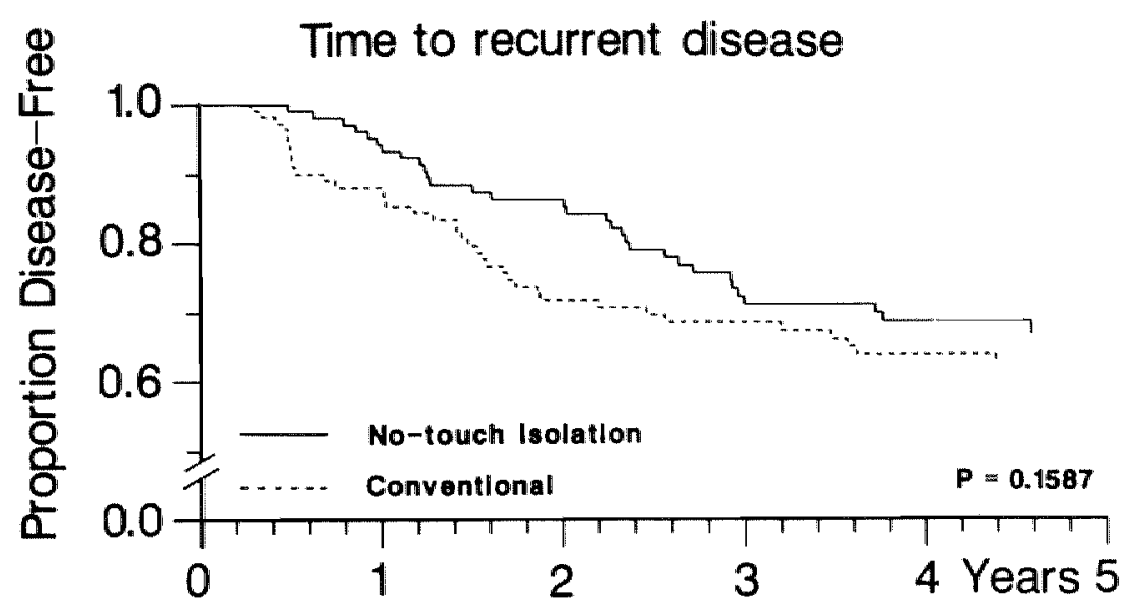

Figure 5.1: Time to recurrence due to all causes, according to treatment group.

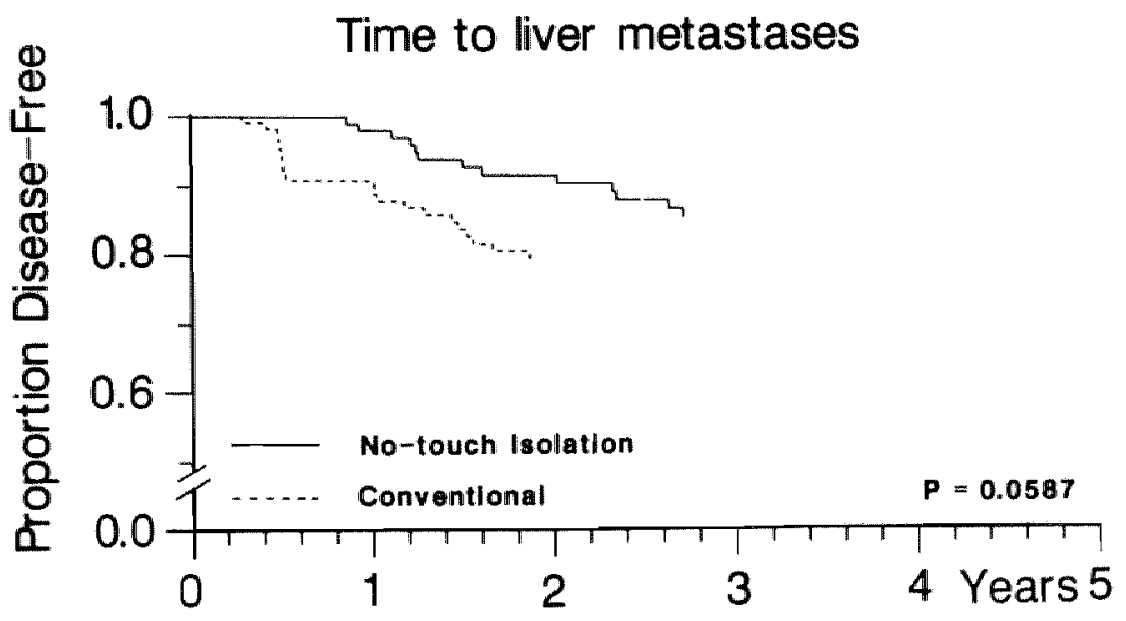

Figure 5.2: Time to recurrence for liver metastases only, according to treatment group. 
Four patients (two in both groups) developed a new metachronous carcinoma far from the suture line.

\section{Survival.}

Of the 236 patients in this analysis 63 have died as a result of their colon cancer 35 in the conventionally operated group and 28 in the no-touch isolation group. No patients were lost. In table 5.6 figures are presented for disease and non-disease related death. The actuarial 5-year survival rates among the different subgroups show one remarkable difference (table 5.7 ). The death rate in the conventionally operated group is significantly higher in the group with

Table 5.6: Deaths according to treatment arm

Conventional No-touch isolation Total (percentage of total number of patients)

$\begin{array}{lccr}\text { Death due to recurrent disease } & 35(29.4) & 28(23.9) & 63 \\ \text { Death due to ofher causes } & 12 & 14 & 26 \\ \text { Lost for follow-up } & 0 & 0 & 0 \\ & - & -42(35.9) & 89\end{array}$

Table 5.7: Death rates among the treatment arms according to sex, localization of the primary tumor, stage and angio-invasive growth

Conventional No-touch isolation Total

death due to tumor/patients $(\%)$

Sex

male

remale

$14 / 46(30.4)$

$21 / 73(28)$

Localization

right

transverse

left

rectosigmaid

Stage
A
B
C

Angio-invasive growth absent present

$20 / 89(22.5)$
$11 / 29(37.9)$
$6 / 15(40.0)$
$13 / 49(26.5)$
$5 / 26(19.2)$

$5 / 30(16.7)$

$15 / 53(28.3)$

$15 / 36(41.7)$

$2 / 26(7.7)$

$12 / 54(22.2)$

$14 / 37(37.8)$
$29 / 106(27.4)$

$34 / 130(26.2)$
16. $58(27.6)$

$11 / 28(39.3)$

$22 / 92(23.9)$

14. $58(24.1)$
7. $56(12.5)$

$27 / 907(25.2)$

$29.73(39.7)$

$18 / 85(21.2)$ $10 / 32(31.3)$ 
angio-invasive growth $(51.7 \%$ versus $31.3 \%)$ whereas if angio-invasion was not observed, survival rates were equal $177.5 \%$ versus $78.8 \%$ ). In fact the deteriorating effect of angio-invasive growth on prognosis disappeared in the no-touch group $(p=0.2356)$ whereas it remained present in the conventionally operated group $(p=0.0061)$. Although in every analysis there is a slight advantage for the notouch group, life table analysis failed to discover significant diffe. rences, by comparing the two treatment arms both for the total number of deaths $(p=0.4719)$ and the disease related deaths $(p=0.2851)$ (figure 5.3).

\subsection{Discussion}

Two hundred and thirty six patients with primary colon carcinoma, without evidence of distant metastases, were enrolled in a prospective study between January 1979 till February 1981 in order to evaluate the effectiveness of the no-touch isolation technique when applied in colon cancer $16,17,19$.

Survival data had to be compared with Turnbull's results 10,27,28. Critics on the value of his data may be summarized as follows: the introduction of a new staging system allowing shifting of stages, the possibility of patient selection, especially with reference to the control group, the lack of specific data on the mutual proportions of llocal recurrence and distant metastases, the contribution in his technique of an extended lymphadenectomy and the noteworthy positive results in cases with lymph node metastases only. In addition

\section{Survival corrected for non-disease related death}

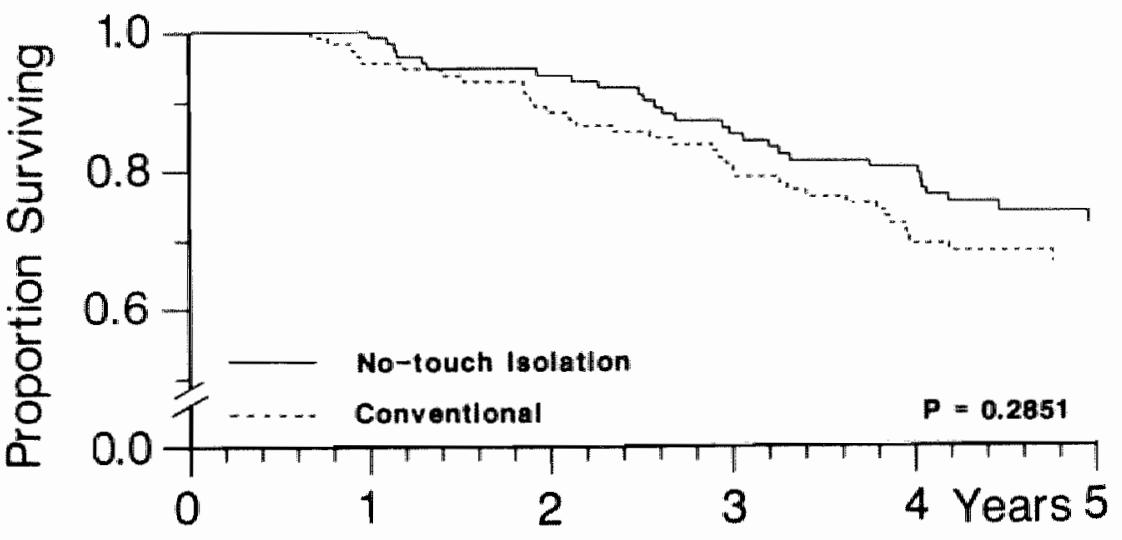

Figure 5.3: Possibility of disease-free survival, according to treatment group. 
to these criticisms, increased morbidity and mortality might occur as a result of ischemic bowel ends causing suture line breakdown and due to damage to ureter or duodenum. Our aim was to show that the large difference between the two groups in his data were unlikely, but that perhaps subgroups could be identified which would benefit from this operation. Since these results had to be an effect of Iymphovascular isolation, before mobilization of the tumor containing bowel segment only, no extended lymphadenectomies had to be performed.

The interpretation of the present study should carefully consider some of its limitations. In order to have sufficient quality control on the operation by a limited number of surgeons experienced in this technique, randomization had to be performed before all eligibility criteria could be fulfilled. This caused withdrawals after exploratory laparotomy during which sometimes, liver metastases or locally advanced tumor were discovered. Theoretically it would have been better if the envelope was opened after reaching the stage of the operation where the difference in technique had to be started ${ }^{29}$. The disregard of patients ( 20 in both groups) because no malignancy or two tumors were discovered in the resected specimens seems to be of less importance. An extensive comparison (table 5.3) between the two treatment groups was performed to justify the similarity among the treatment groups. Both patient and surgeon related variables $^{30}$ seemed equal. This was especially reassuring for those factors known to be very strong prognostic variables like staging ${ }^{1,21}$ and CEA levels both pre- and postoperatively ${ }^{31.32 .33}$.

The equal distribution among the two groups regarding the length of resected bowel, the number of resected lymph nodes and the average number of lymph nodes containing metastases, were convincing with respect to the premise of a similarity of the extent of lymphadenectomy. The major drawback of this kind of study is the impossibility of measuring minimal residual disease present before resection. Even palpation of the liver during operation is not always correct and, although new generations of CT-scans ${ }^{34}$ are able to detect smaller metastases it is still impossible to detect masses smaller than 0.5 centimetre

The number of patients was sufficient to confirm or reject the large differences observed by Turnbull15 but too small to detect subtile smaller differences. After two years, all the participants found it unjustified to continue the conventional resection technique because it was clear, by that time that the lymphovascular isolation technique was a safe and good procedure. Differences in disease free survival distributed over the various sites of recurrence, are the most ideal 
way to evaluate the effect of this therapy. However, the exact knowledge of the localization of all metastatic disease is impossible. Survival can be easily and reliably registered for all cases, but is inaccurate in its own way, because non-disease related death and the treatment of metastatic disease, although ineffective in colorectal cancer, are not reflected in these calculations. Evaluation of nondisease related death and overall survival did not result in substantiall differences.

The application of the no-touch technique did not cause an increase in morbidity. Per-and postoperative complications were also equally distributed among the treatment groups. The postoperative mortality of $3.4 \%$ was similar to that of the control group and to the $2.2 \%$ from Turnbull's data ${ }^{15}$. Of course this percentage is lower than for series reporting on all stages. Mortality rates for curative resections only, are hardly reported in literature but should be below $5 \%$. The fear of more suture line leakages ( 4 in both groups) as a result of an inadequate blood supply, caused by early vascular ligation, appeared to be unfounded. Blood loss during operation was not consistently recorded in our series but in one report from the Lahey Clinic ${ }^{35}$, it is mentioned to be less if compared with techniques by which the tumor is mobilized as the first step of the operation. This gain may by itself be worthwhile since adverse effects of blood transfusions have been described recently ${ }^{36}$.

Although the results of this trial have not provided of significant benefit for the patients in the no-touch isolation arm, there is a strong tendency of an improved disease free survival whereas, in all analyses regarding survival the no-touch group has superior results. The reduced number of liver metastases with similarity for all other sites of recurrences and the late time of occurrence of the liver metastases in the no-touch group is of interest. This reduction of liver metastases is observed particulary if the tumor was situated in the sigmoid area. It is reasonable to contribute this gain to the following mechanism. Complete vascular isolation preventing outflow of tumorcells during operation, is difficult to perform. Experiments in dogs showed an increased overflow, via the marginal vein if the central vein was ligated before the occlusion of the artery ${ }^{37}$. The inconstant vascular anatomy in the transverse colon (including both flexures) and the impossibility of achieving complete ligation of the distal marginal vessels in the rectosigmoid area make these areas, on theoretical grounds, not very suitable for this technique. This presumption is supported by our data since no difference in the incidence of liver metastases is seen in the transverse colon and rectosigmoid. The left sided colon is both for central ligation and disruption of the 
marginal flow the most ideal area. The fear that overflow to the central circulation after occlusion of the central draining vein to the systemic circulation via portocaval shunts might cause an increase in lung metastases 38 was not confirmed by a longer follow-up in the study of Morgan ${ }^{39}$ and in this material.

The reduction in the number of liver metastases, by the application of the no-touch technique in the group of patients with angio-invasive growth is an important observation since the occurrence of liver metastases is strongly related to angio-invasive growth ${ }^{40}$. This effect was even more strongly reflected in the survival curves in which the negative effect of angio-invasive growth on survival disappeared in the no-touch group. No effect in this regard was observed for the presence or absence of lymph node metastases. Although logical, it remains speculative to contribute this phenomenon to the reduction of dislodged tumor clumps to the liver. It is also possible that massive embolization during surgery is responsible for the observed early occurrence of liver metastases in the conventionally operated group. The influence of tumor factors, liberated by manipulation on already present deposits is another explanation for the differences in number and time of the liver deposits.

The absolute five year survival in both the no-touch and conventionally operated groups is high, $64.1 \%$ and $60.5 \%$ respectively. This is in accordance with several personal series advocating a certain technique ${ }^{16.18 .19 .41}$ and with both the control and treatment arm in the prospective series of the GITSG'. It is impossible to know if this high survival rate is due to patient selection or a result of real improvement. It is however again a strong plea for a control group in these kind of studies ${ }^{1.42}$.

In summary this study has demonstrated that the big difference in surwival rates stated by Turnbull are most likelly a result of patient selection. Although outcome of the disease is mainly determined at the moment of diagnosis, every attempt should be made to prevent worsening of the prognosis during operation. The no-touch isolation technique is a neat and simple technique that did not result in an increased morbidity or mortality. Differences in the occurrence of liver metastases were observed mainly in the sigmoid area and in cases with angio-invasive growth. All the analyses had a tendency in favour of the no-touch isolation technique. It is our point of view that this technique should be used for all tumors. Since it is not possible to know the existence of angio-invasive growth in advance, special emphasis should be put on all tumors in areas where it is easily applicable. Even small improvements in prognosis are valuable in this disease with such a high incidence. At the present time the 
differences observed are too small to be detected significantly by clinical trials. We need better methods in detecting minimal residual disease both locally and in the liver before definite answers about the possibilities of influencing dissemination during surgery can be given.

\subsection{References}

1. Gastrointestinal tumor study group. Adjulvant therapy of colon cancer - results of a prospectively randomized trial. N Engl J Med 310: 737-734, 1984.

2. Papillon J. Intracavitary irradiation of earlly rectal cancer for cure. Cancer 36 $696-701,1975$

3. Gastrointestinal tumor study group. Prolongation of the disease-free interval in surgically treated rectal carcinoma. N Engl J Med 312:1465-1472.1985.

4. Cuitler SJ, Myers MH, Green SB. Trendis in survival rates of patients with cancer. N Engl J Med 293: 122-124, 1975.

5. Péloquim $\mathrm{AB}$. Cancer of the colon and rectum: comparison of the results of three groups of surgeons using different techniques. Can J Surg 16:28-34, 1973.

6. Sugarbaker $\mathrm{PH}$. Corlew $\mathrm{S}$. Influence of surgical techniques on survival in patients with colorectal cancer. A review. Dis Colon Rectum 25: 545×557, 1982.

7. Engell, HC. Cancer cells in the circulating bioad. Acta Chir Scand Suppl 201 10-70, 1955 .

8. Moore GE, Sako K. The spread of carcinoma of the colon and rectum: a Study of invasion of blood vessels, lymph nodes and peritomeum by tumor cells. Dis Colon Rectum 2: 92-96, 1959.

9. Griffiths JD. Mckinna JA, Rowbotham HD, Tsolakidis P, Salsbury Avl Carcinoma of the colon and rectum: circulating malignant cells and five-year survival. Cancer $31: 226-236,1973$.

10. Fidler IJ. The relationship of embolic homogeneity, number size and viability to the incidence of experimental metastasis. Eur $\Downarrow$ Cancer 9: 223*227, 1973.

11. Buinauskas P. McDonald $\mathrm{GO}$, Cole WH. Role of operative stress on the resistance of the experimental arimal to inoculated cancer cells. Ann Surg 148: 642-648. 1958.

12. Lundy J. Anesthesia and surgery: a double-edged sword for the cancer patient. I Surg Oncol 14:61-65, 1980.

13. Cole WH. Humphrey L. Need for ümmunologic stimulators during immunosup. pression produced by major caincer surgery. Ann. Surg. 202: 9-20, 1985 .

14. Barnes JP. Physiologic resection of the right colon. Surg Gynecol Obstet 94 $723-726,1952$.

15. Turnbull RB Jir, Kyle K, Watson FR. Spratt J. Cancer of the colon: the influence of the no-touch isolation technic on survival rates. Ann Surg 166:420-427, 1967

16. Fazio WW, Pilipshen SJ. Techniques for the resection of colon cancer: an appraisal of the no-touch isolation technique. In Beahrs OH. Higgins GA. Weinstein Ju (eds): Coloractal tumors, chapter 22. JB Lippincott Company, Philadelphia, 1985.

17. Stearns MW. Schottenfeld D. Techniques for the surgical management of colon cancer, Cancer 28: 165-169, 1971.

18. Block GE, Enker WEE. Controversies in surgery for large bowel cancer. In Enker WEE (ed): Carcinoma of the colon and rectum, chapter 5. Year Book Medical Publishers, Chicago-London, 1978.

19. Enker WE, Laffer UT, Block GE. Enhanced survival of patients with colon and rectal cancer is based upon wide anatomic resection. Ann Surg 190: 350-360, 1979

20. Jagelman DG, Turnbull RB jr. Colectomy for malignant disease of the colon: The "no-touch" isolation technique. In Todd IP (ed): Operative surgery fundamental 
techniques: colon, rectum and anus, p 106-117. Butterworths, London-Boston. 1977

21. Blenkinsopp WK, Stewart-Brown S. Blesowsky L. Kearney G, Fielding LP. Histopathology reporting in Iarge bowel cancer. I Clin Pathol 34: 509-513, 1981.

22. Hull CH, Nie NH. SPSS update. MicGraw Hill New York, 1979.

23. Dixon Wd. Brown MB. BMDP-79. Biomedical Computer Programs P-Series, University of California Press, Berkeley, 1979

24. Kaplan EL, Meier $\mathbb{P}$. Nonparametric estimation from incomplete observations. I Am Stat Assoc 53:457-481, 1958

25. Mantel $\mathbb{N}$. Evaluation of survival data and two new rank order statistics arising in its consideration. Cancer Chemother Rep 50:163-170, 1966.

26. Breslow $\mathrm{N}$. A generalized Kruskat. Wallis test for comparing $\mathrm{K}$ samples subject to unequal patterns of censorship. Biometrika 57:579-594, 1970.

27. Turnbull AB Jr. Cancer of the collon. The five- and ten-year survival rates following resection utitizing the isolation technique. Ann $R$ Coll Surg Engl 46: 243-350. 1970

28. Turnbull PB Jr. Cancer of the simgoid colon. The influence of the no-touch isolation technic on survival. In Welvaart $K$, e.a. (eds): Colorectal cancer. Boerhaave series, wol 18, Leiden University Press, The Hague, Boston, London, 1980

29. Vanderlinden W. Pitfalls in randomized surgical trials. Surgery $87: 258-262,1980$.

30. Fielding LP. Stewart-Brown S, Dudley HAF. Surgeon-related variables and the clinical trial. Lancet ii: $778-779.1978$

31. Goslin R. Steele G. Macintyre J, Mayer R, Sugarbaker P. Cleghorn K. Wilson $R$, Zamcheck $N$. The use of preoperative plasma CEA levels for the stratification of patients after curative resection of colorectal cancers. Ann Surg 192. 747. 751.1980

32. Wolmark N, Wieand HS, Rockette HE Fisher B. Glass A Lawrence W. Lerner $H$, Cruz AB, Volk $H$, Shibata $H$. Evans J, Prager D. The prognostic significance of tumor location and bowel obstruction in Dukes $\mathrm{B}$ and $\mathrm{C}$ colorectal cancer. Ann Surg 198: 743-752, 1983

33. Steele G, Ellenberg $S$, Ramming K, O'Connell M. Moertel C, Lessner H, Bruckner H. Horton J, Schein P. Zamcheck N, Novak J, Holyoke ED. CEA monitoring among patients in multiinstitutional adjuwant G.I. therapy protocols. Ann Surg 196: 162 . 169. 1982 .

34. Finlay 1G. Meek DR, Gray HW, Duncan JG, McArdle CS. Incidence and detection of occult hepatic metastases in colorectal carcinoma. Br Med J 28.4: 803-805, 1982.

35. Bacon HE, Dirbas F. Myers TB, Ponce de Leon F. Extensive Iymphadenectomy and high ligation of the inferior mesenteric artery for carcinoma of the left colon and rectum. Dis Colon Rectum 1; 457-465, 1958.

36. Tartter Pl, Slater G. Papatestals AE. Aufses AH. The prognostic significance of alevated serum alkaline phosphatase levels preoperatively im patients with carcinoma of the colon and rectum. Surg Gynecol Obstet 158: 569.571, 1984.

37. Ackerman NB. Vascular influences on intestinal lymph flow and their relationship to operation for carcinoma of the intestine. Surg Gynecol Obstet 137:801-804. 1973.

38. Salsbury AJ, Mckinna JA, Griffiths JD, Morgan CN. Circulating cancer cells during excision of carcinomas of the rectum and colon with high ligation of the inferior mesenteric vein. Surg Gynecol Obstet $120: 1266-1270,1965$

39. Morgan $\mathrm{CN}$. Carcinoma of the rectum. Ann R Coll Surg Engl 36: 73-97, 1965.

40. Talbot 1C. Ritchie S. Leighton MH. Hughes AO, Bussey HJR, Morson BC. The clinical significance of invasion of veins by rectal cancer. Br $₫ S u r g ~ 67: 439$ 442, 1980 .

41. Ferguson LK, Boland JP. Thomen FJ. Anterior segimental resection for carcinoma of the upper rectum, rectosigmoid and sigmoid. Surgery 52: 741-746, 1962.

42. Rosenberg SA, Tepper J, Glatstein E, Costa J, Young R, Baker A, Brennan MF, Demoss EV, Seipp $C_{2}$ Sindelar WF. Sugarbaker P. Wesley R. Prospective randomized evaluation of adjuwant chemotherapy in adults with soft tissue sarcomas of the extremities. Cancer 52:424-434, 1983 


\section{Prognostic significance of CEA immunoreactivity patterns in large bowel carcinoma tissue}

\subsection{Introduction}

Preoperative estimation of plasma levels of carcinoembryonic antigen (CEA) in patients with colorectal cancer has an established role as an independent prognostic parameter and as a parameter for detection and monitoring of recurrent disease'.

CEA tissue immunoreactivity, in contrast, is considered to be of less significance. Its value as yet has been limited to the identification of a small group of patients without CEA expression in tumor cells. These carcinomas are usually poorly differentiated and monitoring of plasma CEA levels during follow-up is not useful in these cases ${ }^{2}$.

However, there are indications that both the presence of CEA in tissue $^{3}$ and its localization within the cel/4.5 are related to the histological grade of colorectal tumors and thus could be of potential prognostic value.

We therefore studied the immunoreactivity patterns at the cellular level of one polyclonal anti CEA antibody and one CEA specific monoclonal antibody on histological specimens of 312 and 231 colorectal carcinoma patients respectively. The CEA staining patterns were correlated with stage and grade of the carcinomas as well as with data on patient survival.

\subsection{Material and methods}

\section{Patients.}

The material for this study was obtained as part of a prospective multicenter trial comparing the no-touch isolation technique of Turnbullo with a conventional surgical technique. History, liver function tests, tumor localization and type of operation were recorded. Follow-up to determine disease free interval was performed every three/six months according to a strict schedule. Mean duration of 
follow-up was 51.9 months (range $44.1-60.0$ months). Survival was corrected for non-disease related death.

\section{Histological specimens.}

All sections and paraffin blocks available of the specimens including regional lymph nodes (ranging from 2 to 15 per case) were collected from the different centers, participating in the trial and were reviewed regarding stage, histologicall grade and CEA immunoreactivity according to the following criteria:

\section{Stage.}

A method of staging derived from the Dukes classification was used ${ }^{6}$ :

A tumor confined to the bowel wall;

B. tumor extension into the pericolic fat:

C. both $A$ or $B$ with regional lymph node metastases;

D. infiltrative growth in adjacent organs or distant metastases.

\section{Grading.}

The degree of differentiation was assessed according to a modification of the criteria employed by Blenkinsopp ${ }^{7}$ : well differentiated (tumors entirely consisting of glandular formation having up to two layers of lining cells with preserved nuclear polarity), poorly differentiated (tumors with more than $10 \%$ of a solid growth pattern), moderately differentiated (tumors covering spectrum between well and poorly differentiated) and undifferentiated (no glandular structures). At least two different sections of each tumor were reviewed and grading was based on the least differentiated areas observed.

\section{Antibodies.}

The conventional rabbit anti CEA antibody was purchased from Dakoimmunoglobulin (Copenhagen, Denmark). The characteristics of the monoclonal CEA reactive antibody (Parlam 1) produced in our institution have been described in detail elsewhere ${ }^{8}$.

\section{Immunohistochemistry.}

One block of formalin fixed and paraffin-embedded tumor tissue preferably containing normal adjacent mucosa was used for immunohistochemistry. Immunostaining with the conventional antibody was performed with the unlabeled peroxidase-antiperoxidase procedure, whereas the monoclonal antibody Parlam 1 was applied in an indirect peroxidase labeling technique using rabbit-antimouse Ig as a second layer. Details of the procedure have been published before ${ }^{89}$. 
Scoring of immunoreactivity.

The pattern of immunoreactivity of the CEA reactive antibodies was scored semiquantitatively as follows: tumors were classified as negative if less than $80 \%$ of the individual tumor cells displayed immunoreactivity. Tumors were classified as positive if more than $80 \%$ of the tumor cells showed CEA expression. In addition with regard to CEA localization within the individual tumor cell a distinction was made in tumors with more than $80 \%$ apical and/or cytoplasmic staining pattern (figure 6.1a) and in tumors with immunoreactivity confined to the cell membranes in more than $80 \%$ of the tumor cells (figure 6.1 b).

(a)

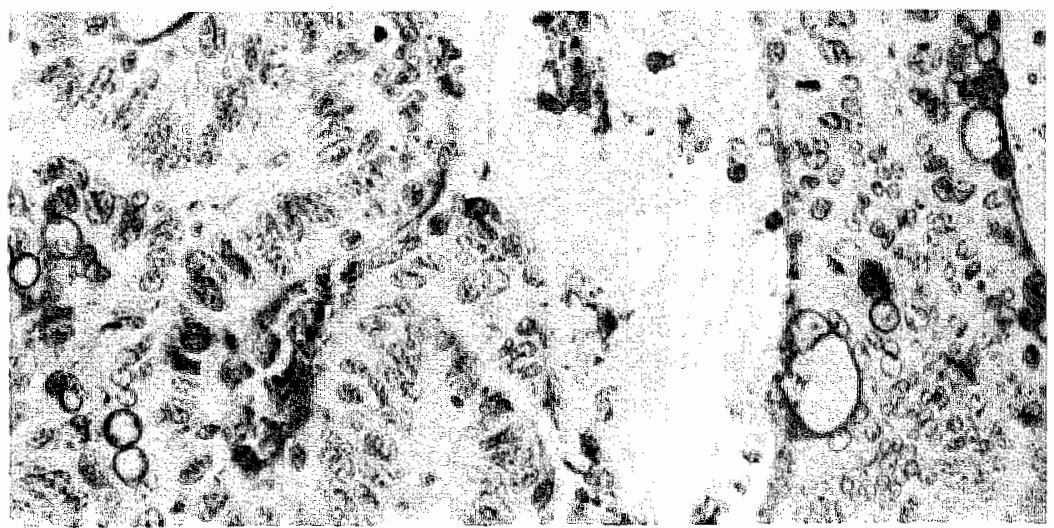

(b)

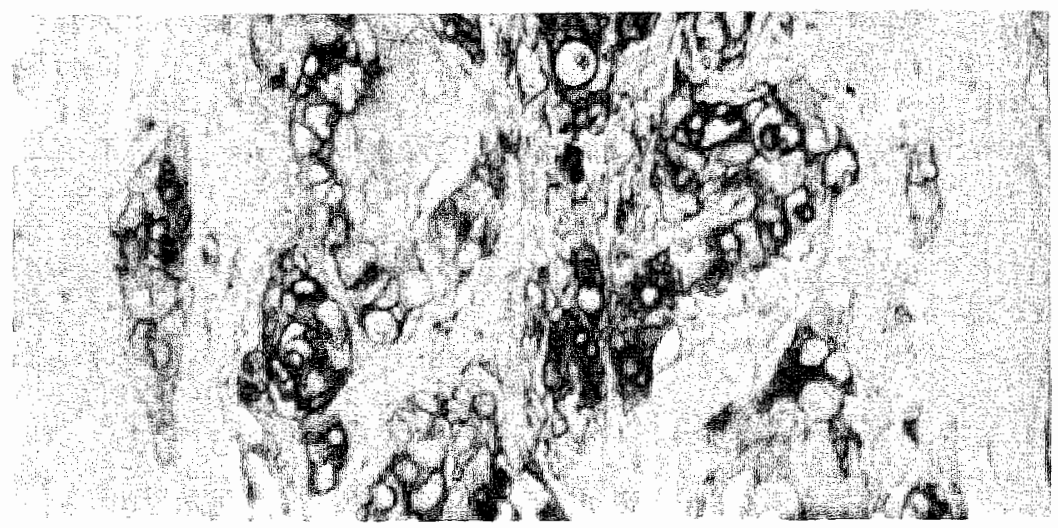

Figure 6.1: CEA immunoreactivity patterns in colorectal carcinoma

(a) colonic carcinoma with a positive, apical staining pattern

(b) colonic carcinoma with a predominant membranous staining pattern

(immunaperoxidase CEA, $\times 250$ ). 


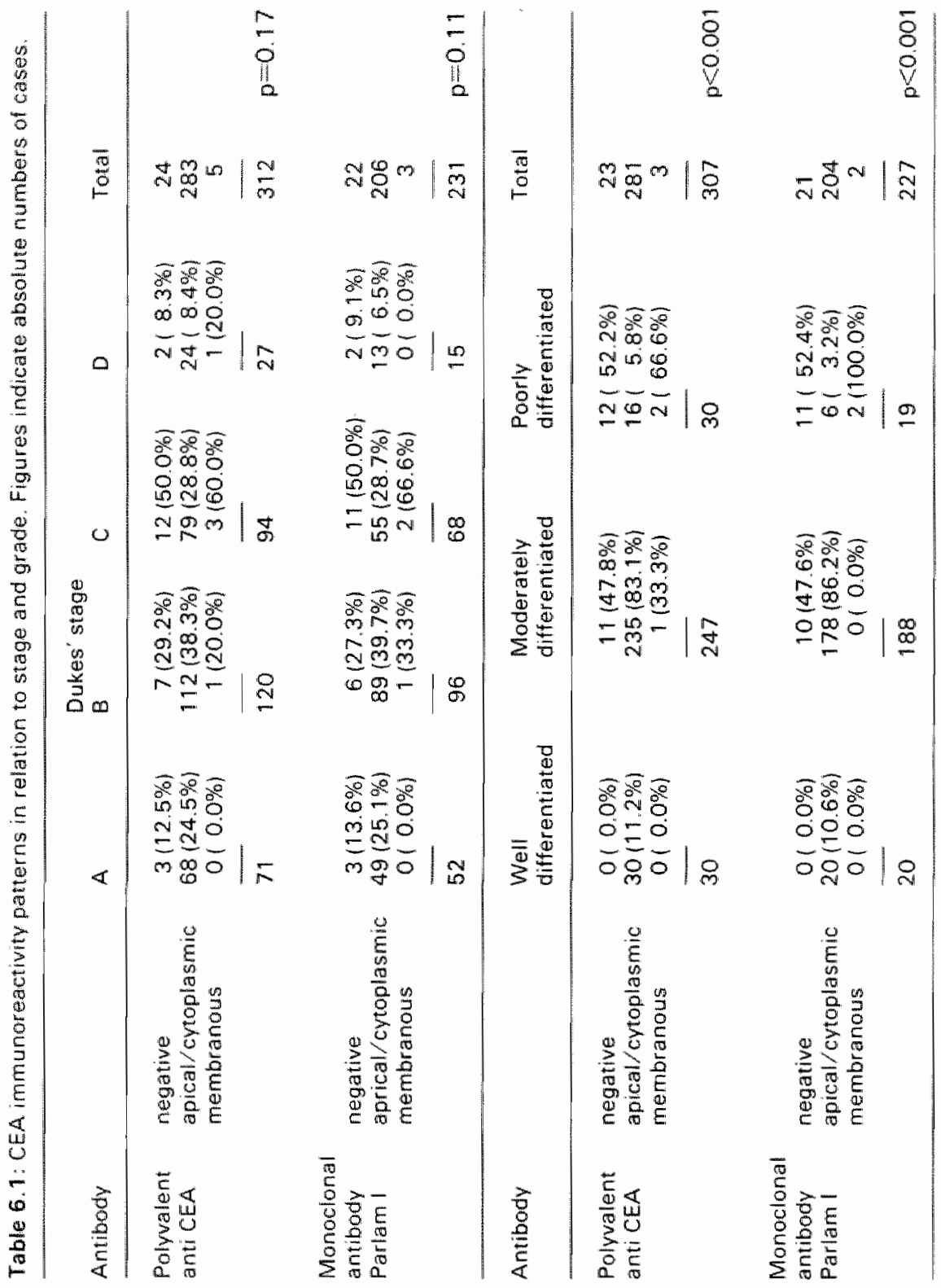


Statistical analysis.

All patients data were stored on a computer. A chi-square analysis for association was used for interpretation of the cross tabulations between immunoreactivity pattern and histological grading or staging. The calculations were made with the aid of SPSS (Statistical Package for Social Sciences).

Life tables were computed with the BMDP program (Biomedical Computer Program P-series). They are based on the product limit method of individual survival times (Kaplan-Meier). Calculations of the significance of observed differences were made using the logrank test (Mantel Cox) and the generalized Wilcoxon test (Breslow).

\subsection{Results}

\section{CEA immunoreactivity patterns.}

Twenty-four out of $312(7.7 \%)$ large bowel carcinomas showed no or only focal CEA immunoreactivity. In the remainder of the cases marked CEA expression was observed in either an apical/cytoplasmic or membranous pattern. The apical and cytoplasmic staining patterns gradually merged, whereas a predominant membranous CEA immunoreactivity could be easily distinguished in five cases (1.6\%). No striking difference was noticed in the distribution or localization pattern of CEA as detected by the polyclonal anti CEA antiserum and the monoclonal antibody Parlam 1, which was employed in a more restricted number of cases (231).

CEA immunoreactivity patterns in relation to stage and grade.

in table 6.1 the immunoreactivity patterns of the CEA reactive monoclonal antibody Parlam 1 and polyvalent anti CEA antibody are compilled in relation to stage of tumor extension and histological grade.

CEA negative carcinomas predominated in the more advanced stages of tumor extension and the group of poorly differentiated tumors $(p=0.11, p<0.001$, respectively).

Tumors with membranous CEA expression tended to occur mainly in the advanced stages of tumor extension $(p=0.11)$ and the group of poorly differentiated tumors $(p<0.001)$.

CEA immunoreactivity patterns in relation to patient survival.

In figure 6.2 patient survival is shown in relation to CEA positive and CEA negative tumors. Patients with CEA negative tumors demonstrate a poor survival in comparison with patients with CEA positive carcinomas (Wilcoxon $p=0.02$. Mantel/Cox $p=0.04$ ).

Figure 6.3 illustrates the difference in survival between patients 


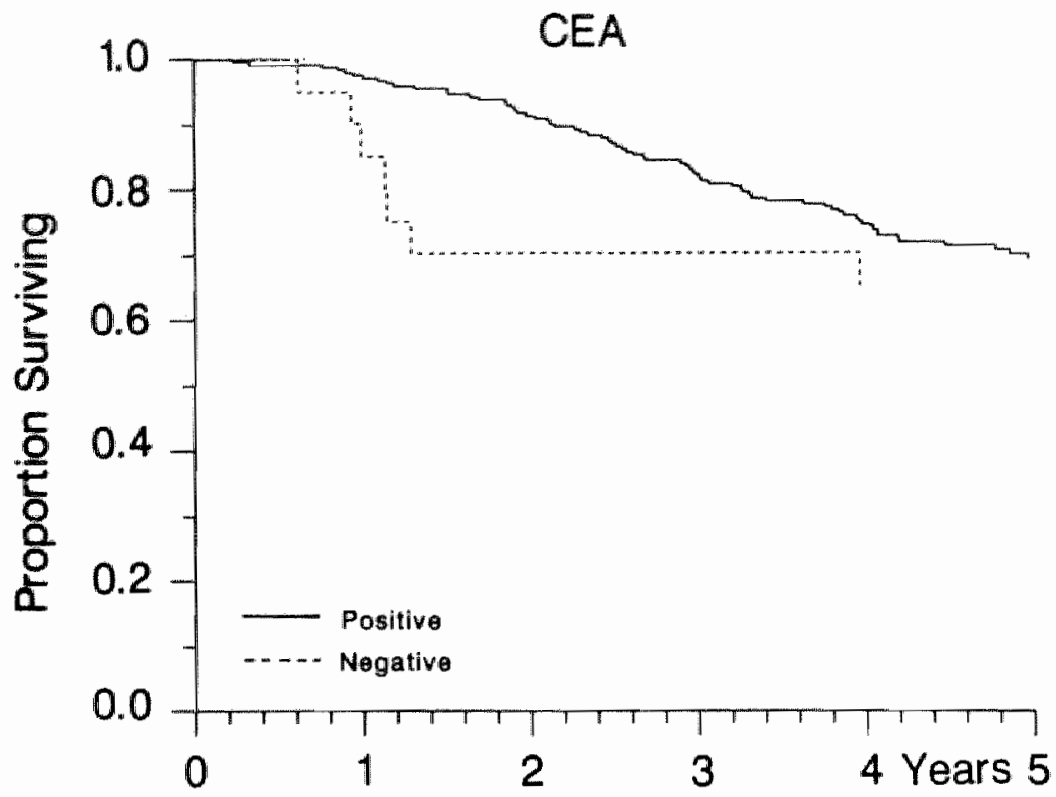

Figure 6.2: Survival corrected for non-disease related death of patients with CEA negative tumors and CEA positive tumors as detected with polyvalent anti CEA. (Wilcoxon $\mathrm{p}=0.02$; Mantel Cox $\mathrm{P}=0.04$ ).

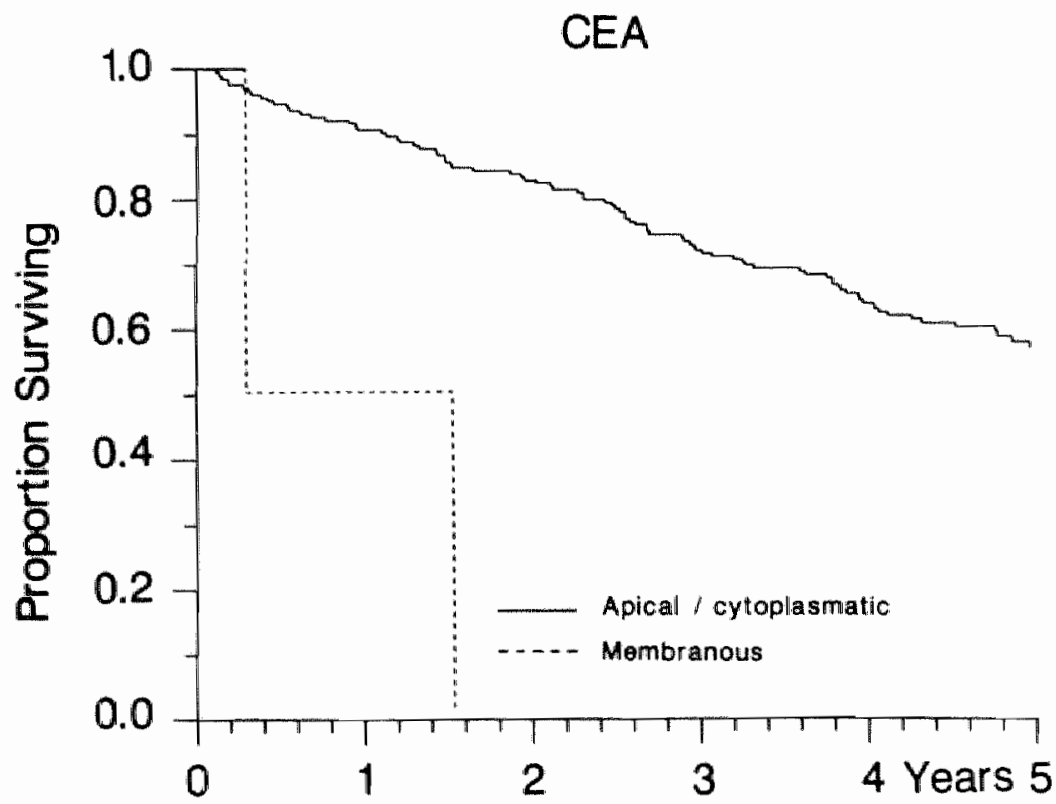

Figure 6.3: Survival corrected for non-disease related death of patients with predominantly apical cytoplasmic and membranous staining patterms as detected with monoclonal antibody Parlam 1 (Wilcoxon p<0.001; Mantel Cox p<0.001). 
with tumors demonstrating an apical/cytoplasmic immunoreactivity pattern and tumors with membranous CEA expression. Patients from the latter group showed a markedly poorer survival than patients with apical/cytoplasmic positive carcinomas (Wilcoxom $\mathrm{p}<0.001$, Mantel/Cox $\mathrm{p}<0.0011$.

\subsection{Discussion}

The majority of large bowel carcinomas express CEA and a correlation between CEA immunoreactivity and histological grade has been repeatedly recorded in the literature $3,10.11,12$. Whereas well differentiated carcinomas generally demonstrate strong CEA expression, poorly differentiated and undifferentiated neoplasms may be devoid of the antigen. In this context CEA negative tumors are thought to behave more aggressively. This notion has been confirmed in our study correlating the CEA expression status directly to data on survival in a large series of patients with long well documented follow-up periods. Rognum et al. ${ }^{13}$ " however, were not able to show a correlation between the intensity of CEA expression and differentiation of large bowel tumors. Moreover plasma CEA levels do not seem to correspond with the intensity of CEA immunoreactivity in individual patients ${ }^{14}$ Although for these reasons the clinical relevance of tissue CEA detection remained limited, there are indications that the role of CEA tissue immunoreactivity in the diagnosis and management of colorectal cancer patients needs reconsideration. Most workers focussed on the intensity of CEA immunoreactivity and little attention so far has been paid to the pattern of CEA localization in the large bowel cancer cell Yet, the pattern of CEA expression may be more relevant to study the biological behavior of colorectal carcinomas than the intensity of the immunoreaction, which is variable and depends on several factors, such as tissue preservation and the affinity of the antibodies used. Ahnen et al. " observed a polar distribution of CEA with immunoelectronmicroscopy in the microvilli of the apical plasmamembranes of normal colonic epithelium. whereas in neoplastic epithelium a gradual loss of polarity occurred in relation to the grade of anaplasia. Poorly differentiated tumors demonstrated CEA over the entire cell surface. These observations suggest that the pattern of CEA immunoreactivity described in terms of apical/cytoplasmic or membranous localization in tumor cells may be related to histological grade and thus may be of prognostic significance. Hamada et all. ${ }^{5}$ indeed showed that large bowel carcinomas with CEA expression along the basolateral cell surface generally belong to the moderately and poorly differentiated group of tumors, but did not provide data on how this was correlated with patient survival. 
Our study demonstrates that the subdivision of CEA expression into apical/cytoplasmic and membranous patterns at the light microscope level is feasible and confirms that tumors with a membranous expression pattern predominate in the more anaplastic histological grades. Moreover, carcinomas with a membranous expression pattern were shown to behave more aggressively in patients than tumors with an apical/cytoplasmic pattern of immunoreactivity.

In the application of rigorous criteria for the classification of tumors into patterns of CEA expression however, we were unable to distinguish between apical and cytoplasmic staining patterns and therefore these had to be lumped together. Moreover, only very few tumors with a predominantly membranous pattern of expression could be discerned, resulting in two imbalanced groups, which may introduce a bias in the statistical evaluation of the data. This situation, which drastically restricts the practical relevance of our observations, appeared to be due to considerable intra tumor heterogeneity in the pattern of CEA expression. To pathologists, who have since long recognized the difficulty of grading large bowel carcinomas due to to intra tumor heterogeneity of differentiation ${ }^{15}$, this is familiar. Our data therefore illustrate the practicality of characterizing tumors according to a feature heterogeneously expressed in relation to biological behavior, which represents the outcome of the interrelation and interaction of several clones differing in this feature. Nevertheless, our study confirms the observations 4.5 in that the pattern of CEA expression closely reflects the degree of differentiation of individual large bowel cancer cells and in addition demonstrates that tumors displaying a rather homogeneous membranous CEA expression pattern behave aggressively.

Further studies on the correlation between the pattern of CEA expression and clinical course in large bowel cancer patients applying other criteria for the classification of these patterns are therefore warranted. Also, in a multivariate analysis of prognostic factors in colorectal carcinoma the pattern of CEA expression should be in. cluded.

\subsection{References}

1. Anonymous, Carcinoembryonic antigen: its role as a marker in the management of cancer - National Institutes of Health Consensus Development Conference Statement. Cancer Res 41:2017-2018, 1981

2. Gostin $R$, O:Brien MJ. Steele G, Mayer $R$, Wilson $R$, Corson JM, Zamcheck $N$ Correlation of plasma CEA and CEA tissue staining in poorly differentiated colorectal cancer. Am J Med 71: 246-253, 1981

3. Goldenberg DM, Sharkey RM, Primus FJ. Carcinoembryonic antigen in histopathology: Immunoperoxidase staining of conventional tissue sections. I Natl Cancer Inst $57: 11-22,1976$. 
4. Alynen DJ, Nalkane PK. Brown WR. Ultrastructural localization of carcinoembryonic antigen in normal intestine and colon cancer. Cancer 49:2077.2090, 1982.

5. Hamada $Y$, Yamamura $M$, Hioki $K$, Yamamoto $M$, Nagura $H$, Watanabe $K$. Immunohistochemical study of carcinoembryonic antigen in patients with collorectal cancer. Cancer 55: 136-141, 1985.

6. Turnbull RB Jr, Kyle K, Watson FR, Spratt J. Cancer of the colon: the influence of the no-touch isolation technic on survival rates. Ann Surg 166:420 427, 1967.

7. Blenkinsopp WK, Stewart-Brown S, Blesowsky L. Kearney G, Fiellding LP. Histo. pathology reporting in large bowel cancer. J Clin Pathol 34: 509-513, 1981

8. Verstijnen CPHJ, Airends JW, Moerkerk PTM, Hilgers J, Bosman FT. CEA-specificity of CEA-reactive monoclonal antibodies. Immunochemical and immunocytochemical studies. Anti Cancer Res 6: 97-104, 1986.

9. Arends JW, Verstijnen C. Bosman FT. Hilgers $J$, Steplewsiki Z. Distribution of monoclonal antibody-defined monosialoganglioside in normal and cancerous human tissues: an immunoperoxidase study. Hybridoma 2: 219-229, 1983.

10. Denk H. Tappeiner G, Eckenstorfer R. Holzner JH. Carcinoembryanic antigen (CEA) in gastrointestinal and extragastrointestinal tumors and its relationship to tumorcell differentiation. Int J Cancer 10: 262-272, 1972.

11. Huitric $E$, Laumonier $R$, Burtin $P$, Von Kleist $S$, Chavanel $G$. An optical and ultrastructural study of the localization of carcinoembryonic antigen (CEA) in normal and cancerous human rectocolonic mucosa. Lab Invest 34: 97-107, 1976.

12. O'Brien MJ, Zamcheck N, Burke B, Kirkham SE, Saravis CA, Gottlieb LS. Immunocytochemical localization of carcinoembryonic antigen in benign and mal igmant colorectal tissue. Am J Clin Pathol 75: 283-290, 1981.

13. Rognum TO, Thorud E, Elgjo D. Brandtzaeg P. Orjasaeter JH. Nygaard K. Large bowel carcinomas with different ploidy, related to secretory component, $|\mathrm{g}| \mathrm{A}$ and CEA in epithelium and plasma. $\mathrm{Br} J$ Cancer 45: 921-934, 1982.

14. Lewis JCM, Keep PA. Relationship of serum CEA lewels to tumour size and CEA content in nudle mice having colonic tumour xenografts. $\mathrm{Br} J$ Cancer 44 : 381 . $387,1981$.

15. Qualheim RE, Gall EA. Is histologic grading of colon carcinoma a valid procedure? Arch Pathol 56: 466 472, 1953. 



\section{A multivariate analysis of pathological prognostic indicators in large bowel cancer}

\subsection{Introduction}

Morphologically, carcinomas of the large bowel represent a rather uniform group of tumors, the outcome of which shows great variability and unpredictability. Traditionally, the stage ${ }^{\text {a }}$ of the tumor extension in combination with the presence or, absence of lymph mode and distant metastases and, to a lesser extent, the histological grade 2 have been used as parameters for the identification of subgroups of patients with a different prognosis. In addition, other pathology variables such as, shape and size of the tumor, the proportion of the bowel wall circumference involved, the degree of lymphocytic infiltration in the tumor stroma, angio-invasive growth and the number and localization of lymph node metastases have been used to obtain prognostic information.

More recently, new variables have been tested for their potential prognostic value. Of these, estimation of tumor cell DNA content, by static ${ }^{3}$ or flowcytometrical means ${ }^{4}$, and the expression of antigens associated with large bowel cancer ${ }^{5}$, appear to be of particular interest.

In previous studies, we have shown that the DNA content of large bowel carcinomas is a prognostic indicator in Dukes ${ }^{\circ} \mathrm{C}$ staged tumors ${ }^{6}$. We also demonstrated a correlation between patient survival and the expression patterns of two large bowel carcinoma associated antigens carcinoembryonic antigen (CEA) ${ }^{7}$ and $\mathrm{Ca}$ 19-98. Similar associations were shown for secretory component ${ }^{9}$, serotonin ${ }^{10}$ and mucin ${ }^{11}$, products of normal resorptive, enterochromaffin and goblet cells respectively. The prognostic significance of these parameters however, was determined by univariate analysis. Therefore, the question remains as to whether interrelation with other prognostic factors, such as, tumor stage, may account for the findings. It is the aim of the present study to evaluate, by means of a regression 
model the prognostic relevance of tumor stage, grade and DNA content, as well as expression patterns at a cellular level of the above mentioned antigens.

\subsection{Material and methods}

\section{Patients.}

The specimens of colorectal tumors for this study were mostly derived from patients entering two prospective multicenter trials from 1979 to 1981 . One was regarding colon cancer in which a conventional and a no-touch isolation resection technique were compared. The other was a trial with regard to preoperative irradiation in rectal cancer. Although for the trials patients with distant metastases were excluded, some were included in the present study bringing the total number of patients up to 350 . Patients with previous malignancies were excluded. Extensive pre- and peroperative investigations have been performed in order to detect or exclude distant metastases.

\section{Follow-up.}

A standarized follow-up program was instituted, including routine blood count and chemistry studies including the CEA level every three months and after three years every six months. Ultrasound of the liver, chest $X$-ray and colonoscopy were performed annually.

\section{Criteria for recurrence.}

All patients were followed closely and both the disease free interval and survival data were obtained. For this analysis only death due to recurrent disease was used, excluding postoperative mortality within 30 days and non-disease related death.

\section{Localization.}

Tumors of cecum and ascending colon were classified as right sided tumors. Tumors of both flexures were included in transversal coion. Left sided tumors comprised the colon descendens and the sigmoid. The rectosigmoid and rectal tumors were taken together as well.

\section{Histological specimens.}

Blocks of paraffin-embedded cancer tissues and lymph nodes were collected from the contributing hospitals and reviewed with regard to stage, histologicall grade, angio-invasive growth and immunoreactivity of the studied antigens according to following criteria:

* Stage.

A clinicopathological staging derived from the Dukes" classifi- 
cation was used 12. Stage A: tumor confined to the bowel wall; stage B: extension outside the serosa and/or into the pericolic/ rectal fat; stage $\mathrm{C}$; either $\mathrm{A}$ or $\mathrm{B}$ with lymph node metastases; stage D: infiltrative growth in adjacent organs or distant meta. stases.

Grade.

The degree of differentiation was assessed according to a modification of the criteria employed by Blenkinsopp ${ }^{13}$ : well differentiated (tumors consisting entirely of glandular formation having up to two layers of lining cells with preserved nuclear polarity), poorly differentiated (tumors with more than $10 \%$ of a solid growth pattern), moderately differentiated (tumors covering the spectrum between well and poorly differentiated). The undifferentiated tumors (no glandular structures) were few in number and put together with the poorly differentiated ones. At least two different sections of each tumor were reviewed and grading was based on the least differentiated areas observed.

* Angio-invasive growth.

Avallable $H /$ E sections were studied for the presence of angioinvasive growth for at least 20 minutes.

* Antibodies.

Five colorectal tissue reactive antibodies were used in this study. The polyvalent rabbit anti-CEA antibody and the antisecretory component antibody were purchased from Dakopatts (Copenhagen, Denmark). The serotonin antiserum was raised in rabbits by repeated subcutaneous immunization with a formaldehyde conjugated serotonin-albumin complex. Details of this procedure have been reported previously ${ }^{10}$. Presence of mucin was demonstrated with the high-iron diamine/alcian blue stain distinguishing between sialated and sulphated mucins. The antibody Ca 19.9 was of monoclonal origin. Details about this antigen and its source are described elsewhere 8.14

* Immunohistochemistry.

The details of the immunocytochemical procedures of most antibodies have been reported in detail elsewhere 7.8 .9 .110$. Briefly, one block of formalin fixed paraffin-embedded tumor tissue, preferably containing normal adjacent mucosa was used for immunohistochemistry. The polyvalent antibodies were applied in the unlabeled peroxidase-antiperoxidase procedure using peroxidase conjugated swine anti-rabbit lg as a second antibody. The mouse monoclonal antibody was employed in an indirect peroxidase labeled antibody procedure, using rabbit-antimouse $\mathrm{lg}$ as a second layer. The effect of routine tissue processing did not affect the 
results since staining patterns of frozen sections of colorectal cancers were comparable with those of trypsinized paraffin sections of the same tumors.

* Scoring of immunoreactivity.

Immunoreactivity of most antibadies was scored semiquantitatively. It was considered as positive if over $80 \%$ of the individual celis expressed the antigen, and negative if less than $5 \%$ of the tumor cells expressed the antigen. The pattern was scored focally positive if between five and 80 percent of the cancer cells showed immunoreactivity. For the anti CEA antibody, tumors were classified as positive if the apical plasma membrane and/or the entire cytoplasm stained, or negative, if immunoreactivity was focally among the individual cells. Tumors with immunoreactivity confined to the cell membrane were classified as membranous. Only a few tumors displayed this last mentioned staining pattern. Since these tumors were correlated with a poor prognosis ${ }^{7}$ they were analysed together with the tumor classified as negative. Regarding the mucim stains, a subdivision into three groups was made: one group staining predominantly for sulphomucins, a second group staining mainly for sialomucins and a rest group staining either negatively or displaying a mixed pattern.

\section{Flowcytometry.}

Details of the DNA flowcytometry with paraffin-embedded tissue derived nuclei have been published elsewhere ${ }^{15}$. Briefly, a slice of paraffin-embedded tissue was scraped off the block and was rehydrated after clearing the paraffin. After trypsination and filtration, approximately $2-3 \times 10^{6}$ cells were stained according to the method of Vindelovia. Cellular DNA content was measured on a FACS IV cell sorter (Becton and Dickinson, Sunnyvale, CA). The DNA index was calculated as a ratio of the aneuploid to the diploid $G_{10}$ peak. Tumors were classified as diploid IDNA index 1.0) or aneuploid (DNA index $>$ 1.0). A special category was formed by tumors displaying a broad diploid peak (classified as 4.0 ).

\section{Statistical analysis.}

The relative prognostic importance of all pathological parameters, including localization of the primary tumor and age was investigated using Cox's regression model ${ }^{17}$ and the computer program BMDP2L ${ }^{18}$. As for most parameters a substantial number of values were missing. two analyses were performed: one using the 225 patients with complete data records for the above mentioned variables and one. including a separate category 'missing', for each parameter with 
missing values. Inspection of the data revealed no statistically significant associations between the parameters, when dichotomized as 'present' versus 'missing" and survival.

In the Cox proportional hazards regression madel the outcome of all parameters $x_{1}, x_{2}, \ldots x_{\beta}$ is measured at baseline for an individual patient (i). A prognostic score (S) for this patient can be written as: $\mathrm{S}_{\mathrm{i}}=\beta_{1} \mathrm{x}_{\mathrm{i} 1}+\beta_{2} \mathrm{x}_{\mathrm{i} 2}+\beta_{3} \mathrm{x}_{\mathrm{i} 3}+\ldots+\beta_{\mathrm{p}} \mathrm{x}_{\mathrm{ip} .}$.

Here $x_{i j}$ is the value of the $j$-th prognostic variable $(j=1,2, \ldots, p)$ for the $i$-th patient $(i=1,2, \ldots, n)$ and the parameter $\beta$ j demotes the difference in the prognostic score of patients who differ by one unit in the $j$ th variable, all other prognostic variables for those patients being at the same level.

A prognostic variable with two or more categories of outcome is represented by a number of variables and parameters equal to the number of its categories minus one. The category not included as a variable is the reference category. The Dukes' classification for example, is represented by three prognostic variables in the prognostic score, one representing Dukes $B_{r}$ the second representing Dukes $C$ and the third representing Dukes $D$, with respective parameters $\beta_{1}$, $\beta_{2}, \beta_{3}$ say. A patient i classified as Dukes B gets a 'Dukes' contribution of $\beta_{1}$ to this/her prognostic score, a patient classified as Dukes $A$ gets no 'Dukes' contribution to his/her prognostic score since the A state is absorbed in the reference hazard.

The prognostic score $\mathrm{Si}$ is related to the survival outcome by: $\lambda_{i}(t)=\lambda_{0}(t) \exp \left(S_{i}\right)$, where $\lambda_{i}(t)$ represents the instantaneous risk or hazard of death at time $t$ for patient $i$ given that this patient was alive just before $t: \lambda_{1}(t) \times h$ gives the probability of dying in a small interval $t$ to $t+h$. $\lambda_{0}(t)$ denotes a reference hazard, that is the hazard for patients with a prognostic score $S=0$.

Exp $\left(\beta_{2}\right)$ denotes the excess risk for patient $\mathrm{i}$, with respect to the reference hazard if that patient is classified as Dukes $C$, and $\beta_{2}$ is the parameter associated with Dukes $C$ in the prognostic score.

\subsection{Results}

Survival rates of the traditional pathological parameters are summarized in table 7.1 and shown in figure 7.1. Tumors with a diameter between 3.5 and 6 centrimetre are related to a better survival, in comparison with small and very large tumors $(p=0.02)$. Ulcerative growth is associated with a poorer prognosis $(p=0.01)$ compared to exophytic growth, while patients with sessile and polypoid tumors had a similar survival. Patients with a lack of angio-invasive growth showed significantly longer survival in relation to its presence 
Table 7.1: Summary of the iraditional variables entered in the regression model

\begin{tabular}{|c|c|c|c|c|}
\hline Variable & Categories & $\begin{array}{l}\text { ber of } \\
\text { irvations }\end{array}$ & $\begin{array}{l}\text { Number of } \\
\text { disease related } \\
\text { death }(\%)\end{array}$ & $\begin{array}{l}\text { P.walue of } \\
\text { Logrank lest }\end{array}$ \\
\hline $\begin{array}{l}\text { Size of the tumor } \\
(\mathrm{cm})\end{array}$ & $\begin{array}{l}<3.5 \\
3.5-6.0 \\
>6.0\end{array}$ & $\begin{array}{r}118 \\
157 \\
59\end{array}$ & $\begin{array}{l}42(35.6) \\
37(23.5) \\
22(37.3)\end{array}$ & 0.02 \\
\hline Shape of the tumor & $\begin{array}{l}\text { polypoid } \\
\text { sessile } \\
\text { ulcerative }\end{array}$ & $\begin{array}{c}48 \\
51 \\
236\end{array}$ & $\begin{array}{r}8(16.7) \\
10(19.6) \\
84(35.6)\end{array}$ & 0.01 \\
\hline $\begin{array}{l}\text { Angio-invasive } \\
\text { growth }\end{array}$ & $\begin{array}{l}\text { present } \\
\text { absent }\end{array}$ & $\begin{array}{r}93 \\
236\end{array}$ & $\begin{array}{l}45(48.4) \\
56(23.7)\end{array}$ & 0.00 \\
\hline $\begin{array}{l}\text { Central node } \\
\text { involvement }\end{array}$ & $\begin{array}{l}\text { positive } \\
\text { negative }\end{array}$ & $\begin{array}{r}29 \\
321\end{array}$ & $\begin{array}{l}20(69.0) \\
95(29.6)\end{array}$ & 0.00 \\
\hline Stage & $\begin{array}{l}A \\
B \\
C \\
D\end{array}$ & $\begin{array}{r}78 \\
132 \\
99 \\
41\end{array}$ & $\begin{array}{l}6(7.7) \\
31(23.5) \\
44(44.4) \\
34(82.9)\end{array}$ & 0.00 \\
\hline Grade & $\begin{array}{l}\text { well differentiated } \\
\text { moderately differentiated } \\
\text { poorly differentiated }\end{array}$ & $\begin{array}{r}35 \\
264 \\
35\end{array}$ & $\begin{array}{r}8(22.9) \\
79(29.9) \\
18(51.4)\end{array}$ & 0.00 \\
\hline Localization & $\begin{array}{l}\text { right sided } \\
\text { transversal } \\
\text { left sided } \\
\text { rectosigmoid/rectal }\end{array}$ & $\begin{array}{r}73 \\
41 \\
110 \\
126\end{array}$ & $\begin{array}{l}25(34.2) \\
18(43.9) \\
32(29.1) \\
40(31.7)\end{array}$ & 0.34 \\
\hline Age (years) & $\begin{array}{l}<60 \\
60-70 \\
>70\end{array}$ & $\begin{array}{r}97 \\
90 \\
163\end{array}$ & $\begin{array}{l}31(32.0) \\
28(31.1) \\
56(34.3)\end{array}$ & 0.26 \\
\hline
\end{tabular}

$(p=0.00)$. Central node involvement was associated with significantly shorter survival $(p=0.00)$. Prognosis was strongly related to staging $(p=0.00)$ and grading although for the last variable only the poorly differentiated tumors discriminated with respect to the well and moderately differentiated carcinomas $(p=0.00)$. There was no significant difference in survival according to localization $(p=0.34)$ and age $(p=0.26)$ (figures not shown).

in table 7.2 the new variables are summarized and plotted in figure 7.2. There was a tendency for poorer survival for CEA negative tumors $(p=0.06)$, the focally and positive Ca $19-9$ staining tumors $(p=0.11)$, the serotonin positive tumors $(p=0.12)$ and for the tumors with a DNA index greater than $1.0(p=0.12)$. Positive staining for secretory component $(p=0.01)$ and excess of sulphomucin $(p=0.04)$ were associated with a better survival whereas, differences in either extracellular or intracellular mucin production, were of no significance $(p=0.46)$ 

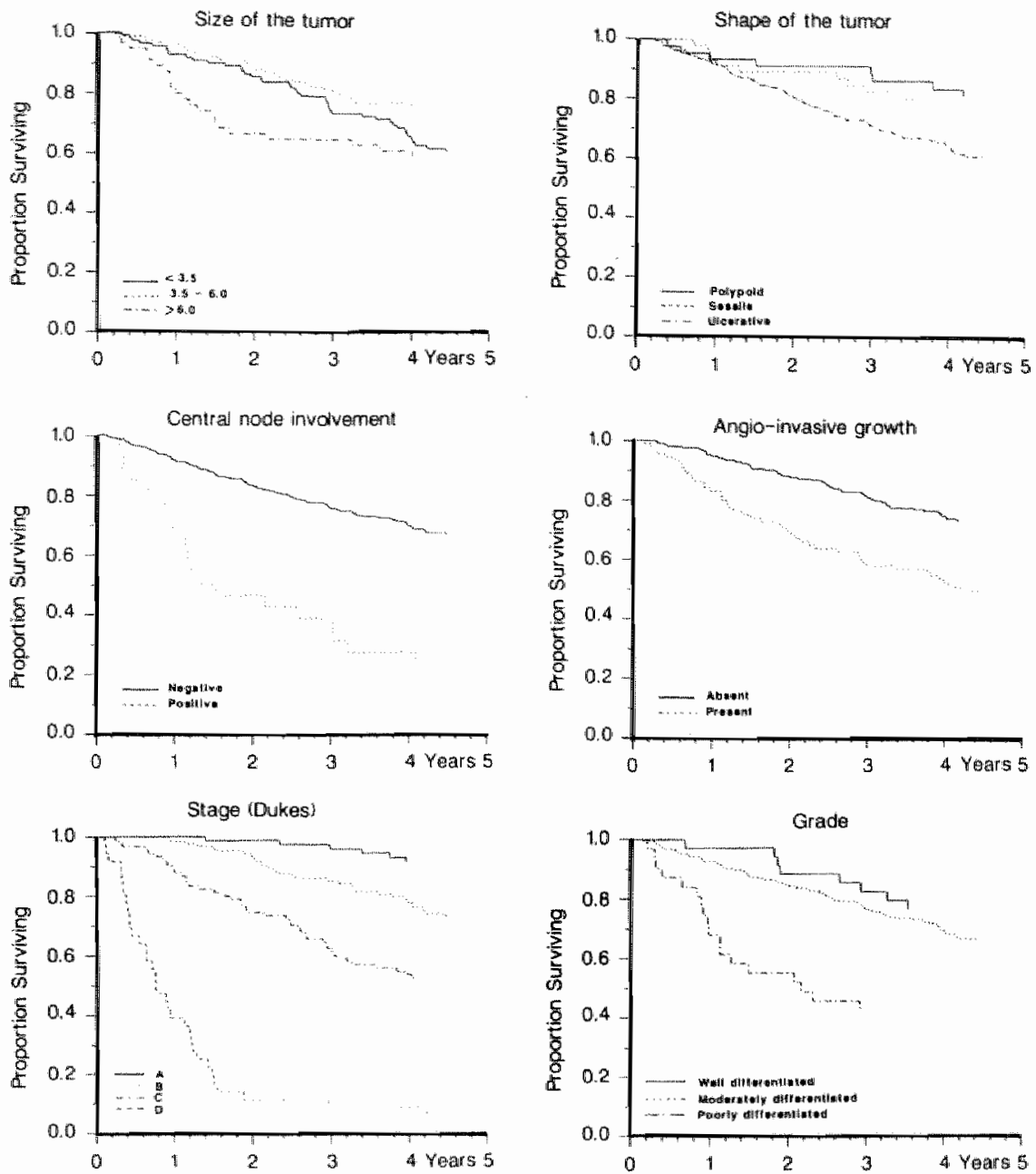

Figure 7.1: Survival curves for traditional parameters. Postoperative deaths are excluded and unrelated deaths are censored at the time of death.

\section{Multipie regression analysis.}

The parameters, derived from the regression models which offer independent prognostic information, are summarized in the tables 7.3 and 7.4. Backward elimination, using Wald and likelihood-ratio tests was employed to select parsimonious models. Only parameters with $\mathrm{p}$-values smaller than 0.05 were included in the model with 'missing' categories. In the model using complete records parameters with $p$-values smaller than 0.10 were included. However all $p$-values, except those for the flowcytometry $(p=0.09)$ and for serotonin $(p=0.09)$ 
Table 7.2: Summany of the new variabies entered in the regression model

\begin{tabular}{|c|c|c|c|c|}
\hline Variable & Categories & $\begin{array}{l}\text { ber of } \\
\text { rvations }\end{array}$ & $\begin{array}{l}\text { Number of } \\
\text { disease related } \\
\text { death } \%)\end{array}$ & $\begin{array}{l}\text { P.value o } \\
\text { Logrank }\end{array}$ \\
\hline CEA & $\begin{array}{l}\text { negative/membranous } \\
\text { apical/cytoplasmatic }\end{array}$ & $\begin{array}{r}29 \\
283\end{array}$ & $\begin{array}{l}12(41.4) \\
85(30.0)\end{array}$ & $\begin{array}{l}0.06 \\
0.00^{*}\end{array}$ \\
\hline Ca $19-9$ & $\begin{array}{l}\text { megative } \\
\text { focally } \\
\text { positive }\end{array}$ & $\begin{array}{c}112 \\
166 \\
33\end{array}$ & $\begin{array}{l}27(24.1) \\
59(35.5) \\
12(36.4)\end{array}$ & $\begin{array}{l}0.11 \\
0.02^{*}\end{array}$ \\
\hline Secretory component & $\begin{array}{l}\text { negative/focally } \\
\text { positive }\end{array}$ & $\begin{array}{r}245 \\
68\end{array}$ & $\begin{array}{l}86(35.1) \\
12(17.6)\end{array}$ & $\begin{array}{l}0.01 \\
0.00^{*}\end{array}$ \\
\hline Serotonin & $\begin{array}{l}\text { negative } \\
\text { positive }\end{array}$ & $\begin{array}{r}277 \\
24\end{array}$ & $\begin{array}{l}85(30.7) \\
10(41.6)\end{array}$ & $\begin{array}{l}0.12 \\
0.09^{*}\end{array}$ \\
\hline \multirow[t]{2}{*}{ Miucus } & $\begin{array}{l}\text { negative/combined } \\
\text { sialomucin } \\
\text { sulphomucin }\end{array}$ & $\begin{array}{r}233 \\
31 \\
36\end{array}$ & $\begin{array}{r}77(3.3 .9) \\
12(38.7) \\
6(16.7)\end{array}$ & $\begin{array}{l}0.04 \\
0.04\end{array}$ \\
\hline & $\begin{array}{l}\text { negative } \\
\text { focally } \\
\text { individual cells } \\
\text { positive }\end{array}$ & $\begin{array}{r}146 \\
67 \\
53 \\
38\end{array}$ & $\begin{array}{l}48(32.9) \\
23(34.3) \\
16(30.2) \\
8(22.9)\end{array}$ & $\begin{array}{l}0.46 \\
0.02^{*}\end{array}$ \\
\hline Flowcytometry & $\begin{array}{l}\text { DNA index }=1.0 \\
\text { DNA inde } x \geqslant 1.1<4 \\
\text { DNA index }=4.0\end{array}$ & $\begin{array}{r}89 \\
163 \\
27\end{array}$ & $\begin{array}{r}19(21.3) \\
55(33.7) \\
6(22.2)\end{array}$ & $\begin{array}{l}0.12 \\
0.00^{*}\end{array}$ \\
\hline
\end{tabular}

*) Log rank test including the missing values

were smaller than 0.05 (table 7.3). Some combinations of categories were not represented in the data and for this reason, it was not possible to investigate systematically interactions so that interaction terms are not included. The proportional hazards assumption was checked graphically for each parameter and appeared to be adequately fulfilled.

After the final set of prognostic variables (summarized in the tables 7.3 and 7.4 ) had been selected, the fit of the model may be examined, by plotting survival curves predicted by the model against those obtained for the same patients by the Kaplan-Meier method (figure 7.3). The first step is to calculate the value of the prognostic index $S=\beta_{1} x_{1}+\beta_{2} x_{2}+\ldots+\beta_{n} x_{p}$ for each patient in each treatment group.

These $S$ 's may then be arranged in ascending order and divided into three risk groups. The predicted survival curve for each risk group is the weighted mean of the individual survival curves in that group. Any systematic deviations of the Kaplan-Meier curves from those predicted by the model might suggest the inappropriateness of the 

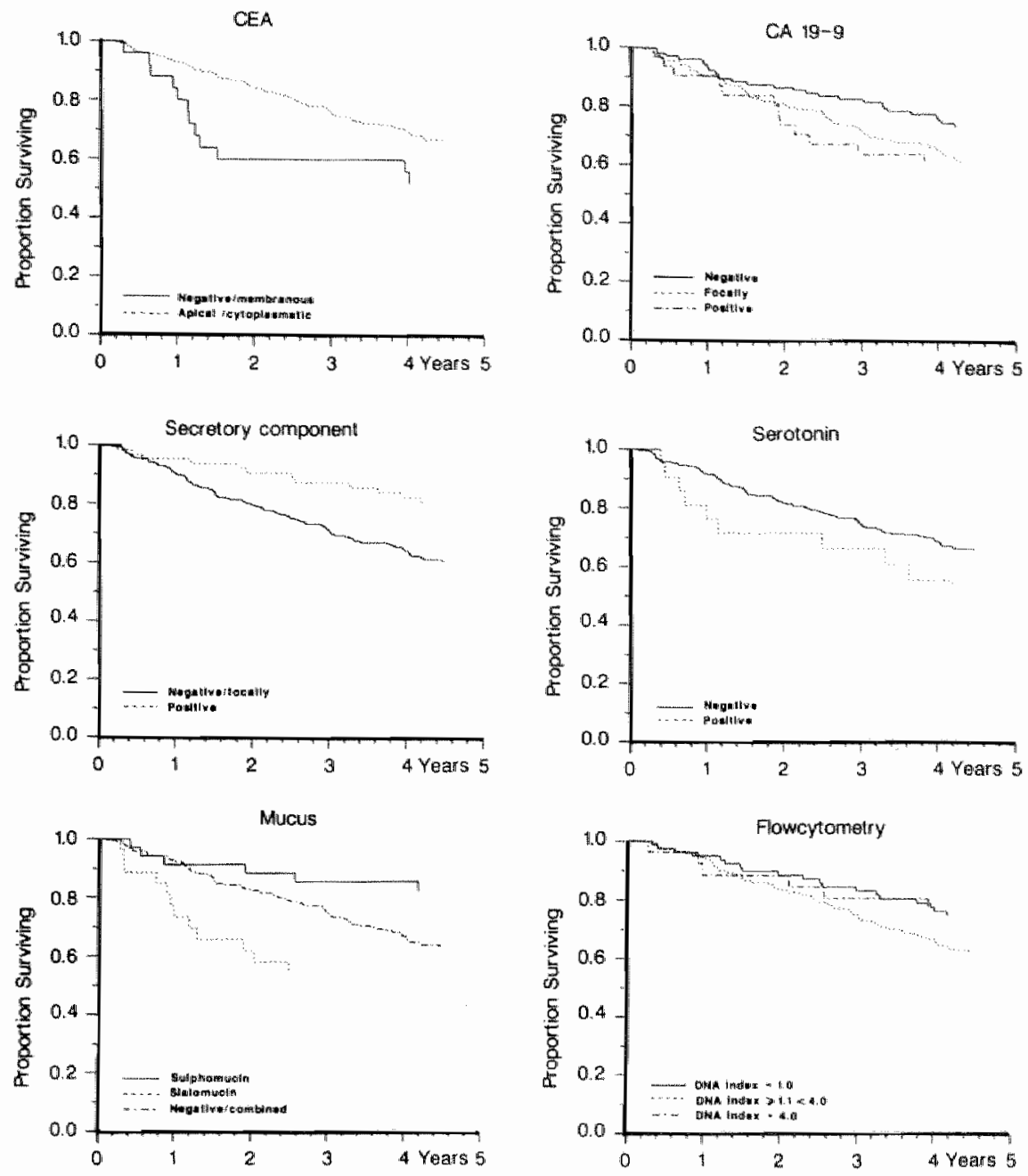

Figure 7.2: Survival curves for antigen expression and DNA.index. Postoperative deaths are excluded and unrelated deaths are censored at the time of death.

model to describe the data adequately and consequently reflect on the validity of the prognostic index.

The prognostic value of the model should ideally have been tested by drawing a random sample, of say $75 \%$, of the patients on which to fit the Cox regression model and then testing the fit, as described above, on the remaining $25 \%$ of the patients.

However the relatively small overall sample size, in combination, with the relatively large number of missing values on some variables made this procedure impracticable. 
Table 7.3: Proportional thazafds regression model based on 225 patients with complete data records

\begin{tabular}{|c|c|c|c|c|}
\hline Variable & Category & Coefficient & $\begin{array}{l}\text { Standard } \\
\text { error }\end{array}$ & $\begin{array}{l}\text { Hazard } \\
\text { ratio }\end{array}$ \\
\hline Stage & $\begin{array}{l}B \\
\mathrm{C} \\
\mathrm{C}\end{array}$ & $\begin{array}{l}0.92 \\
1.43 \\
2.96\end{array}$ & $\begin{array}{l}0.57 \\
0.56 \\
0.61\end{array}$ & $\begin{array}{r}2.52 \\
4.17 \\
19.29\end{array}$ \\
\hline Central node & involved & 1.28 & 0.36 & 3.59 \\
\hline $\begin{array}{l}\text { Size primary } \\
\text { tumor }(\mathrm{cm})\end{array}$ & $\begin{array}{l}3.5-6 \\
>6\end{array}$ & $\begin{array}{r}-0.41 \\
0.52\end{array}$ & $\begin{array}{l}0.28 \\
0.39\end{array}$ & $\begin{array}{l}0.66 \\
1.68\end{array}$ \\
\hline Shape of the tumor & $\begin{array}{l}\text { sessille } \\
\text { ulcerative }\end{array}$ & $\begin{array}{r}-0.62 \\
0.79\end{array}$ & $\begin{array}{l}0.73 \\
0.54\end{array}$ & $\begin{array}{l}0.54 \\
2.19\end{array}$ \\
\hline CEA & positive & -0.96 & 0.42 & 0.38 \\
\hline Serrotonin & positive & 0.71 & 0.42 & 2.03 \\
\hline Flowcytometry & $\begin{array}{l}\text { DNA index }>1.0 \\
\text { DNA index }=4.0\end{array}$ & $\begin{array}{r}0.56 \\
-0.43\end{array}$ & $\begin{array}{l}0.35 \\
0.57\end{array}$ & $\begin{array}{l}1.76 \\
0.65\end{array}$ \\
\hline
\end{tabular}

Table 7.4: Proportional hazards regression model based on all 350 patients including extra categories for missing values. The coefficients for the missing categories are not inclluded in the table.

\begin{tabular}{|c|c|c|c|c|}
\hline Variable & Category & Coetficient & $\begin{array}{l}\text { Standard } \\
\text { error }\end{array}$ & $\begin{array}{l}\text { Hazard } \\
\text { ratio }\end{array}$ \\
\hline Stage & $\begin{array}{l}B \\
C \\
D\end{array}$ & $\begin{array}{l}1.03 \\
1.81 \\
3.28\end{array}$ & $\begin{array}{l}0.46 \\
0.46 \\
0.49\end{array}$ & $\begin{array}{r}2.79 \\
6.08 \\
26.47\end{array}$ \\
\hline Central node & involved & 1.12 & 0.31 & 3.07 \\
\hline $\begin{array}{l}\text { Size primary } \\
\text { tumor }(\mathrm{cm})\end{array}$ & $\begin{array}{l}3.5 \cdot 6 \\
>6\end{array}$ & $\begin{array}{r}-0.48 \\
0.29\end{array}$ & $\begin{array}{l}0.24 \\
0.31\end{array}$ & $\begin{array}{l}0.62 \\
1.33\end{array}$ \\
\hline Shape of the tumor & $\begin{array}{l}\text { sessile } \\
\text { ulcerative }\end{array}$ & $\begin{array}{l}0.09 \\
0.81\end{array}$ & $\begin{array}{l}0.53 \\
0.41\end{array}$ & $\begin{array}{l}1.10 \\
2.24\end{array}$ \\
\hline Grade & $\begin{array}{l}\text { moderately } \\
\text { poorly }\end{array}$ & $\begin{array}{l}0.36 \\
1.15\end{array}$ & $\begin{array}{l}0.39 \\
0.47\end{array}$ & $\begin{array}{l}1.44 \\
3.14\end{array}$ \\
\hline Serotonin & positive & 0.96 & 0.35 & 2.62 \\
\hline Flowcytometry & $\begin{array}{l}\text { DNA index }>1.0 \\
\text { DNA index }=4.0\end{array}$ & $\begin{array}{r}0.37 \\
-0.27\end{array}$ & $\begin{array}{l}0.29 \\
0.51\end{array}$ & $\begin{array}{l}1.45 \\
0.75\end{array}$ \\
\hline
\end{tabular}




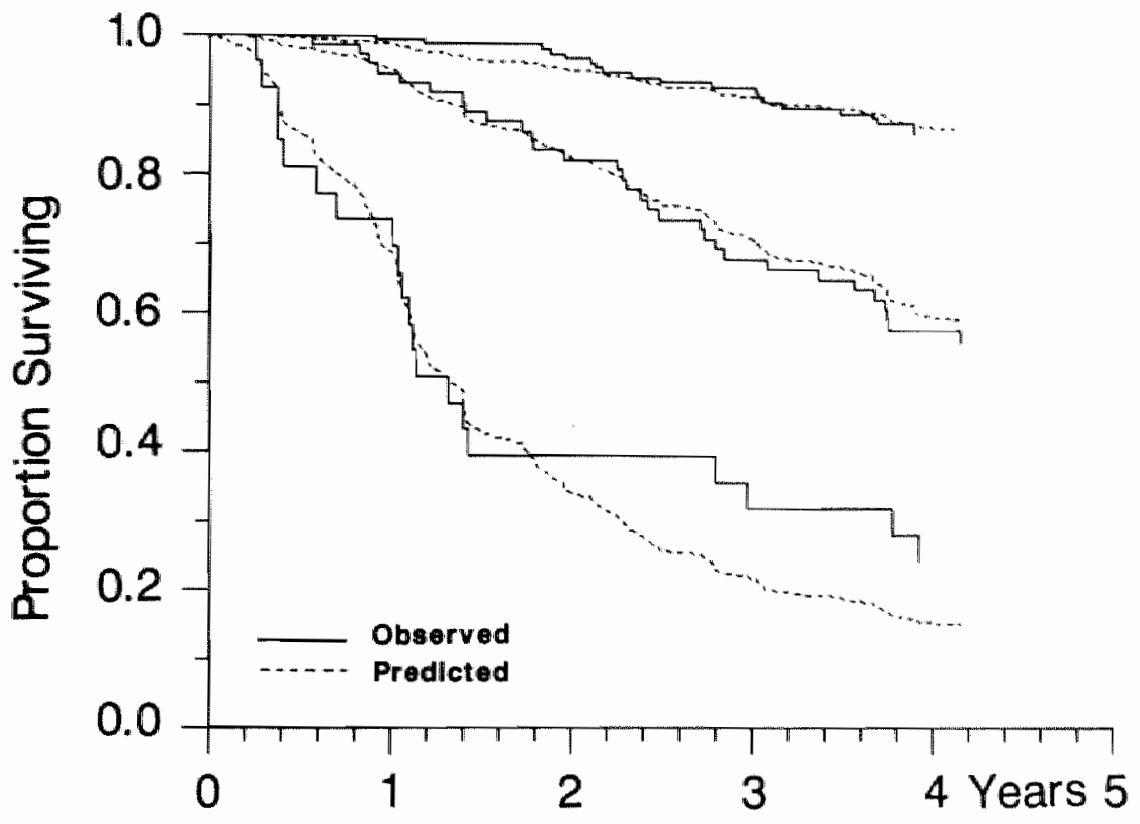

Figure 7.3: Survival curves predicted by the proportional hazards regression model and observed by the Kaplan-Meier method for three risk groups, defined by cutpoints 2.62 and 3.89 in the prognostic score distributions.

In summary, the best predictive model for determination of prognosis resulted in the contribution of the following parameters: stage. grade, central nodal involvement, size and shape of the primary tumor. expression patterns of CEA and serotonin and finally the flowcytometric analysis of the DNA index.

\subsection{Discussion}

To be of prognostic relevance a variable should be easily assessable with a limited inter- and intraobserver variability and allow the identification of a number of patient groups with a clearly distinct prognosis. Preferably, the variable should also be independent of other prognostic parameters.

Traditionally the stage of the tumor extension has emerged as a prognostic variable meeting most of these criteria. In this study, a multivariate analysis has been performed including traditionall parameters, as well as, the expression pattern of colon cancer associated antigens and the DNA index.

The value of this type of analysis depends largely on the com- 
pleteness of the data and the quality of the follow-up. Since this study was part of a prospective trial with a predefined follow-up schedule, survival data regarding disease and non-disease related death can be considered to be reliable. Central review of all pathologic specimens gave completeness of stage and grade data. However, estimation of the antigen expression and the determination of the DNA index had to be performed on blocks of paraffin-embedded material. There is a chance that not always representative samples were obtained moreover not from every patient sufficient material was available for all determinations. This resulted in analyses with and without missing data, as shown in tables 7.3 and 7.4 . The results of the two analyses are not in complete agreement. It is reassuring that the same prognostic variables were selected in both analyses, the only difference being the replacement of grading by the expression pattern of CEA when the cases with missing variables were included. The influence of a missing category might however, introduce a possible selection bias for any parameter.

Five traditional parameters were selected for inclusion in the prognostic index. In addition to staging, grading, central node involvement, size and shape of the primary tumor are correlated with survival.

Exophytic growth in comparison with ulcerative growth, has been found to correlate with better prognosis ${ }^{19}$ but its strong relationship with stage ${ }^{20}$ has limited the importance of this parameter. In our analysis ulcerative growth of the tumor correlated with a poorer survival.

The impression that the size of the primary tumor is an unimportant prognostic indicator has been reported previously, by others, analyzing multiple prognostic factors 2122.23 . No correlation was found between the diameter of the primary tumor and the presence of Iymph node metastases ${ }^{24.25}$. In our material a subset of large tumors (between 3.5 and $6.0 \mathrm{~cm}$ ) showed a better survival. This may be in accordance with the observation of an inverse relationship between tumor volume, and stage ${ }^{24}$ and survival ${ }^{26}$ respectively. It is however difficult to determine the relevance of this feature since, especially, the volume of colonic tumors is very difficult to measure and different cut off points are used in the literature. Spratt et al. ${ }^{21}$ have suggested, in this regard, that certain colorectal carcinomas may grow very large without metastasizing

The presence of central lymph node metastases is an important variable. Since sampling and determination of the most central node were performed by the local pathologist and surgeon, it is difficult to have good quality control and considerable differences in the total 
number of detected lymph nodes have been reported in multicenter studies 14 . The subclassification of the extent of lymph node metastases has caused a lot of confusion 27.28 .29 , but Phillips et al. ${ }^{30}$ found in a multivariate analysis, both the absolute number of involved lymph nodes (cut point four) and the involvement of the apical node independent prognostic variables.

Despite the substantial interobserver variety ${ }^{13}$ grading remained in the multivariate analyses, of several studies, consisting of a large number of cases, a prognostic factor independent from stage 23.30.31.32. Of seven grade related factors analysed in the material of St. Marks Hospital in London, only lymphocytic infiltration, tubular configuration and pattern of growth remained after a Cox regression analysis ${ }^{33}$. Introduction to the afore mentioned analysis of stage related factors, such as depth of tumor infiltration, node status and lymphocytic infiltration, left lymphocytic infiltration the only factor of interest. Our observation that poorly or undifferentiated carcinomas $110.5 \%$ of the total material) predicted a poor outcome was in agreement with the data of Philips et al. ${ }^{30}$. In order to compare data among series reliably, several blocks of the least differentiated areas ${ }^{13}$ should be studied, and characteristics to be scored, should be exactly defined ${ }^{33}$.

The unique role of staging has been reported in all other regression analyses 21.23 .30 .34 with the exception of one ${ }^{35}$. With the introduction in 1929 by Dukes ${ }^{36}$ it began as a pure pathological system, mainly based upon the extension of infiltrative growth into the bowel wall. The systematical report of lymph node involvement was introduced a few years later ${ }^{37}$. With the addition of a clinical stage defining irresectable or disseminated disease ${ }^{12}$, a quite uniformely accepted and well-balanced system became available. Further refinement, by subdivision of the depth of invasion 23 has caused a lot of confusion and did not provide supplementary information in a regression analysis ${ }^{30}$. Therefore, clinicopathological staging is still the best conventional prognostic parameter. A possible explanation for its significance may be the fact that tumor stage reflects the interaction between the host and the tumor. The other conventional prognostic indicators are mainly descriptors of the biology of individual tumor cells, although angio-invasive growth may also be determined by host factors $^{38}$. The two main drawbacks for the use of this last factor are its strong relation with staging and the problems in its reliable estimation.

With the availability of the study of patterns of antigen expression at cellular level, it was of interest to study the possibility of competition of these factors with the afore mentioned factors. For this analysis CEA and Ca 19-9, two colorectal cancer associated antigens were 
evaluated. Both are heterogenerously expressed in benign and neoplastic tissue. By univariate analysis $\mathrm{Ca}$ 19-9 immunoreactive tumors showed a tendency for poorer survivale. No additional information. in the multivariate analysis however was obtained with inclusion of this parameter.

For CEA the situation is somewhat more complex. Normall colonic luminal cells show CEA immunoreactivity of the apical brush border. Over $90 \%$ of the tumors shows extensive CEA expression, either diffusely cytoplasmic or apical membrane bound. Some tumors display the antigen only focally or membrane bound, but with loss of polarity. This last group of tumors showed significantly poorer survival when compared with the group of extensively CEA immunoreactivity?. In the regression model this group (constituting $10 \%$ of the total population) remained as a weak factor.

Secretory component (SC) is a product of the normal columnar cells. The different expression patterns of SC luniform, focal or negative) are correlated with the histological grade of colorectal tumors. Well differentiated tumors show more extensive secretory component expression compared with the poorly differentiated tumors. Homogeneous SC expression was related to better survival ${ }^{9}$ but this effect disappeared in the regression analysis.

We further tested the prognostic significance, of not only the distribution (defined as extra- or intracellular) of mucins but also the shift from sulpho- to sialomucin production. In rectal cancer, data regarding stage and prognosis in relation to mucin production are controversial 20 . Two authors found a poorer prognosis in tumors with extensive mucus production $>60 \%$ of the tumor volume $)^{39,40}$. In our series by univariate analysis not the extent of the mucin production. but its composition appeared to be relevant because a predominance of sialomucins was related to a poorer survival. However, in the Cox regression model this effect was no longer apparent.

We finally tested the prognostic significance of endocrine differentiation by immunostaining for serotonin. Serotonin immunoreactive cells were detected in $8 \%$ of the large bowel carcinomas ${ }^{10}$. In these cases, serotonin immunoreactive cells occurred, either as focal clusters or as occasional single cells. Neuroendocrine differentiation was associated with poorer survival and this effect was maintained in the regression analysis. The explanation of this last feature may be lack of relation with other factors, such as, stage, since the observation of this phenomenon is restricted to a few individual cells only.

So far the determination of antigen expression at cellular level has been of limited value with the exception of CEA and serotonin. 
Two factors are of importance, firstly, malignant tumors are heterogeneic and consist of different clones ${ }^{41}$. The expression patterns of the antigens presently studied always contain large numbers with mixed staining patterns classified as focal. Exclusion of focally staining tumors improves the discriminating properties for certain factors, but this exclusion is undesirable for factors, part of a staging system. Secondly, the antigens presently studied are either colorectal carcinoma associated or end products of the mature cell and ${ }_{n}$ in this regard strongly related to grade. In fact, the study of antigen expression making differences in biological behavior of morphological identical tumors is still in an initial phase. Normal colonic cells in varying stages of maturation, fetal colonic cells and cells from undifferentiated carcinomas may serve as immunogens for the production of new antibodies.

Another approach was the analysis of the DNA content of tumor cells in relation to prognosis. Earlier, Wolley et al. ${ }^{3}$ showed the DNA index to be of prognostic significance. In this study newly developed techniques allowing DNA analysis on tissues rescued from paraffin blocks 4.15 , were used. The DNA index (calculated as the ratio of aneuploid to diploid $\mathrm{G}_{1 / 0}$ peak channel) was divided into three groups. The group of patients with a DNA index $>1.0$ (aneuploid) was both in the univariate and multivariate analysis related to a poorer survival. This confirms the observation of others describing a correlation between aneuploidy and stage 42.43 $^{4}$ and survival42,44. A drawback of the flowcytometry is the classification of tumors showing more than one abnormal peak ${ }^{43}$ and heterogeneity regarding the spot of sampling in colon and rectal carcinomas has been described ${ }^{45,46}$. More refined information may be derived from cell kinetic analysis by $S$ phase fraction determination or bromodeoxyuridine incorporation.

In conclusion, our results indicate that, in multivariate analysis, tumor stage emerges as the most important prognostic factor in large bowel cancer. However, central node involvement, size and shape of the primary tumor may also be included in a prognostic index. although their effect on of survival will be limited because either the number of cases in the discriminating subgroup is small le.g. central node involvement) or, the hazard ratio is low (e.g. tumor size over six centimetre).

Our results also show that clinicopathological staging can be refined with introduction of new prognostic variables such as CEA expression. neuroendocrine differentiation and DNA analysis. Finally, we have shown that the value of every new pathological prognostic indicator needs to be confirmed in multivariate analysis. 


\subsection{References}

1. Lockhart-Mummery HE, Ritchie JK. Hawley PR. The results of surgical treatment for carcinoma of the rectum at St Mark's Hospital from 1948 to 1972 . Br $\mathbb{J}$ Surg $63: 673-677,1976$.

2. Broders AC. Carcinoma. Grading and practicall application. Arch Pathol Lab Med 2: $376-381,1926$.

3. Wolley RC. Schreiber K, Koss LG, Karas M. Sherman A. DNA distribution in human colon carcinomas and its relationship to climical behavior. J Natl Cancer Irist 69: $15 \cdot 22,1982$.

4. Armitage NC, Robins RA, Evans DF, Turner DR, Baldwin RW, Hardcastle JD. The influence of tumour cell DNA abnormalities on survival in colorectal cancer. Br J Surg 72: 828-830, 1985.

5. Arends JW. Bosman FT. Hilgers J. Tissue antigens in large bowel carcinoma. Blochim Biophys Acta 780: 1-19, 1985

6. Blihham G, Scthutte B, Reynders M. Wiggers Th, Arends J, Volovics L, Bosman F. Flowcytometric (FCM) determination of ploidy level and life cycle analysis on 279 paraffin embedded colorectal carcinoma specimens. In: Proceedings of ASCO 4. $22,1985$.

7. Wiggers T, Arends JW, Verstijnen C, Moerkerk PM. Bosman FT. Prognostic significance of CEA immunoreactivity patterns in large bowell carcinoma tissue Br.J Cancer 5.4: 409-414, 1986

8. Arends JW, Wiggers T, Verstijnen C. Hilgers J, Bosman FT. Gastrointestimal cancer-associated antigen (GICA) immunoreactivity in colorectal carcinoma in relation to patient survival. Int J Cancer 34: 193-196, 1984

9. Arends JW, Wiggers T, Thijs CT, Verstijnen C. Swaen GJV, Bosman FT. The value of secretory component (SC) immunoreactivity in diagnosis and prognosis of colorectal carcinomas. Am J Clin Pathol 82: 267-274, 1984.

10. Arends JW. Wiggers T, Verstijnen C, Bosman FT. The occurrence and clinicopathological significance of serotonim immunoreactive cells in large bowel carcinoma. J Pathol 149:97-102, 1986.

11. Arends JW. Unpublished observations.

12. Turnbull RB Jr, Kyle K, Watson FR, Spratt J. Cancer of the colon: the influence of the no-touch isolation technic on survival rates. Ann Surg 166:420-427, 1967

13. Blenkinsopp WK, Stewart-Brown S, Blesovsky L, Kearney G, Fielding LP. Histo pathology reporting in large bowel cancer. J Clin Pathol 34:509-513, 1981.

14. Koprowski H. Steplewski $Z$. Michell K. Colorectal carcinoma antigens detected by hybridoma antibodies. Som Cell Gen 5: $957-972.1979$

15. Schutte B, Reynders MMJ, Bosman FT, Bligham GH. Flow cytometric determination of DNA ploidy level in nuclei isolated from paraffin-embedded tissue. Cytometry 6: $26-30,1985$.

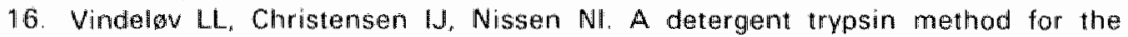
preparation of nuclei for flow cytometric DNA analysis. Cytometry 3: 323-327. 1983.

17. Cox DR, Oakes D. Analysis of survival data. Chapman and Hall, London, 1984

18. BMDP Statistical Software Dept. of Biomathematics, University of California. University of California Press, Berkeley, 1981.

19. Grinnell RS. The spread of carcinoma of the collon and rectum. Cancer $3: 641$ $652,1950$.

20. Colhen AM. Wood WC. Gunderson LL. Shinnar M. Pathological studies in rectal cancer. Cancer 45:2965-2968, 1980

21. Spratt JS. Spjut HJ. Prevalence and prognosis of individual clinical and pathologic variables associated with colorectal carcinoma. Cancer 20:1976-1985, 1967.

22. Chung CK, Zaino RJ, Stryker JA. Colorectal carcinoma: evaulation of histologic grade and factors influencing prognosis. J Surg Oncol 21: 143-148, 1982.

23. Chapuis PH, Dent OF, Fisher R, Newland FC. Pheils MT, Smyth E, Colquhoun 
K. A multivariate analysis of clinical and pathollogical variables in prognosis after resection of large bowel cancer. Br. J. Surg. 72: 698.702, 1985.

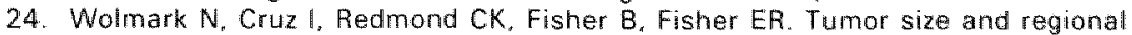
lymph node metastasis in colorectal cancer. Cancer 51:1315-1322, 1983.

25. Sugarbaker PH. Carcinoma of the colon-prognosis and operative choice. Current problems in surgery 18: 753-802. Year Book Medical Publishers, Chicago-London. 1981.

26. Osnes SV. Carcinoma of the colon and rectum. A study of 353 cases with special reference to prognosis. Acta Chir Scand 110:378-388, 1955.

27. Gabriel WB, Dukes: C. Bussey HJR. Lymphatic spread in cancer of the rectum. Br J Surg 23: 395-413, 1935 .

28. Astler VB, Coller FA. The prognostic significance of direct extension of carcinoma of the colon and rectum. Ann Surg 139:846.852 "1954.

29. Gastrointestinal tumor study group. Adjuvant therapy of colon cancer - results of a prospectively randomized trial. N Engl J Med 310:737-734, 1984

30. Phillips RKS, Hittinger R. Bliesowsky L. Fry JS, Fielding LP. Large bowel cancer: survival pathology and its relationship to survival. Br J Surg 71:604-610, 1984.

31. Newland RC, Chapuis PH, Pheils MT, MacPherson JG. The relationship of survival to staging and grading of colorectal carcinoma: a prospective study of 503 cases. Cancer 47: 1424-1429, 1981.

32. Freedman LS, Macaskill P. Smith AN. Multivariate analysis of prognostic factors for operable rectal cancer. Lancet ii: $733-736,1984$.

33. Jass JR, Atkin WS, Cuzick J. Bussey HJR, Morson BC, Northover JMA, Todd IP. The grading of rectal cancer: historical perspectives and a multivariate analysis of 447 cases. Histopathology $10: 437-459,1986$.

34. Wied U, Nillssion T, Knudlsen JB, Sprechler M, Johansen A, Postoperative survival of patients with potentially curablie cancerr of the colon. Dis Colon Rectum 28: $333-335,1985$.

35. Knudsen JB, Nilsson T, Sprechler M, Johansen $\AA$, Christensen $N$. Venous and nerve invasion as prognastic factors in postoperative survival of patients with resectabile cancer of the rectum. Dis Colon Rectum 26: 613-617, 1983.

36. Gordon-Watson C, Dukes $C$. The treatment of carcinoma of the rectum with radium with an introduction on the spread of cancer of the rectum. Br J Surg 17:643$669,1929 / 1930$

37. Dukes CE. The classification of cancer of the rectum. J Pathol Bacteriol 35: 323 $332,1932$.

38. Talbot IC, Ritchie S, Leighton M. Hughes AO, Bussey H.JR, Morson BC. Invasion of veins by carcinoma of rectum: method of detection, histological features and significance. Histopathology 5: 141-163, 1981.

39. Symonds DA, Vickery AL. Mucinous carcinoma of the colon and rectum. Cancer 37: $1891-1900,1976$.

40. Umpleby HC. Panson DL, Williamson RCN. Peculiarities of mucinous colorectal carcinoma. Br J Surg 72: 715-718, 1985.

41. Fidler $1 J$ Kripke ML. Metastasis results from preexisting variant cells within a malignamt tumor. Science 197: 893-895, 1977.

42. Ragnum TO. Thorud E. Elgjo K, Brandtzaeg P. Orjasaeter $H$, Nygaard K. Largebowel carcinomas with different ploidy, related to secretory component, IgA and CEA in epithelium and plasma. Br J Cancer 45: 921-934, 1982.

43. Tribukait B, Hammarberg C. Rubio C. Ploidy and proliferation patterns in colorectal adenocarcinomas related to Dukes iclassification and to histologicall differentiation. Acta Path Microbiol \|mmunol Scand Sect A 91: 89-95, 1983.

44. Kokal W. Sheibani Kk, Terz J, Harada JR. Tumor DNA content in the prognosis of colorectal carcinoma. JAMA 255:3123-3127, 1985

45. Petersen SE, Bichel P. Lorentzen M. Flow-cytometric diemonstration of tumour cell subpopulations with different DNA content in human colo-rectal carcinoma. Europ J Cancer 15: 383-386, 1978:

46. Hiddemann W, Von Bassewitz DB, Kleinemeier HJ. Schulte-Brochterbeck E. Hauss J. Lingemann B. Büchner T, Grundmann E. DNA stemline heterogeneity in colorectal cancier. Cancer 58: 258-263, 1985 



\section{Regression analysis of prognostic factors in colorectal cancer after 'curative' resections}

\subsection{Introduction}

Prognostic factors, derived from clinical, laboratory and pathological data of colorectal cancer patients are important for the determination of high risk groups for recurrent disease'. Not only, disease related death but also the first site of relapse is important for a proper choice between surgical, radiotherapeutical and chemotherapeutical modalities.

Many studies have been published about the prognostic value of parameters determined by univariate analyses but, with the availability of a stepwise regression model ${ }^{2}$ it has become possible to establish the contribution and relative importance of a certain parameter. Since no single factor, or marker, is capable of determining the possibility of growth of residual disease after 'curative' resections. a set of parameters included in a prognostic index may be used for this purpose.

It is the aim of this study to analyse the prospectively collected data of 310 patients of which the primary tumors of the colon or rectum could be curatively resected. For this purpose, preoperative symptoms, laboratory data, operation details, pathological findings and postoperative complications are included in a multivariate analysis.

\subsection{Material and methods}

\section{Patients.}

Between 1979 and 1981,310 patients with a histological diagnosis of adenocarcinoma of the colon and rectum were entered in the study. These patients underwent potential curative resections and were part of a prospective multicenter study ${ }^{3}$. Follow-up was standarized, with an average duration of 58 months (range 48-60 months). Survival 
data were avalable on all patients. For this amalysis death due to recurrent disease, excluding mortality within 30 days was used.

\section{History.}

At admission a standard form was used to record the first presenting symptoms (blood loss, change of bowel habits, abdominal discomfort, tumor found by chancel and bowell movements at the time of diagnosis (regular blood loss, change in frequency or quality, unchanged). The patients were allocated to four groups according to the duration of their symptoms: less than one week, one week - two months, twosix months, over six months. Age was classified into two groups: below or above 65 years.

\section{Laboratory.}

Hemoglobin, leucocyte count, erythrocyte sedimentation rate (ESR). blood group, gamma-glutamyl transpeptidase (GGTP), serum glutamic oxaloacetic transaminase (SGOT), serum glutamic pyruvic transaminase (SGPT), lactic dehydrogenase (LDH), serum protein and carcinoembryonic antigen (CEA) were routinely determined. Due to change and variety of methods in determination, alkaline phosphatase could not be included in the final analysis.

\section{Operation.}

During laparotomy, site of the primary tumor (right, transverse, left rectosigmoid, rectum), extent of resection, clinical impression of Iymph node metastases, fixity to adjacent organs, complications fover 1 litre of blood loss, tumor spill) were recorded.

\section{Treatment.}

Patients with colon tumors were entered into a randomized trial in which one group was operated on with the no-touch isolation technique of Turnbull ${ }^{4}$ and the second group via a conventional resection technique. Design and details of the trial have been described in chapter 5.2. The patients, which could not be included in the trial for different reasons (emergency operation, age, double tumors). were classified as other patient factors. Low lying tumors for which preoperative radiotherapy was considered were classified as distal.

\section{Pathology}

Paraffin-embedded specimens of all resected tumors were reviewed centrally by one pathologist. Size and shape of the primary tumor. distance of free margins, lymph node involvement, Dukes" classi- 
fication ${ }^{4}$ and grade ${ }^{5}$ were recorded. Details of the criteria employed for the pathological investigations have been described in chapter 7.2 .

\section{Postoperative}

The postoperative course was classified either, as uneventful or, as complicated by an infection, directly related to the operative procedure.

\section{Statistical analysis}

Log-rank and Cox regression ${ }^{2}$ analyses of the parameters included were performed using the computer program BMDP2 $L^{6}$. As for most parameters included a substantial number of missing values were present, two analyses were performed: one analysis using the patients with complete data only and a second analysis including a separate category 'missing' for each parameter with missing values. No statistically significant differences were noted between the outcome of the parameters, when dichotomized as 'present' versus 'missing".

A prognostic score (S) for an individual patient (i) can be written as: $S_{i}=\beta_{1} x_{i 1}+\beta_{2} \times_{i 2}+\ldots+\beta_{p} x_{i p}$. Bèta $(1-p)$ is the regression coefficient of the observed value of that particular variable $\left(x_{1}\right) \ldots$ $\left.x_{i p}\right)$. A prognostic variable with two or more categories of outcome is represented by a number of values equal to the number of its categories minus one. The category not included as a value is the reference category.

\subsection{Results}

The outcome of the parameters included in the regression model is summarized in table 8.1. Some corresponding survival curves are plotted in figure 8.1 and 8.2 .

Patients with blood loss as a first presenting symptom had a tendency of a better disease free survival in the univariate analysis in comparison with patients with other symptoms initially $(p=0.12)$. The quality of the bowel movements at the moment of admission was of no significance $(p=0.27)$. Very short (less then one week), or long (over six months) duration of symptoms were associated with a poorer survival in relation to the patients with symptoms ranging from one week to six months, whereas intermediate duration of symptoms was correlated with a longer survival. However, this was not significant $(p=0.68$ ). Obstruction, resulting in a diverting colostomy as a first operation, was of no significance. Location of the primary tumor was not important for disease related survival $(p=0.49)$. 
Table 8.1: Summary of the variables entered in the regression model

Variable

Caltegories

Number of

Number of

P-value of obserwations

disease related Logrank test death $(\%)$

\section{First presenting symptom}

Bowel movements
at admission
Duration of
Symptoms
Diverting collostomy
prior to resection
Location
Palpable lymph nodes
during laparotomy
Fixity to adjacent
orgains
Complications during
surgery

Surgeons opimion

Angio-invasive growth

Stage (Dukes)

Grade

Postoperative complications

Traatment

Sex

Age (years)
Blood loss

Change in bowel thabits

Abdominal pair

Other

Blood loss

Changed

Unchanged

$<1$ week

1 week - 2 months

$2-6$ months

$>6$ months

No

Yes

Right

Transverse

Left.

Rectosigmoid

Rectum

Cllose to bowel wall

Proximal/distal nodes

No nodes palpable

No

Yes

No

Blood loss > 1 litre

Spill (tumor)

Curative resection

Palliative resection

Absent

Present

A

B

C

Well differentiated

Moderately differentiated

Poorly or undifferentiated

Nome

Infectious

No-touch isolation colon

Conventional colon

Other ocation (distal)

Other patient fartors

Male

Female

$\leqslant 65$

$>65$
108

80

72

50

63

149

98

28

93

102

80

255

20

64

34

98

66

48

43

53

205

249

59

252

29

25

260

44

226

77

78

133

99

33

235

32

244

63

117

119

38

36

149

161

132

178
$21(19.4)$

0.12

23 (28.8)

$26(36.1)$

$16(32.0)$

$12(19.0)$

$44(29.5)$

$30(30.6)$

\subsection{7}

$10(35.7)$

$24(25.8)$

0.68

$26(25.5)$

$24(30.0)$

$0.61 \%$

$65(25.5)$

9 (45.0)

0.07

$0.09^{k}$

$18(28.1)$

$14(41.2)$

$24(24.5)$

$16(24.2)$

$15(313)$

0.49

$15(34.9)$

$16(30.2)$

$53(25.9)$

0.16

$0.19^{*}$

$66(26.5)$

0.05

$20(33.9)$

$0.00^{\circ}$

64 (25.4)

0.05

$11(37.9)$

$11(44.0)$

$0.11 *$

$68(26.2)$

$16(36.4)$

0.02

$0.02^{*}$

52 (23.0)

$32(41.6)$

0.00

$0.00^{*}$

$7(9.0)$

$35(26.3)$

$45 \cdot(45.5)$

$6(118.2)$

$61(26.0)$

$\| 6$ (50.0)

0.00

$66(27,0)$

$20(31.7)$

$28(23.9)$

$35(29.4)$

$11(28.9)$

$13(36.1)$

$42(28.2)$

$45(28.0)$

$40(30.3)$

$47(26.4)$
0.11

$0.20^{*}$

0.17

0.00

$0.00 \%$

0.84

0.89 

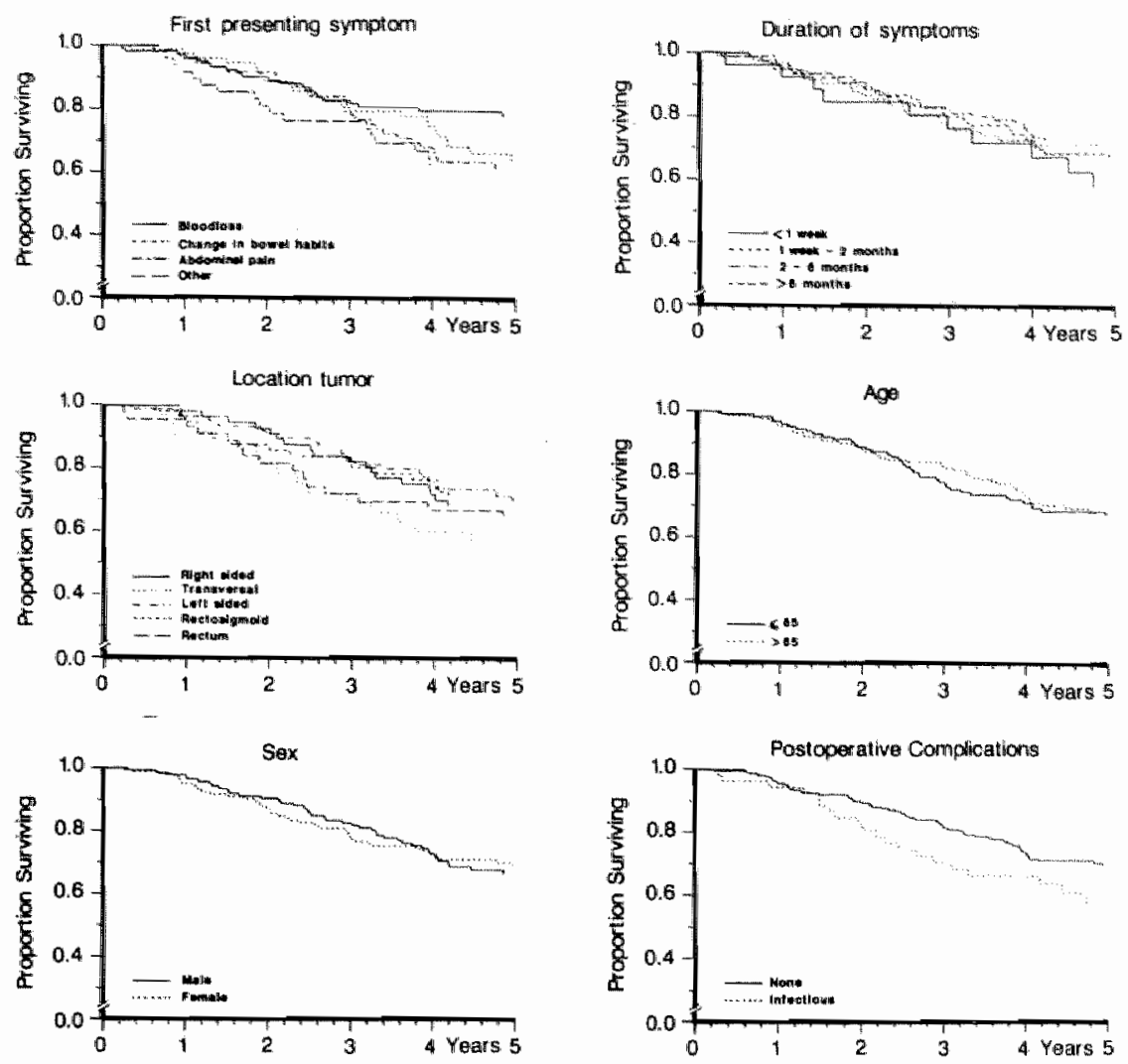

Figure 8.1: Disease related survival by patient characteristics

Presence of palpable lymph nodes close to the bowel wall had a tendency of a shorter survival in comparison with the abscence of palpable nodes $(p=0.16)$. A significantly diminished survival was present if fixity to adjacent organs was recorded $(p=0.05)$. Tumor spill resulted in a less favourable outcome if compared with operations without complications $(p=0.05)$. The opinion of the surgeon after operation was important in the prediction of the final prognosis of the patient $(p=0.02$ ). All the histopathological data included in the univariate analyses were of significant importance in prediction of poorer survival: presence of angio-invasive growth, advance in stage and loss of differentiation.

After correction of non-disease related death, postoperative complications were not influencing the chance of dying as a result of recurrent tumor. Application of the no-touch isolation technique was 

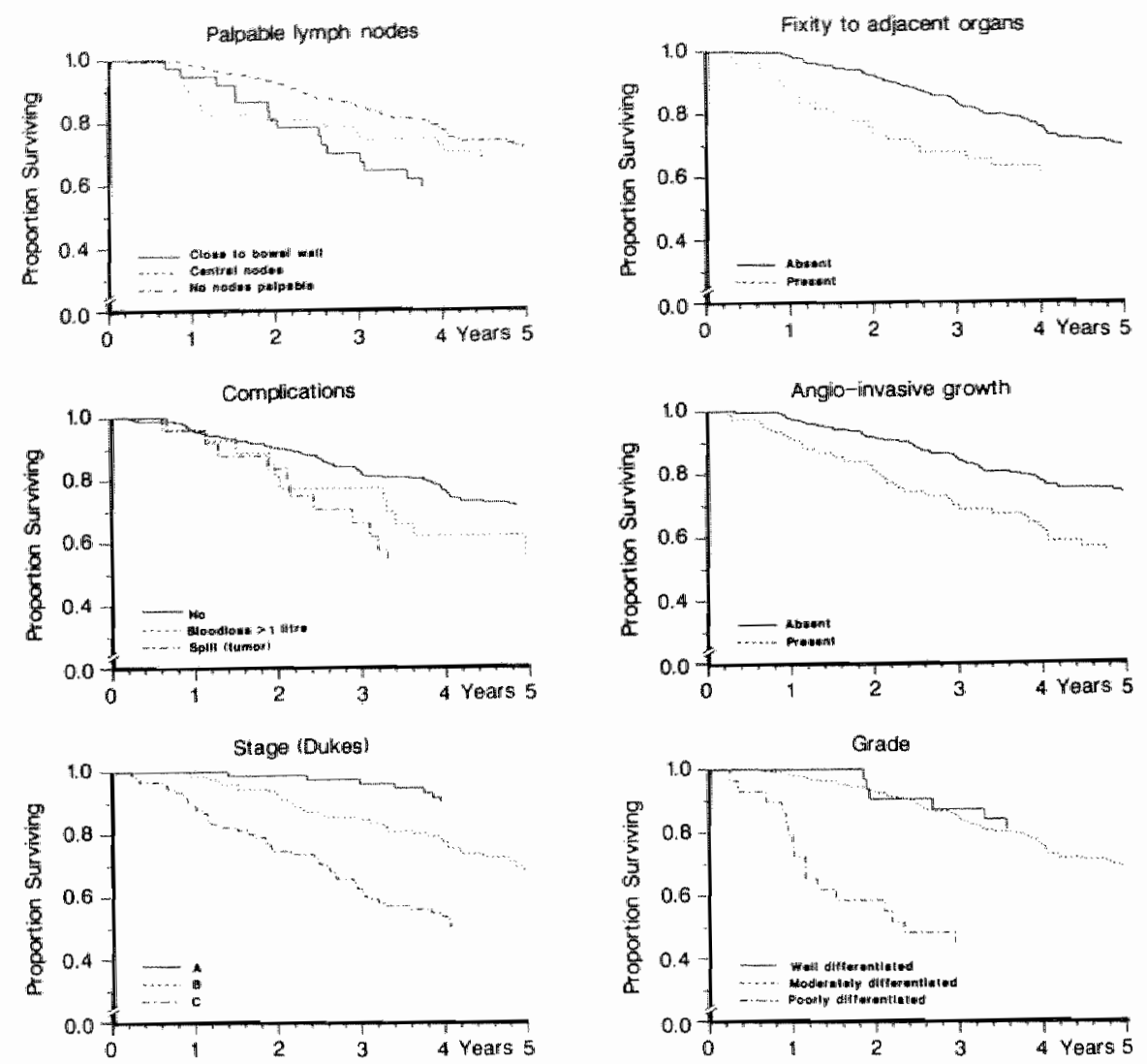

Figure 8.2: Disease related survival by some operative findings and pathological features

slightly better than the use of the conventional technique $(p=0.17)$. The other two categories cannot be considered in this regard.

Both age $(p=0.89)$ and sex $(p=0.84)$ were not associated with a difference in survival.

The laboratory data are summarized in table 8.2 and some are shown in figure 8.3. Only a low protein level $(p=0.02)$ and a high CEA level $(p=0.005)$ were related to a diminished chance of longer survival, whereas all the other hematological and liver function data were of no interest in the univariate analyses.

\section{Multiple regression analysis.}

The parameters derived from the multivariate analysis are listed in table 8.3. Backward elimination, using Wald and likelihood-ratio 
Table 8.2: Summary of laboratory data entered in the regression model

\begin{tabular}{|c|c|c|c|c|}
\hline Variable & Cut point & $\begin{array}{l}\text { Number of } \\
\text { observations }\end{array}$ & $\begin{array}{l}\text { Number of } \\
\text { disease related } \\
\text { death }(\%)\end{array}$ & $\begin{array}{l}\text { P-value of } \\
\text { Logrank test }\end{array}$ \\
\hline $\begin{array}{l}\text { Hemoglobin } \\
\text { (mmol/L) }\end{array}$ & $\begin{array}{l}d \leqslant 9, q \leqslant 8 \\
d>9,9>8\end{array}$ & $\begin{array}{l}166 \\
141\end{array}$ & $\begin{array}{l}42(25.3) \\
44(31.2)\end{array}$ & $\begin{array}{l}0.36 \\
0.63^{*}\end{array}$ \\
\hline $\begin{array}{l}\text { Leucocytes } \\
\left(10^{9} / \mathrm{L}\right)\end{array}$ & $\begin{array}{l}\leqslant 7.5 \\
>7.5\end{array}$ & $\begin{array}{l}147 \\
147\end{array}$ & $\begin{array}{l}38(25.9) \\
47(31.9)\end{array}$ & $\begin{array}{l}0.11 \\
0.12 *\end{array}$ \\
\hline $\begin{array}{l}\text { ESR } \\
(\mathrm{mm} / 1 \mathrm{hr})\end{array}$ & $\begin{array}{l}\leqslant 10 \\
>10\end{array}$ & $\begin{array}{r}73 \\
225\end{array}$ & $\begin{array}{l}23(31.5) \\
60(26.7)\end{array}$ & $\begin{array}{l}0.66 \\
0.62\end{array}$ \\
\hline Blood group & $\begin{array}{l}A \\
B \\
O\end{array}($ incl. $A B)$ & $\begin{array}{r}117 \\
34 \\
124\end{array}$ & $\begin{array}{l}32(27.4) \\
11(32.6) \\
37(29.8)\end{array}$ & $\begin{array}{l}0.95 \\
0.78 *\end{array}$ \\
\hline $\begin{array}{l}\text { GGTP } \\
(U / L)\end{array}$ & $\begin{array}{l}\leqslant 20 \\
>20\end{array}$ & $\begin{array}{l}190 \\
103\end{array}$ & $\begin{array}{l}50(26.3) \\
30(29.1)\end{array}$ & $\begin{array}{l}0.59 \\
0.35\end{array}$ \\
\hline $\begin{array}{l}\text { SGOT } \\
(U / L)\end{array}$ & $\begin{array}{l}\leqslant 20 \\
>20\end{array}$ & $\begin{array}{r}214 \\
79\end{array}$ & $\begin{array}{l}59(27.6) \\
22(27.8)\end{array}$ & $\begin{array}{l}0.78 \\
0.72\end{array}$ \\
\hline $\begin{array}{l}\text { SGPT } \\
(U / L)\end{array}$ & $\begin{array}{l}\leqslant 20 \\
>20\end{array}$ & $\begin{array}{r}239 \\
52\end{array}$ & $\begin{array}{l}66(27.6) \\
13(25.0)\end{array}$ & $\begin{array}{l}0.62 \\
0.32^{*}\end{array}$ \\
\hline $\begin{array}{l}\mathrm{LDH} \\
(\mathrm{U} / \mathrm{L})\end{array}$ & $\begin{array}{l}\leqslant 300 \\
>300\end{array}$ & $\begin{array}{l}103 \\
169\end{array}$ & $\begin{array}{l}31(30.1) \\
42(24.9)\end{array}$ & $\begin{array}{l}0.34 \\
0.28\end{array}$ \\
\hline $\begin{array}{l}\text { Protein (total) } \\
(\mathrm{Gm} / \mathrm{L})\end{array}$ & $\begin{array}{l}\leqslant 65 \\
>65\end{array}$ & $\begin{array}{r}85 \\
199\end{array}$ & $\begin{array}{l}31(36.5) \\
49(24.6)\end{array}$ & $\begin{array}{l}0.02 \\
0.07^{*}\end{array}$ \\
\hline $\begin{array}{l}\text { CEA } \\
(\mathrm{ng} / \mathrm{ml})\end{array}$ & $\begin{array}{l}\leqslant 5 \\
>5\end{array}$ & $\begin{array}{r}137 \\
83\end{array}$ & $\begin{array}{l}31(22.6) \\
26(31.3)\end{array}$ & $\begin{array}{l}0.05 \\
0.04^{*}\end{array}$ \\
\hline
\end{tabular}

* Log rank test including the missing values
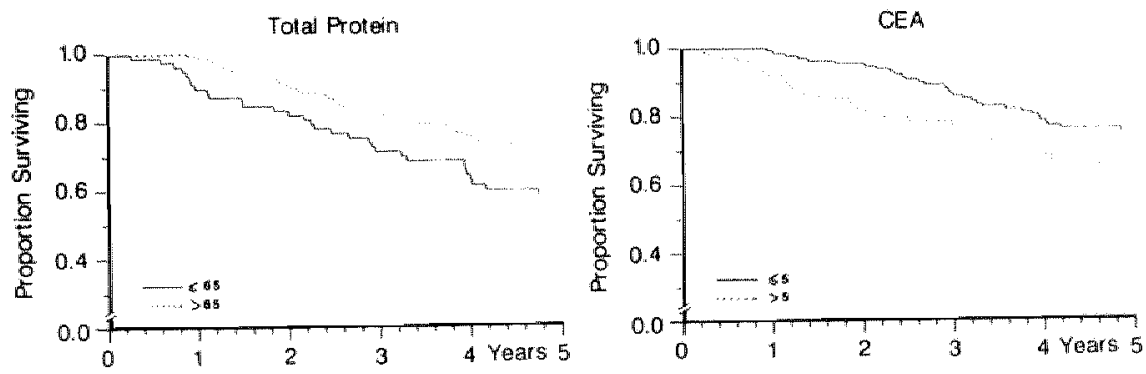

Figure 8.3: Disease related survivall by some laboratory data 
Table 8.3: Proportional hazards regression model based on the patients with complete data records

\begin{tabular}{|c|c|c|c|c|}
\hline Variable & Category & Coefficient & $\begin{array}{l}\text { Sitandard } \\
\text { errar }\end{array}$ & $\begin{array}{l}\text { Hazard } \\
\text { ratio }\end{array}$ \\
\hline $\begin{array}{l}\text { First presenting } \\
\text { symptom }\end{array}$ & $\begin{array}{l}\text { Change in bawel habits } \\
\text { Abdominal pain } \\
\text { Other }\end{array}$ & $\begin{array}{r}0.73 \\
1.16 \\
-0.20\end{array}$ & $\begin{array}{l}0.49 \\
0.55 \\
0.62\end{array}$ & $\begin{array}{l}2.07 \\
3.18 \\
0.82\end{array}$ \\
\hline Duration of symptoms & $\begin{array}{l}1 \text { week - } 2 \text { monilhs } \\
2-6 \text { months } \\
>6 \text { months }\end{array}$ & $\begin{array}{l}0.30 \\
0.89 \\
1.49\end{array}$ & $\begin{array}{l}0.69 \\
0.64 \\
0.67\end{array}$ & $\begin{array}{l}1.35 \\
2.44 \\
4.42\end{array}$ \\
\hline $\begin{array}{l}\text { Palpable lymph nodes } \\
\text { during laparotomy }\end{array}$ & $\begin{array}{l}\text { Proximal/distal nodes } \\
\text { No palpable nodes }\end{array}$ & $\begin{array}{l}-1.84 \\
-0.41\end{array}$ & $\begin{array}{l}0.66 \\
0.52\end{array}$ & $\begin{array}{l}0.16 \\
0.67\end{array}$ \\
\hline $\begin{array}{l}\text { Fixity to adjacent } \\
\text { organs }\end{array}$ & Yes & 1.18 & 2.71 & 326 \\
\hline $\begin{array}{l}\text { Complications during } \\
\text { surgery }\end{array}$ & $\begin{array}{l}\text { Bllood loss }>1 \text { litre } \\
\text { Spill }\end{array}$ & $\begin{array}{r}.0 .57 \\
1.64\end{array}$ & $\begin{array}{l}0.81 \\
3.46\end{array}$ & $\begin{array}{l}0.57 \\
5.15\end{array}$ \\
\hline Stage & B & $\begin{array}{l}1.24 \\
2.83\end{array}$ & $\begin{array}{l}0.66 \\
0.68\end{array}$ & $\begin{array}{r}3.46 \\
16.86\end{array}$ \\
\hline Grade & $\begin{array}{l}\text { Moderately differentiated } \\
\text { Poorly differentiated }\end{array}$ & $\begin{array}{l}1.99 \\
2.59\end{array}$ & $\begin{array}{l}0.71 \\
0.84\end{array}$ & $\begin{array}{r}7.29 \\
13.40\end{array}$ \\
\hline Treatment & $\begin{array}{l}\text { Conventional colon } \\
\text { Other location distal } \\
\text { Other patient factors }\end{array}$ & $\begin{array}{l}0.58 \\
1.09 \\
1.86\end{array}$ & $\begin{array}{l}0.41 \\
0.62 \\
0.64\end{array}$ & $\begin{array}{l}1.78 \\
2.97 \\
6.45\end{array}$ \\
\hline Leucocyte count & $>7,5.109 / \mathrm{L}$ & 0.73 & 0.40 & 2.08 \\
\hline Total protein & $>65 \mathrm{Gm} / \mathrm{L}$ & -1.17 & 0.38 & 0.31 \\
\hline CEA & $>5 \mathrm{ng} / \mathrm{ml}$ & 0.69 & 1.83 & 1.99 \\
\hline
\end{tabular}

test, resulted in parsimonious models including a limited number of variables. The model, providing the best prediction for the determination of prognosis included the following parameters: first presenting and duration of symptoms, palpation of lymph nodes during laparotomy, fixity to adjacent organs, complications during surgery, stage, grade, type of treatment, leucocyte count, total protein and preoperative CEA level.

\subsection{Discussion}

The aim of this study was to select parameters of interest in the determination of the risk of dying due to recurrent disease, after curative resections. In most series patients with distant metastases or local residual disease at first admission are included in the analysis. Since these cases have a poor prognosis, irrespectively of other factors, they were left out of this analysis. 
The significance of a relatively good prognosis for patients with rectal bleeding as a presenting symptom has been reported, quite uniformly, in univariate studies by other authors 7,89.10. After correction, for stage and localization this effect disappears 8.9 or becomes less important ${ }^{10}$. In our analysis altered bowel habbits and abdominal pains were associated with poorer survival. These features are most likely related to an increased intraluminal pressure and may be (partly) classified in other series as obstructive carcinomas with a known poor prognosis ${ }^{9,10,11}$.

Symptom duration and survival have been the subject of many studies. In most reports short duration of symptoms is associated with a poorer 12.13 .14 or equal survival ${ }^{15.10}$ in comparison with long lasting symptoms. After correction for stage this effect sometimes disappears ${ }^{9}$. Since many patients with Dukes" D stage have short duration of symptoms ${ }^{14}$, this may explain the inverse relation in those series and why, in this study short duration of symptoms, determined by a multivariate analysis, is associated with a better survival. It seems that for patients with the possibility of curative resections, prevention of delay in diagnosis and appropriate action on early symptoms, such as bleeding, are worthwhile. The favorable prognosis of asymptomatic patients supports this assumption.

Age and sex were of no prognostic significance for death due to recurrent disease. In the multivariate analysis of Chapuis ${ }^{9}$, young patients and females had a good prognosis. However, survival data in most studies ${ }^{9,17}$ were for death from any cause. It is, however, important to realize that both age and sex are influenced by death from other causes.

The standard liver function tests (GGTP, SGOT, SGPT, LDH) were not able to predict the presence of occult livermetastases in peroperative palpatory normal livers. The same observation was reported for alkaline phosphatase: in patients, with preoperatively, elevated levels and normal livers at laparotomy, no greater risk was observed of developing metastases during follow-up in comparison with patients with normal preoperative levels ${ }^{18}$. Levels of hemoglobin and ESR were of no significance and the negative effect of leucocytosis observed in this analysis is not easily explained.

An interesting finding was the negative effect on disease related survival of low preoperative protein levels since postoperative mortality was excluded from the analysis. The same effect has been reported previously by Spratt et al.1. Further investigations are necessary to find out if this parameter is a non-specific indicator for a depressed immune status of the patient and, in this regard, related to the risk of recurrence. 
The significant relation between preoperatively elevated CEA levels and survival was in accordance with other series 19.20 .21 . Although strongly interrelated with stage, this effect was maintained in the regression model. The present limitations of this test are mainly due to the impossibility of distinguishing between production in the primary tumor and undetectable micrometastases. In fact, postoperatively determined levels should be better in this regard because the primary tumor, as source of production, is eliminated.

Although generally, rectal and cecal tumors are known for their higher chance of local recurrence ${ }^{22}$ and poorer prognosis, this effect disappeared in our and other multivariate analyses 7.9 .19 . Adjustment for stage and the limited effect on survival of local recurrence must be responsible for this observation.

No definite answer concerning the importance of obstruction can be drawn from our data, since this feature was only indirectly recorded as diverting colostomy preceeding a resection. Several institutions performed two stage procedures, with primary resection, instead of three stage procedures under these circumstances. All regression analyses are, however, clear about the fact that if this finding is present this is a grave prognostic sign 79.10 .

Palpation of lymph nodes with suspicion for metastatic disease during an operation was included in the analysis. Lack of agreement with the final pathology report and an unexplained good prognosis for patients with palpable nodes, both central and close to the bowel wall made this observation of no value. Biopsy of suspected lymph nodes is the only way to confirm metastatic disease.

In fixed tumors the high risk of a local recurrence, as a first site of relapse in combination with a poor survival, has been reported in univariate 1.23 .24 .25 and multivariate analyses ${ }^{9}$. Microscopical invasion of adjacent organs, not detected by histopathology examination. must be responsible for this feature since cases with known residual disease were excluded from the study.

Spill of tumor during the operation, either from the extra- or intraluminal site, had, independent of stage or fixity, a deteriorous effect on survival and this is in agreement with other studies 23.26 .27 . Increased intraluminal pressure but especially, exfoliation of tumor cells may be responsible for this effect.

The paramount importance of clinicopathological staging, with the most distinguishing hazard ratio's in this analysis, has also been reported in other regression models ${ }^{9.28 .29}$ "Grade was shown to have a significant effect on survival, whereas angio-invasive growth was not independent and related to stage. An extensive analysis of pathology data is presented in chapter 7 and since no essential 
improvement could be derived from other factors, these were not further studied.

We finally included postoperative infectious complications since in one study postoperative fever was the most unfavourable prognostic factor $^{30}$. Although in our material crude survival was worse for patients with infections, this is most likely a result of death due to other causes since exclusion of the last category obscured the significance of this factor.

The procedure of surgical treatment (no-touch isolation or conventional) for colon tumors had to be incorporated as a variable since most patients were randomized and part of a multicenter study comparing both techniques ${ }^{3}$. The remaining categories, out of trial patient factors and out of trial location factors had a diminished survival which is not surprising and a result of patient selection. It was reassuring that the relative better prognosis of the no-touch technique was maintained in the multivariate analysis.

The regression analysis resulted in a model including the following variables: surgical procedure, first presenting symptom, duration of symptoms, protein level, CEA, fixity at operation, peroperative complications, stage and grade. These factors can be included in a prognostic index, with hazard ratios derived from table 8.3 , on base of which an accurate prediction of the individual prognosis can be given. The clinicopathological stage is still the major determinant for prognosis and represents in the best way the balance between tumor and host. Close collaboration between pathologist and surgeon can even increase the value of this factor. New pathological features, such as, the expression patterns of tumor associated antigens and estimation of the DNA index have already contributed to refinement of stage related factors but further investigations are necessary before they can be incorporated into the index (Chapter 7.3).

It is attractive to try to modulate some factors from the index in the hope of improving prognosis. Further investigations are necessary to determine if; appropriate action on rectal bleeding. prevention of delay in diagnosis, improvement of nutritional status and aggressive local therapy (with application of measurements to prevent spill to liver or abdominal cavity) will improve survival substantially.

It is remarkable that regression analyses from other countries (Australia ${ }^{9}$, USA $^{10}$, UK $^{11}$ ) reveal, depending on the factors included, the same prognostic variables. Standarization of pathological examinations and uniform recording of history and operation details could result in a widely accepted prognostic index. This would enable the comparison of the results of different centers and allow multicenter studies of adjuvant therapy for high risk groups. 


\subsection{References}

1. Spratt JS, Spjut HJ. Prevalence and prognosis of individual clinical and pathological wariables associated with colorectal carcinoma. Cancer 20, 1976-1985, 1967.

2. Cox DR, Oakes D. Analysis of survival datal. Chapman and Hall, Londom, 1984.

3. Wiggers $T$, Jeekel $J$. Arends JW. Brinkhorst AP, Kluck HM. Luyk Cl, Munting JDK, Povel AJ, Rutten APN, Greep JM. The no-touch isolation technique in colon cancer: a prospective controlled multicentre trial. Br Jl Surg 72 suppl: $S 135$. 1985

4. Turnbull PB Jr, Kyle K, Watson FR, Spratt J. Cancer of the colon: the influence of the no-rouch isolation technic on survival rates. Ann Surg 166:420-427, 1967.

5. Blenkinsopp WK, Stewart-Brown $S$, Blesovsiky $L$, Kearney $G$. Fielding LP. Histopathology reporting in large bowel cancer. J Clin Pathol 34: 509-513, 1981

6. BMDP Statistical software. Dept of Biomathematics, University of California. University of California Press, Berkeley 1981

7. Mzabi R, Himal HS, Demers R, MacLean LD. A multiparametric computer analysis of carcinoma of the colon. Surg Gynecol Obstet 143: 959-964, 1976.

8. Kim U, Papatestas AE, Augses AH. Factors influencing survival of colorectal cancer. Mt Sinai J Med 45: 210-214, 1978.

9. Chapuis $P H$, Dent OF, Fisher $R$, Newland RC, Pheils MT, Smyth E, Colguhonn K. A multivariate analysis of clinical and patholagical variables in prognosis after resection of large bowel cancer. Br J Surg 72:698-702, 1985.

10. Steinberg SM, Barkin JS, Kaplan RS, Stablein DM. Prognostic indicators of colon tumors. The Gastrointestinal Study Group Experience. Cancer 57: 1866-1870, 1986.

11. Phillips RKS, Hittinger R, Fry JS, Fielding LP. Mialignant large bowel obstruction. Br.J Surg 72: 296-302, 1985

12. McDermott FT, Hughes ESR. Pihl E. Milne BJ. Price AB. Prongosis in relation to symptom duration in colon cancer. Br J Surg 68: 846-849, 1981.

13. Pescatori M. Maria G. Beltrani G. Mattana C. Site, emergency and duration of symptoms in the prognosis of colorectal cancer. Dis Colon Rectum $25,33-40$, 1982

14. Stubbs RS, Long MG. Symptom duration and pathologic staging of colorectal cancer. Eur J Surg Onc 12:127-130, 1986

15. Pollissar L. Sim D. Phil M. Francis A. Survival of colorectal cancer patients in relation to duration of symptoms and other pragnostic factors. Dis Colon Rectum 24: $364-369,1981$

16. Khubchandani $M$. Relationship of symptom duration and survival in patients with carcinoma of the colon and rectum. Dis Colon Rectum 28: 585-587. 1985

17. Wied U, Nilsson T, Kmudsen JB, Sprechler M, Jahansen AA. Postoperative survival of patients witly potentially curable cancer of the colon. Dis Colon Rectum 28 . $333-335,1985$

18. Tartter PH, Slater G. Papatestas AE. Aufses AH. The prognostic significance of elevated serum alkaline phosphatase levels preoperatively in patients with carcinoma of the collon and rectum. Surg Gynecol Obstet 158: 569-571, 1984.

19. Wanebo HJ, Rao B. Pinsky CM, Hoffman RG, Stearns M, Schwartz MK, Oettgen HF. Pre-operative carcinoembryonic antigen level as a prognostic indicator in colorectal cancer. N Engl J Med 299: 448-451, 1978.

20. Staab HJ. Anderer FA, Brummendarf T. Stumph E. Fischer R. Prognostic value of preoperative serum CEA level compared to cllinical staging. I. Collorectal carcinoma. Br J Cancer $44.652-662,1981$

21. Wolmark N. Fisher B. Wieand HS, Henry RS. The prognostic significance of preoperative carcinoembryonic antigen levels in colorectal cancer. Ann Surg 199: $375-381,1984$.

22. Olson RM. Perencewich NP, Malcolm AW, Chaffey JT, Wilson RE. Patterns of recurrence following curative resection of adenocarcinoma of the colon and rectum. Cancer 45: 2969-2974, 1980 . 
23. Kelley WE. Brown PW. Lawrence W. Terz JJ. Penetrating. obstructing and perforating carcinomas of the colon and ractum. Arch Surg $116: 381-384,198 \%$,

24. Habib NA, Peck MA. Sawyer CN, Blaxland JW, Luck RJ. Does fixity affect prognosis in colorectal tumours? Br J Surg 70: 423-424, 1983 .

25. Umpleby HC. Bristol JB, Rainey JB, Williamson RCN Surwival of 727 patients with single carcinomas of the large bowel. Dis Colon Rectum 27:803-810, 1984

26. Ranbarger KR. Johnston WD, Chang JC. Prognostic significance of surgical perforation of the rectum during abdominoperineal resection for rectal carcinoma. Am J Surg 143: 186-188, 1982.

27. Slanetz CA. The effect of inadvertent intraoperatiwe perforation on survival and recurrence in colorectall cancer. Dis Colon Recturn 24: 792-797, 1984.

28. Phillips. RKS, Hittinger R. Blesovsky $L$. Fry JS. Flelding LP. Large bowel cancer: survival pathology and its relationship to survival. Br J Surg 71: 604-610, 1984.

29. Jass JR, Atkin WS, Cuzick J, Bussey HJR, Morson BC. Northover JMN, Todd IP. The grading of rectal cancer: historical perspectives and a multrivariate analysis of 447 cases. Histopathology $10: 437-459_{*}, 1986$

30. Nowacki MP, Szymendera JJ. The strongest prognostic factors in colorectal carcinoma. Dis Colon Rectum 26: 263*268, 1983. 



\section{Discussion and conclusions}

\subsection{Introduction}

Since surgery offers the best possibility for cure in primary colorectal cancer it is important to define the optimal technique for a standard resection.

As for many other solid tumors, $50 \%$ of patients remains disease free after surgery. The remaining $50 \%$ develops recurrent disease which is often fatal. Study of patterns of failure provides indispensable information concerning the natural history of colorectal cancer.

A further increase of our knowledge about the biological behavior of residual tumor may be obtained from the detection of minimal residual disease and analysis of prognostic factors both of tumor and host.

Prospective studies with extensive and accurate recording of clinical, laboratory and pathology data may serve this last purpose and result in the identification of high risk groups. The multivariate analysis is of utmost importance in establishing the relative importance of risk factors. In this final chapter, results of our study will be discussed and some final remarks about minimal residual disease will be made.

\subsection{Surgical techniques}

Recurrence of a tumor has led surgeons to search for a change in their operation techniques in order to cope with this problem. Recognition of local failure has resulted in extensive local operations. Besides the theoretical possibility of homing, of circulating tumor cells, in the primary tumor bed, local recurrence is a result of inadequate resection of the three dimensional spread of the tumor. Not only the primary tumor, but also, residual disease in lymph nodes or tumor emboli in lymphatic vessels need consideration in this regard.

Although the effect on survival is unclear, better local control, by radical resection, is possible for two groups of patients with colorectal cancer. The first group consists of patients with invasive growth in 
adjacent organs. Resection (partial or total) of the invaded structure may result in less local failures in combination with an acceptable five year survival rate. The second group is characterized by tumors located in areas with small margins to adjacent structures. It seems however, that, in the pelvis the limits of extensive local resections have been reached since more radical operations are accompanied by high complication rates, whereas resection of lymphatic spread outside the primary drainage area does not result in cure ${ }^{2}$.

The term 'extended' resections has also been applied to extensive upward lymphadenectomy. The main goal of this type of surgery was, not only local control, but also prevention of distant metastases by removing all dislodged tumor cells in the lymphatics within reach of the surgeon. The trend for performing more extensive lymph node dissections is not unique for colonic cancers, but has also been the subject of controversy for breast cancer and melanomas since, for all these tumors metastatic spread to the regional lymph nodes can easily be detected. Until now no prospective studies regarding colon cancer have been performed to evaluate the value of extended lymphadenectomies and since on theoretical grounds, in a 'standard' resection, already $95 \%$ of the potentially affected lymph nodes will be removed, it is unlikely that any important improvement of survival rate will be obtained by more radical resections ${ }^{3}$. It would be difficult to perform a clinical study to distinguish between limited and extensive resections. Too many patients are necessary for the detection of a small difference and the impossibility of defining the exact extent of the resection will hamper participation in this study, whereas in the group with extensive operations a real chance for an increased morbidity and mortality exists.

Dissemination via the hematological route is a continuous process and many distant metastases are already established at the time of surgery of the primary tumor. Dislodging of tumor cell clumps due to manipulation of the tumor during surgery may, in combination with a depressed peri-operative immunologic system, as in animal models, facilitate metastatic disease. Theoretically, spread via the portal vein during surgery of colon tumors and subsequently the take into the liver could be responsible for a substantial number of later
failures.

Turnbull's data ${ }^{4}$ suggested an effect of vascular ligation before tumor mobilisation with regard to prevention of liver metastases. It was the aim of the first part of the study to obtain better insight into this feature. A way to acquire information about this phenomenon was to conduct a prospective randomized trial, in which this technique is compared with a conventional technique. The results of the trial 
are described in Chapter five. The following obserwations were made: equal morbidity and mortality in the two groups, less and later occurrence of liver metastases in the no-touch group especially for the sigmoid area and in cases with angio-invasive growth. However, despite a tendency in favor of the no-touch group in all analyses, no significant improvement in the disease free period for all failures and the disease related survival was achieved. Speculations on the mechanisms of these observations leads to the following hypotheses. Firstly, Turnbull's data about his no-touch group are a result of patient selection, since the survival figures of the control group in the previously described study are also very high and comparable with the data of the no-touch group. Secondly, animal experiments about influencing lymphovascular flow during surgery and clinical experiments about circulating tumor cells after centrall ligation, have given important information about the potential technical difficulties of complete lymphovascular isolation since overflow via the marginal vessels is possible ${ }^{5}$. This is perhaps of clinical rellevance since the difference in the occurrence of liver metastases was found in the sigmoid area only. This part of the colon has the most constant vascular anatomy and is easily accessible for complete vascular isolation as the first step during an operation. In third place, the trend for a reduction of liver metastases by application of the notouch isolation technique was observed in cases with angio-invasive growth only, being an extra support for the validity of the concept of intra-operative portal dissemination. Dislodgement of tumor emboli due to manipulation must be easier in cases in which angio-invasive growth is observed. Finally, a speculative explanation for the late occurrence of some liver metastases in the no-touch group is the prevention by this technique of massive tumor embolization to the liver during surgery. The few tumor deposits already present preoperatively grow slowly to become detectable metastases after a long time. In the conventionally operated group these liver metastases present at the time of surgery are of no clinical significance since tumor emboli dislodged during operation are responsible for early recurrences, obscuring the already existing ones.

The absence of a significant difference in survival may be due to several possibilities, too few numbers in the two treatment arms may abscure the significance of little differences (type II error)b. However, another explanation is possible as well. In the modern concept of dissemination tumor cells pass from the vascular to the lymphatic system and vice versa. This is an inseparable process. In previous studies improved local control by surgery ${ }^{7}$ or radiotherapy ${ }^{8}$ resulted in the detection of more distant metastases as the first site 
of failure. As a consequence of this concept, reduction or delay in distant metastases, due to the no-touch isolation technique, can result in the earlier detection of failures e.g. local recurrences elsewhere. The final outcome in survival will then still be more or less the same and in accordance with the observation that local recurrence is a part of systemic disease in most cases.

The controversy among surgeons stressing the importance of resecting lymph nodes while others perform vascular isolation is artificial. Since the prognosis of the disease has been mainly determined at the moment of diagnosis the influence of any type of operation on the final outcome is limited. Surgical practice today should consist of optimal local resection, lymphadenectomy limited to the mesentery and vascular isolation. It seems not worthwhile to conduct further trials on surgical technique at this moment ${ }^{9}$. Definition and detection of minimal residual disease by modern techniques is a necessary prerequisite before e.g. the effect of more extended lymphadenectomies may be the subject of study.

\subsection{Prognostic factors}

The second aim of the study was the definition of prognostic factors. For this purpose clinical, laboratory and pathology data were used. After identification of individual prognostic factors, of which the CEA immunoreactivity pattern analysis in Chapter six is an example. multivariate models are necessary to select the most important variables. A combination of these variables may result in a prognostic index in which the importance of the value of a certain variable is weighted by the hazard ratio.

Theoretically several prognostic indices are possible. An index based on a combination of preoperative factors may result in an optimal determination of treatment modalities. After adjusting intraoperative findings it is possible to calculate an index and base on this the operative procedure. Factors e.g. determining the likelihood for local recurrence may result in a justified choice for sphincter saving procedures, like colo-anal anastomosis, for low lying rectal tumors ${ }^{10.11}$. A combination of all pre-, per- and postoperative data can be used in an index for the planning of adjuvant treatment schedules.

From the anallysis of clinical and laboratory data it is clear that, although interesting information can be derived, no reliable treatment plan for a primary tumor can be made. All factors analysed are indirectly, indicating a relative risk. The relative favorable outlook for patients with short duration of symptoms and rectal bleeding as 
initial presenting symptom must be considered as an important message with regard to the prevention of doctor and patient delay.

Laboratory tests preoperatively are of limited walue for the prediction of disease free survival with the exception of total protein value and CEA level. The first must be an indicator of the importance of the nutrition status of the patients. Further investigations are warranted for the effect of peri-operative nutritional support both on postoperative morbidity and recurrence rates. High CEA levels preoperatively must be considered with caution since little is known about production in, and shedding from, the primary tumor into the bowel lumen and blood. Elevated levels of CEA only were of prognostic significance for patients with lymph node metastases. Probably these patients have a substantial residual tumor burden which is not detected by conventional techniques during laparotomy

Clinical assessment of fixity of the primary tumor is an important determining factor derived from the multivariate analysis for local recurrence as the first site of relapse in these cases. The pathologist was not able to identify tumor cells, at the resection margin probably due to poorly marking of the site at risk. This finding should, especially when found in the pelvis, influence the decision to perform a sphincter saving procedure.

Analysis of pathology data did enable us to increase our knowledge about the identification of 'at risk' groups for recurrence. Clinicopathological staging remained the starting point of every prognostic index. New variables like the DNA index, CEA and serotonin expression appeared to be of importance. These parameters can be determined on preoperative biopsies. Together with size and shape of the primary tumor, in combination with more accurate preoperative diagnostic modalities like better CT scans ${ }^{12}$ and intraluminal ultrasound 13 "this can result in a staging system calculated entrely preoperatively. It may have the capacity to determine the risk of local recurrence. Identification and testing of new antigens or oncogens ${ }^{14}$ revealing more of the biological nature of the primary tumor is an essential step in this process.

The prognostic index, calculated after operation may be refined by the same tumor factors, as derived from the preceeding analysis. in combination with host factors like Iymphocytic infiltration around the tumar $\$ 5$ and the hyperplastic reaction with enlargement of the regional lymph nodes ${ }^{16}$. Both factors, if present, although difficult to quantify, have a prognostic value. Characterisation of the subsets of the lymphocytes in these infiltrates, with functional lymphocyte markers, have identified $T$-cells and $T$-helper cells as the main component ${ }^{17}$. 
However, all these indices should become less important with the availability of methods for the detection of minimal residual disease.

\subsection{Future directions}

This thesis was written because of interest in manipulation and determination of minimal disease during and after so called "curative" resections. For those studies reported in the previous chapters, only indirect methods of determination and manipulation of residual tumor cells were available. This resulted in the estimation of the disease free period and the disease related death as a consequence of the previous existence of tumor remnants. Since the start point of the trial in 1979, more information and new modalities have become available for the identification of high risk groups. A few of the new indirect methods, like antigen expression have been partly incorporated in the pathological data. In this last part, a short review will be given of a few promising modalities in finding small tumor masses and some general remarks about (adjuvant) treatment of colorectal cancer will be made.

\subsubsection{Detection of minimal residual disease}

All imaging techniques presently available will not play a definitive role in the detection of minimal residual disease because the minimal detectable lesion size is too large for identification of single cells or even small clusters of cells. The development of monoclonal antibodies directed against colorectal cancer associated antigens and the introduction of the flowcytometre have stimulated research in this field. E.g. anti-CEA antibodies have a nearly $100 \%$ strong expression on individual colorectal cancer cells $\mathbf{s}^{18}$. Labeling of the antibody to an isotope (radioimmunolocalizaton) or fluorescant has the potential to identify small tumor masses which could not be detected by other means and, this proved to be useful for the selection of patients for second look laparotomy ${ }^{19}$.

The application of the present available antibodies is hampered by the heterogeneity of the cell population in the primary tumor and the crossreactivity with other normal and abnormal tissues. Improvement of targeting is possible with the development of antibadies which are more specific to, and more homogeneously expressed by colonic cancer. Another way to overcome the problem of theterogeneity is the use of cocktails of several antibodies.

Apart from this, the exact biodistribution of the labeled antibodies is not known. Scanning before, during and after surgery for primary 
or secondary cancer can provide important information. Hand held gammaprobes have been used for identification of areas with an increased activity in comparison with surrounding tissues ${ }^{20}$. Different techniques for the administration of the antibody complex such as submucus, intraperitoneal or intraportal injections of the antibody can result in an improved uptake.

It is also possible to identify, with the cell sorter, tumor cells in cell suspensions, of which the portal blood is the best example. After vital staining these cells can even be used for injection, as xenografts, in the nude mouse for testing the viability.

Finally, immunostaining with the peroxidase technique or autoradiography is helpfull for the identification of tumor cells in resected or biopsied organs. It is possible that the application of some, or combinations, of these techniques may facilitate in the future identification of spots at which the tumor is left behind during surgery.

\subsubsection{Manipulation of minimal residual disease}

The effect of chemoprevention, dietary measurements and screeningprograms although within the field of manipulation of minimal disease fall outside the scope of this discussion.

Treatment of minimal residual disease after 'curative' resections is called 'adjuvant' therapy since, as per definition the presence of tumor is probable but uncertain and not detectable by the present imaging techniques. With the development of new diagnostic modalities capable of identifying smaller tumor masses less adjuvant and more directed treatment will be given. There are three traditional modalities for the (adjuvant) treatment of primary colon cancer: surgery, radiotherapy and chemotherapy. Surgical treatment has been evaluated previously.

Chemotherapy for solid tumors is disappointing. The present available cytostatic agents, which have been tested extensively in the past, will not play an important role in the adjuvant setting. Dose limiting factors caused by intravenous injections have led to other routes of administration avoiding systemic exposure. Intraperitoneal 21 and intraportal22 infusions of 5 -fluorouracil, the most extensively tested drug in colorectal cancer, have resulted in the escalation of doses and in improved local control of the primary target organ. However, the diminished number of intraperitoneal failures did not result in an increased overall survival. The final role of intraportal chemotherapy in the direct postoperative phase needs further confirmation, although significant differences in survival were observed for Dukes B cases in the only available randomized study 22 . 
The definite role of radiotherapy is not yet established. Down staging and reduction of local recurrences ${ }^{\beta}$ has been reported after preoperative radiotherapy without an effect on survival. The role of postoperative radiotherapy with regard to high risk groups, is still under study.

The fourth modality of cancer treatment is immunotherapy ${ }^{23}$ which is believed to be especially effective on small tumor masses. In this regard it is of special interest for the modulation of minimal residual disease. Claning of genes via the recombinant technique and the discovery of the hybridoma technique have made quicker progress and a more specific biological approach in the treatment of cancer possible ${ }^{23}$. It is still difficult to translate the effects of the different forms of immunotherapy, tested in animal models, to human cancer. Especially for colonic cancer, there is a big need for a model with liver metastases analogous to the human disease situation 24 . Besides this the conventional way of testing a new modality, in patients with advanced cancers, has been a great disadvantage for methods believed to act on minimal residual disease.

One way of immunotherapy is named immunomodulation and based on the use of biological response modifiers, which shoulld improve the immune response of the host against tumor cells. Many investigations have been carried out and are still ongoing about the use of interferons ${ }^{25}$, interferon inducers and lymphokines such as interleukins and tumor necrosis factor.

Another possibility for immunotherapy is the use of monoclonal antibodies as targeting agents. In contrast with other malignancies, the direct cytotoxic action of the monoclonals in colon cancer has been limited but described ${ }^{26}$. However, the antibodies directed against colorectal cancer associated antigens can be used as vehicles for cytotoxic drugs, toxins like ricin, immunomodulators or radioisotopes. In animal experiments antibody conjugates with vindesine were more effectively than if this drug was administered via the intravenous route alone ${ }^{27}$.

Well conducted phase I trials and limited phase II trials should be quickly followed by the conduction of randomized adjuvant studies both for the immunomodulators and monoclonal conjugates. For colorectal cancer it is possible to define these high risk groups on the basis of the aforementioned prognostic indices. Dukes C cases, extensive rectal tumors (irrespectable of the nodal status) and patients after resection of metastatic or recurrent disease are presently the first groups who have a very high risk of recurrent disease, making them suitable for these studies.

It is the hope that some of the (immuno)therapy modalities will 
become available in the near future as active adjuvant therapy after resections.

\subsection{References}

1. Eldar S, Kemeny MM. Terz JJ. Extended resections for carcinoma of the colon and rectum. Surg Gynecol Obstet 161:319-322.1985.

2. Enker WE, Pilipshen SJ, Heitweil ML, Stearns MW, Janov AJ, Hertz REL, Sternberg SS. En bloc pelvic lymphadenectomy and sphincter preservation in the surgical management of rectal cancer. Ann Surg 203:426-433, 1986.

3. Pezim ME, Nicholls R. Survival after high or low ligation of the inferior mesenteric artery during curative surgery for rectal cancer. Ann Surg 200: 729-733, 1984.

4. Turnbull RB Jr, Kyle K, Watson FR, Spratt J. Cancer of the colon: the influence of the no-touch isolation technic on survival rates. Ann Surg 166:420-427, 1967.

5. Ackerman NB. Vascular influences on intestinal lymph flow and their relationship to operation for carcinoma of the intestine. Surg Gynecol Obstet 137: 801.804, 1973

6. Freiman JA, Chalmers TC, Smith $H$, Knebler RR. The importance of bèta "the type II error and sample size in the design and interpretation of the randomized controlled trial. N Engl Med 299:670-674, 1978

7. Stearns MW. Deddish MR. Five-year results of abdominopelvic lymph node dissection for carcinoma of the rectum. Dis Colom Rectum 2: 169-172, 1959.

8. Gerard A, Berrod J-L. Pene F, Loygue J, Laugier A, Bruckner R, Camelot G, Arnaud

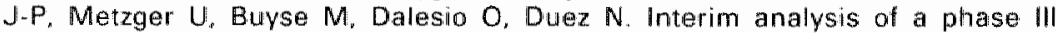
study on preoperatiwe radiation therapy in resectabile rectal carcinoma. Cancer 55: 2373-2379, 1985 .

9. Dudley HAF. Trials and tribulations for surgeons. Br J Surg 72: 255, 1985.

10. Sugarbaker PH. Carcinoma of the colon - prognosis and operative choice. Current problems in surgery 18: 753-802. Year Book Medical Publishers, Chicago-London, 1981.

11. Horbach L. A computer aided system of improving therapeutic measures by long term follow-up. In Lindberg DAB, Reichertiz PL (Eds): Lecture Notes in Medical Informatics II, pp. 666-672, Springer Verlag, Berlin. Heidelberg, New York, 1981

12. Miller DL. Vermess M. Doppman JL, Simon RM, Sugarbaker PH, O'Leary TJ, Grimes G, Chatterji DG. Willis M. CT of the liver and spleen with EOE-13: Review of 225 examinations. A.JR 143:235-243, 1984.

13. Feifel G. Hildebrandt U, Scherr $O$, Dhom G. Comparison of digital examination and endorectal sonography. Br J Surg 72: \$120, 1985

14. Stewart J, Evan G. Watson J. Sikora K. Detection af the c-myc oncogene product in colonic polyps and carcinomas. $8 r \mathrm{~J}$ Cancer $53: 1-6,1986$

15. Jass JR, Atkin WS, Cuzick J, Bussey HJR, Morson BC, Northower JMA, Todd $\| P$. The grading of rectal cancer: historical perspectives and a multivariate analysis of 447 cases. Histopathology 10:437-459, 1986.

16. Murray D. Hreno A, Dutton d, Hampson LG. Prognosis in colon cancer A pathologic reassessment. Arch Surg 110: 908-913, 1975

17. Umpleby HC. Heinemann D. Symes MO. Williamson RCN. Expression of histocompatibility antigens and characterization of mononuclear cell infiltrates in normal and neoplastic colorectall tissues of humans. J Natl Cancer Inst 74:1161. $1168,1985$.

18. Wiggers T. Arends JW, Verstijnen C, Moerkerk PM, Bosman FT. Prognostic significance of CEA immunoreactivity patterns in large bowel carcinoma tissue. Br J Cancer 54, 409-414.1986.

19. Begent RiHJ, Keep PA. Searle F, Green AJ, Mitchell HDC, Jones BE, Dent J, Pendower JEH, Parkins RA, Reymolds KW, Cooke TG, Allen Mersh T, Bagishawe 
KD. Radioimmunolocalization and selection for surgery in recurrent colorectal cancer. Br J Surg 73:64-67, 1986.

20. ODwyer PJ, Mojzisik C, Hinkle G. Olsen J, Tuttle S. Barth R. Thurstin M, Farrar W. McCabe DP. Martin EW. Intraoperative probe-directed radioimmunodetection using a monoclonal antibody. Abstract Society of Surgical Oncology. Washington DC. May 14. 1986.

21. Sugarbaker PH. Gianola FJ. Speyer JC. Wesley R, Barofsky 1. Meyers CE. Prospective, randomized trial of intrawenous versus intraperitoneal 5 -flliorouracil in patients with advanced primary colon or rectal cancer. Surgery 98:414-421. 1985.

22. Tavlor I, Mactin D, Mullee M, Trotter G, Cooke T. West C. A randomized controlled trial of adjuvant portal vein cytotoxic perfusion in colorectal cancer. Br $\Downarrow$ Surg 72: 359-363. 1985.

23. Oldham RK. Biologicals and biological response madifiers: fourth modality of Cancer treatment. Cancer Treatment Rep 68:221-232, 1984

24. Steele G Jr, Ross DS, Zamcheck N. New prospects in colorectal cancer. In Steele G. Osteen RT (Eds): Current concepts in diagnosis and treatment, Chapteir 13. Marcel Dekking Inc. Ne'w York and Basel. 1986.

25. Kirkwood JM, Ernstoff MS. Interferons in the treatment of human cancer. J Clin Oncol 2: $336-352,1984$.

26. Kaszubowsiki PA, Terasaki PI, Chia DS, Kukes GD, Hardiwidjaja SI, Cicciarelli JC. A cytotoxic monoclonal antibody to colon adenocarcinoma. Cancer Res 44 : 1194-1199, 1984.

27. Rowland GF, Simmonds RG, Gore VA, Marsden CH. Smith W. Drug lacalisation and growth inhibition studies of vindesine-monoclonal anti-CEA conjugates in a human tumour xenograft. Cancer Immunol Immumother 21: 183-187, 1986. 


\section{Summary}

Surgical resection is still the treatment of choice for primary colorectal cancer. Turnbull claimed superior survival rates by application of a special technique, of which the first step during operation is vascullar isolation before the tumor is mobilized. However, no standard resection technique is defined since no prospective studies distinguishing between surgical methods have been performed.

About half the patients is not cured after operation. Prediction of the likelithood of recurrence is possible by prognostic factors. It was the aim of this study to evaluate the effect of the no-touch isolation technique in a prospective way and to use the data derived from this study for the determination of prognostic factors.

Pathways and patterns of recurrent disease in colorectal cancer are described in Chapter 2 . The lymphovascular anatomy of the colon is reviewed briefly in order to understand the ways of spread via lymphatic or hematogenous routes. Special emphasis is put on the biological function of the regional lymph node and the presence of circulating cells in the portal blood. In addition, attention has been paid to the possibilities of spread via direct extension and to intramural or exfoliative spread. Eventually, the site of first recurrence and the mutual proportion of local and distant metastases are reviewed in the second part of Chapter 2.

In Chapter 3 the effect of different types of surgery is analyzed. The choice for an optimal local resection technique is determined by the length of bowel wall to be resected, the management of involved adjacent organs and the methods necessary for the prevention of tumor spill. The extent of lymph node dissection and the effect of vascular isolation, as an initial step during resection, both in relation to site of recurrence and patient survival, is reviewed from literature.

Details of the documentation system, necessary for a proper collection and processing of data are given in Chapter 4 . The use of preprinted follow-up forms, with only requests for investigations necessary for that particular follow-up, proved to be of great help. The availability of up-to-date data collections made statistics, necessary for interim analyses and presentation of results, possible in an easy way.

The results of the trial comprising 236 patients are presented in 
Chapter 5. A hundred and seventeen patients were analyzed in the no-touch isolation group and a hundred and nineteen in the conventionally operated group. The two treatment groups were comparable with regard to sex, age, first presenting symptom, duration of symptoms, preoperative CEA level, tumor location, stage, grade, angio-invasive growth, size of the primary tumor, number of resected lymph nodes and number of lymph nodes containing metastases. Postoperative complications, including mortality within 30 days were similar in both groups. A strong tendency $(p=0.0587)$ for a reduction of liver metastases was seen in the no-touch isolation group. This reduced number of metastases is mainly found in patients with the tumor located in the sigmoid area and in cases with angio-invasive growth. No significant differences in overall and corrected survival were observed, although in every analysis a strong tendency in favor of the no-touch technique was found.

In Chapter 6 the prognostic significance of CEA immunoreactivity patterns at tissue level is described. Tumors displaying only focally CEA, or tumors with immunoreactivity confined to the cell membranes, had a worse prognosis in comparison with tumors with an apical and/or cytoplasmatic staining pattern.

A multivariate analysis of pathology features derived from 350 patients is presented in Chapter 7. Traditional parameters, such as, size and shape of the primary tumor, central node involvement, angioinvasive growth, grade and stage have been combined in the analysis with the differences in immunoreactivity patterns of CEA, Ca 19-9, serotonin, secretory component, mucus and the flowcytometric determined DNA content of the primary tumor. The Dukes' classification was the strongest factor in determining prognosis, defined as time to disease related death. Additional prognostic information derived from the proportional hazard model and related to a poor prognosis is the presence of central lymph node metastases, small $(<3.5 \mathrm{~cm})$ or very large $>6 \mathrm{~cm})$ tumors, ulcerative growth, focally staining for CEA, presence of neuroendocrine differentiation and tumor aneuploidy (DNA index $>1.0$ ).

Since many features were collected in a prospective way it was possible to perform a regression analysis of clinical, laboratory and pathological data as well. The results are described in Chapter 8. In this analysis 310 cases, after curative resection only, were included and again the end point was time to disease related death. Sex, age and infectious complications were not important in defining prognosis. Blood loss as a first presenting symptom and short duration of symptoms were found to be independent favorable prognostic factors. of all the laboratory data analysed only a preoperatively low total 
protein and a elevated CEA level were of interest in relation to a poorer prognosis. From the operative findings the palpation of suspected lymph nodes, fixity to adjacent organs and tumor spill were of relative importance included in the proportional hazard model. Again stage was the strongest predictive factor but grade was included in this analysis as well.

In the final Chapter 9 the results derived from the previous Chapters are discussed and some conclusions are drawn. In addition, some future possibilities such as immunomodulation and immunadetection of residual (small) tumor masses are described.

Analysis of prognostic factors has its limitations since it is only an indirect way of determining of residual disease. However, identification of high risk groups remains important for proper patient selection for adjuvant studies because diagnostic techniques for detection of minimal disease are not yet available.

It is concluded that application of different surgical techniques will result in minor changes only, with regard to the chance of cure for the patient. The reason for this is that the prognosis of an individual patient is already greatly determined at the moment of operation. Use of the no-touch technique seems important in the prevention of dissemination in cases with angio-invasive growth, especially in areas where the technique is easily applicable. These findings support the biological relevance of the spread via the portal vein during operation. Presently the use of vascular isolation before mobilization of the tumor followed by aggressive local surgery seems to result in the highest cure rate. Since colorectal cancer is a disease with a high incidence all efforts resulting in minor improvements are worthwhile. 



\section{Samenvatting}

Een kwaadaardig gezwel van de dikke darm dient bij voorkeur operatief verwijderd te worden. Turnbull vermeldt in 1967 hoge genezingspercentages indien tijdens de operatie een speciale techniek wordt gebruikt; hierbij wordt, alvorens de tumor te mobiliseren, de vaatvoorziening naar en van de tumor onderbonden. Naar het effect van deze en andere chirurgische technieken zijn geen prospectieve studies verricht.

$\mathrm{Na}$ operatief verwijderen van het gezwel blijkt de helft van de patienten niet definitief genezen. De kans op terugkeer van de ziekte kan mede bepaald worden door prognostische factoren.

Het is het doel van de hier gepresenteerde studie om door middel van een prospectief vergelijkend onderzoek de waarde van de door Turnbull beschreven techniek te vergelijken met een techniek waarbij het gezwel als eerste stap van de operatie gemobiliseerd wordt. Tevens kunnen de patientengegevens die uit deze studie voortkomen, gebruikt worden voor het vaststellen van die feiten, welke van belang zijn voor het bepalen van de prognose.

In hoofdstuk 2 worden de manier van uitzaaiing en de patronen van terugkeer van de ziekte bij dikke darm kanker beschreven. Aangezien de verspreiding van de ziekte zowel via de lymfbanen als de bloedvaten gaat, wordt eerst een overzicht gegeven van de anatomie van banen en vaten. Speciale aandacht wordt besteed aan de rol van de regionale lymfklieren bij de verspreiding van het gezwel, en aan de betekenis van de aanwezigheid van kankercellen in het bloed dat vanuit de darm naar de lever stroomt. Daarnaast komen de kansen op terugkeer van de ziekte door uitgroei van de tumor buiten en binnen de darmwand, of door losgelaten cellen aan de orde. Tot slot worden in dit hoofdstuk de localisatie van tumorrecidieven, alsmede de onderlinge verhouding van de verschillende plaatsen van uitzaaiing bekeken.

In het derde hoofdstuk worden de verschillende chirurgische technieken geanalyseerd. De keuze van de optimale operatieve techniek op de plaats waar het gezwel zich bevindt, wordt bepaald door de lengte van de te reseceren darm en het peroperatieve beleid indien ingroei in omliggende organen wordt aangetroffen. Aandacht wordt besteed aan maatregelen welke innesteling van losgelaten tumor- 
cellen moeten voorkomen. De uitgebreidheid van lymfklierverwijdering en het effect van vroege onderbinding gedurende de operatie van de vaatsteel van het darmgedeelte waarin de tumor zich bevindt, worden bestudeerd vanuit de literatuur. Het effect van deze operatietechnieken wordt beoordeeld naar de plaats van het tumorrecidief en de kans van overleving van de patient.

In hoofdstuk 4 worden de bijzonderheden, welke noodzakelijk waren voor een goede verzameling en verwerking van de gegevens van het in deze studie gebruikte documentatiesysteem, gegeven. Vooral het gebruik van voorgedrukte formulieren bij poliklinisch controlebezoek, waarin alleen de woor dat bezoek noodzakelijke vragen zijn vermeld, bleek van grote waarde. De beschikbaarheid van een regelmatig bijgewerkte verzameling gegevens maakte statıstische bewerkingen eenvoudig. Dit laatste was noodzakelijk voor tussentijdse overzichten en verslaglegging van resultaten.

De resultaten van het onderzoek, waarin prospectief de chirurgische technieken vergeleken werden, worden vermeld in hoofdstuk 5 . In totaal omvat dit onderzoek 236 patienten: 117 patienten in de groep waarin tijdens operatie de vaatvoorziening als eerste stap werd onderbonden (groep 1) en 119 patienten in de conventioneel geopereerde groep (groep 2). De twee behandelingsgroepen waren goed vergelijkbaar betreffende geslacht, leeftijd, eerste klacht, duur van de klachten, voor de operatie bepaalde CEA waarde, plaats van het gezwel in de dikke darm, grootte van de tumor, stadium, vaatingroei, aantal verwijderde lymfklieren en klieren waarin uitzaaiingen werden aangetroffen. De postoperatieve complicaties met inbegrip van sterfte binnen 30 dagen na operatie, waren gelijk verdeeld over de twee groepen. Het aantal uitzaailingen naar de lever was geringer in groep i. Deze venmitudening van levermetastasen werd vooral gevonden bij patienten bij wie het gezwel zich in het sigmoid bevond en waarbij in het gezwel vaatingroei werd gevonden. Hoewel in elke overlevingscurve een tendens ten gunste van groep 1 was, werd er geen significant verschil gevonden in de 5 -jaars overlevingscijfers.

In hoofdlstuk 6 wordt de voorspellende waarde van verschillen in de verdeling van CEA binnen de cel, na weefselkleuring met behulp van anti-CEA antilichamen beschreven. Gezwellen die slechts sporadisch aankleuren met anti-CEA of gezwellen waarin het kleurpatroon beperkt is tot de celmembraan hadden een slechtere prognose in vergelijking met die gezwellen waarbij het hele cytoplasma en/ of de borstelzoom van de cel aankleurde.

Een multivariant analyse met betrekking tot de pathologischanatomische gegevens van 350 patienten wordt gepresenteerd in hoofdstuk 7. Traditionele parameters zoals vorm en grootte van de 
primaire tumor, centrale klier aantasting, vaatingroei, gradering en stagering werden gecombineerd met verschillen in weefselkleuringen van CEA, Ca 19-9, serotonine, secretoir component, slijm en de flowcytometrische bepaling wan het DNA gehalte van de primaire tumor. De classificatie volgens Dukes bleek de sterkste factor voor de bepaling van de prognose. Aanvullende informatie die van belang was voor bepaling van de prognose werd verkregen met het evenredige risico model volgens Cox. Een slechtere uitkomst, gedefinieerd als sterfte ten gevolge van de ziekte, was gerelateerd aan de aanwezigheid van uitzaaiingen in de centrale klieren, kleine $(<3.5 \mathrm{~cm})$ of grote $(>6 \mathrm{~cm})$ tumoren, tumorgroei met ulceraties, focale kleuring met anti-CEA, aanwezigheid van neuro-endocriene differentiatie en een abnormaal tumor DNA gehalte $(>1.0)$.

Aangezien veel gegevens prospectief verzameld werden in dit onderzoek, was het mogelijk om (in hoofdlstuk 8) eveneens een regressie analyse te verrichten van klinische, laboratorium en pathologisch-anatomische gegevens. In deze regressie analyse werden alleen patienten (310) betrokken die curatief geopereerd waren. Ook in deze analyse was het tijdstip van overlijden ten gevolge van de ziekte het eindpunt. Verschillen in geslacht, leeftijd en ontstekingscomplicaties na de operatie waren niet belangrijk voor de kans op overlijden ten gevolge van de tumor. Bloedverlies als eerste verschijnsel en korte duur van de symptomen bleken gunstige prognostische factoren. Van alle laboratoriumgegevens waren alleen een laag eiwitgehalte en een voor de operatie verhoogd CEA gehalte van belang met betrekking tot een slechtere prognose. Het palperen van verdachte lymfklieren, fixatie van de tumor aan omliggende structuren en het morsen van tumorcellen gedurende de operatieve ingreep konden opgenomen worden in een evenredig risicomodel. Ook in deze analyse bleek het stadium de sterkste factor voor het voorspellen van de kans op een recidief, daarnaast was gradering van belang.

In het laatste hoofdstuk (9) worden de resultaten, zoals beschreven in de voorafgaande hoofdstukken, geëvalueerd "waarna enige conclusies worden getrokken. Tevens worden in het laatste deel van dit hoofdstuk enige toekomstmogelijkheden beschreven; speciale aandacht wordt besteed aan opsporing en behandeling van tumorresten met behulp van immunologische technieken.

Analyse van factoren met een voorspellende waarde heeft beperkingen aangezien deze vorm van analyse slechts een indirecte manier is om achtergebleven kankercellen te identificeren. Desondanks is bepaling van risicogroepen via deze methode nog steeds belangrijk aangezien diagnostische mogelijkheden voor een betere selectie van patienten voor studies waarin aanvullende behandelingsmogelijkheden worden onderzocht, nog ontbreken. 
Er kan geconcludeerd worden dat verschil van gebruikte chirurgische technieken weinig kan bijdragen tot een beter genezingspercentage aangezien de kans op genezing voor de patient al grotendeels bepaald is op het tijdstip van operatie. Gebruik van de techniek waarbij vasculaire isolatie wordt toegepast alvorens de tumor te mobiliseren kan belangrijk zijn om verspreiding van tumorcellen via de bloedbaan te voorkomen. Deze observatie wordt vooral gedalan bij patienten bij wie vaatingroei wordt aangetroffen en bij wie het gezwel zich bevindt op plaatsen in de dikke darm waar vroege onderbinding van vaten gemakkelijk toepasbaar is. Deze twee gegevens ondersteunen de opvatting dat verspreiding via de portale ader gedurende operatie van biologisch belang is.

Op dit moment zal het vroeg onderbinden van de vaatsteel van het darmgedeelte waar de tumor zich bevindt en agressieve chirurgie ter plaatse van het gezwel resulteren in de hoogste genezingspercentages. Aangezien dikke darm kanker zo veel voorkomt, zijn alle factoren die kleine verbeteringen in de prognose geven, van belang. 



\section{Acknowledgements}

Many people are involved in the conduction of a multicenter study and it is impossible to mention and to thank everybody personally. I feel very privileged to be the one presenting most of the results.

Co Greep, has since 1973 stimulated me in his own dynamic way: firstly, to become a surgeon and secondly, to complete this thesis. My debt to him is hereby 'silvered'.

Hans Jeekel was involved from the very beginning with this study. His support during all the years and his critical reading of the manuscript are greatlly appreciated.

Cock van de Velde and Fré Bosman are acknowledged for their well thought-out comments on the manuscript and their suggestions for improvements.

Although from a great distance, Paul Sugarbaker supported me in continuing the study and convinced me of its importance.

Without the collaboration during seven years, of patients, surgeons and secretaries of the participating hospitals, this clinical triall would never have been finished. Cees van der Linden and Peter de Jong wrote the initial protocol. Several staff surgeons, of whom I would like to thank Paul Jorning in particular, went to the different hospitals many times to assist during the operations.

I am very grateful to the Department of Pathology for their close co-operation during the study. Working together with Jan Willem Arends meant critical reviewing of ideas and papers, but most of all encouragement and support for the work that had to be done. Staining of the tissue sections with the different antigens was done by Margriet Pijls and Birgit Engelen. I feel indebted to Carel Thijs for his patience in the classification of the specimens and to Cees Verstijnen for the contribution of the monoclonal antibodies. An extra dimension to the work was provided by Bert Schutte and Michele Reynders, who added the flowcytometric data to the analyses.

The struggle with the computer had its ups and downs, but I could always depend on Harrie Wetzelaer, who patiently solved all the problems with the soft ware. I would also like to thank Gerrion van Wandelloo for the development of the initial computerprogram and the members of the DIV (Data Processing Department) for their help throughout the years. 
Lex Volovics produced the statistics and I feel obliged to him for the sound data. Marion de Leeuw made the statistical calcullations and the figures, fow which I am grateful.

I would also like to thank Marijke van de Berg, for her initial secretarial assistance.

Marcia van Puijenbroek was the central person of the clinical trial. Not only her unwearying collection of the data and her accurate typing of the manuscript, but especially her personal interest in the completion of the study was a great help to me.

Chris Voskamp made the drawings and the final lay-out of the figures was prepared by the Department of Medical Photography of the Daniel den Hoed Clinic. I am grateful for the assistance of the libraries in Rotterdam and Maastricht.

If feel obliged to Helen Storey for correcting the English.

Furthermore I want to express my gratitude to all my surgical colleagues of the Annadal, the Dijkzigt, the Daniël den Hoed Clinic and the Zuider Hospital for their understanding of my regular absences during the last years.

I would also like to mention Nynke, Niels and Marije, because it was their father, who wrote this 'boekje', partly in their time. The work is now over and the loss of computerprints, suitable for drawings, will be compensated for.

The ambivalence of Marja to this kind of work has stimulated me to complete this thesis. Her critical reading of the first and last chapter has improved the style of the manuscript. 


\section{Curriculum vitae}

Theo Wiggers was born on April 2nd 1948 in Groningen, the Netherlands. After attending high school (Gymnasium $\beta$ ) in Amsterdam, he went in 1966 to Medical School at the Free University of Amsterdam and graduated in 1974.

From 1973 to 1976 he worked as a house officer in internal medicine, gynaecology and obstetrics and surgery.

After the National Course in Tropical Medicine and Hygiene at the Royal Tropical Institute in Amsterdam, he worked from 1976 to 1978 in Tanzania (Bukoba Government Hospital) as a medical officer.

Surgical residency was started in 1978 at the surgical department of the Academic Hospital Maastricht (formerly St. Annadal Hospital, chairman: Prof. Dr. J.M. Greep).

He was registered as a general surgeon in June 1984, after which he went to the University Hospital Dijkzigt (Prof. Dr. H. van Houtent, Prof. Dr. J. Jeekel) in combination with the Dr. Daniel den Hoed Cancer Center (Dr. G.A.A. Olthuis, Dr. A.N. van Geel), both in Rotterdam. In November 1986 he was appointed to the Dr. Daniel den Hoed Clinic / Rotterdam Radiotherapeutic Institute, continuing general surgery in the Zuider Hospital, Rotterdam. 